\title{
TEST OF A HOLLOW TILE AND CONCRETE FLOOR SLAB REINFORCED IN TWO DIRECTIONS.
}

\author{
By W. A. Slater, Arthur Hagener, and G. P. Anthes.
}

\begin{abstract}
.
This paper describes the test of a large slab built of hollow clay tiles with reinforced concrete ribs between the rows of tiles and parallel to both panel sides. To avoid complication of results due to settlement of footings a foundation consisting of an inverted flat slab under the entire test structure was employed. Heavy loads were placed on the slabs and measurements of strains and deflections were taken in about $\mathrm{r}, 600$ places at intervals during the loading. The load was left in place for over a year. The purpose of the test was to obtain empirical data to form a basis for the design of such slabs.
\end{abstract}

\section{CONTENTS.}

II. Materials, construction, and testing. ........................ $73^{\circ}$

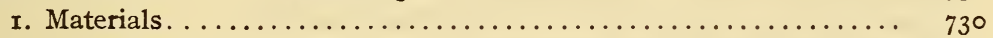

(a) Reinforcement........................... 730

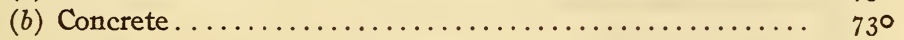

(c) Tiles................................... 732

2. Design and construction of slab..................... 732

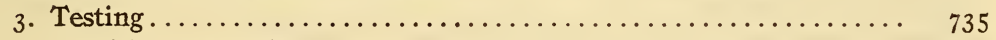

(a) Observations.................................... 735

(b) Loading .................................. 736

(c) Control slabs............................. 739

4. Test data.................................... 742

5. Reliability of results........................... 743

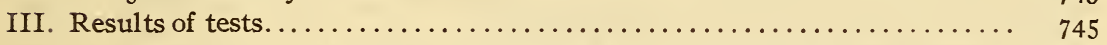

r. Deformations in tiles, control slabs, and large test slab........ 745

2. Deflections for square panels . ...................... $\quad 749$

3. Deflections for intermediate-size panels................ $75 \mathrm{I}$

4. Deflections for long panels......................... 753

5. Recovery from deflection upon removal of load............... 754

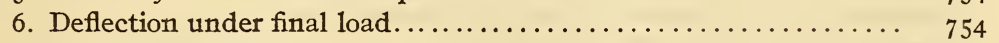

7. Deflection of girders.............................. ${ }_{75}$

8. Torsional resistance of girders........................ 756

9. Measured depth to reinforcement.................... 757

I0. Moment coefficients.............................. $\quad 757$

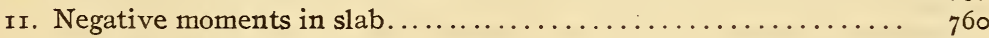

12. Positive moments in slab.......................... 764

13. Moments in cantilevers. .......................... $7_{76}$ 
III. Results of tests-Continued.

I4. Moments in girders.

I5. Anchorage required for negative reinforcement. $\ldots \ldots \ldots \ldots \ldots \ldots$

ı6. Shearing stresses in ribs of slab. $\ldots \ldots \ldots \ldots \ldots \ldots \ldots \ldots \ldots$

I7. Shearing stresses in girders $\ldots \ldots \ldots \ldots \ldots \ldots \ldots \ldots \ldots \ldots \ldots \ldots \ldots \ldots \ldots \ldots$

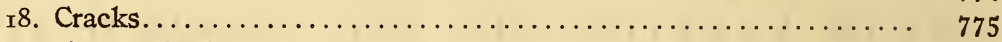

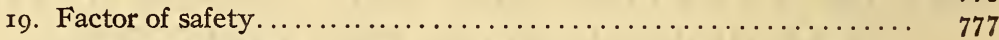

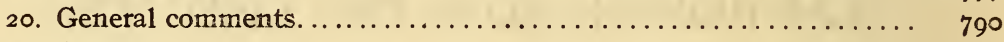

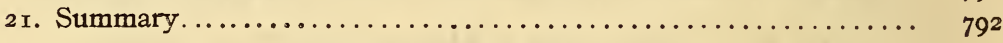

\section{TABLES OF RESULTS.}

I. Tests of slab and girder reiniorcement.

2. Compression tests of concrete.

3. Strength and initial modulus of elasticity of 6 by 12 by 12 inch clay tiles.

4. Log of applied (live) loads...

5. Deflection in square panels under constant load.

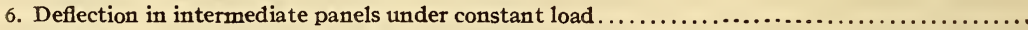

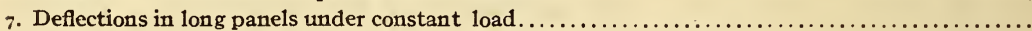

8. Recovery from deflection upon removal of load from exterior panels $\ldots \ldots \ldots \ldots \ldots \ldots \ldots \ldots \ldots \ldots \ldots$

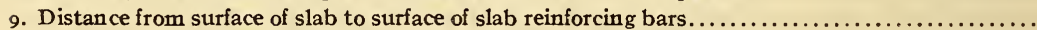

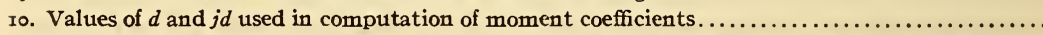

Ir. Weighted maximum tensile stresses in slab reinforcement and resulting coefficients of negative moment. ...

12. Ratios of negative moments in exterior panels to negative moments in interior panels.............

13. Weighted maximum stresses in slab reinforcement and resulting coefficients of positive moment.

14. Ratios of maximum positive moment in exterior panels to maximum positive moment in interior panels.

15. Summary of moment coefficients

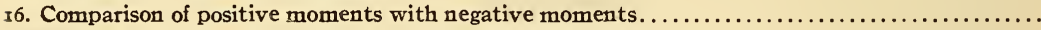

\section{LIST OF FIGURES.}

I. Stress-deformation curves for control specimens of reinforcing steel

2. Stress-deformation curves for control specimens of concrete and tiles.

3. Plan and section of slab showing reinforcement.

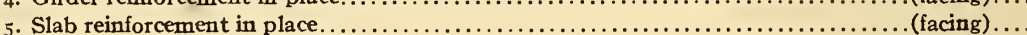

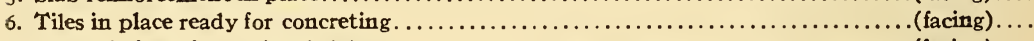

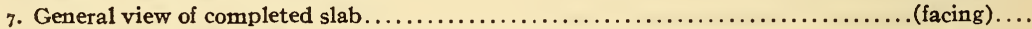

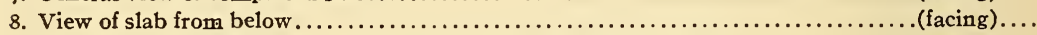

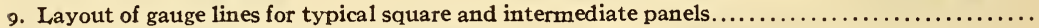

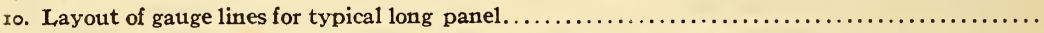

Ir. Temperature-deformation curves for small unstressed slabs for January and February, $1920 . . .$.

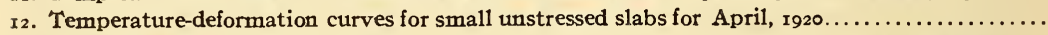

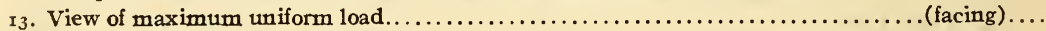

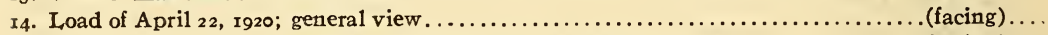

15. Load of April 22, I920; close view showing form of loading bricks................. (facing)....

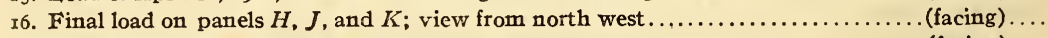

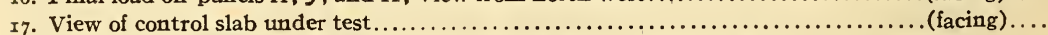

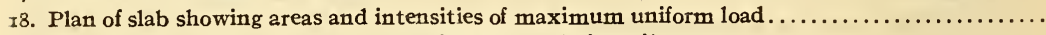

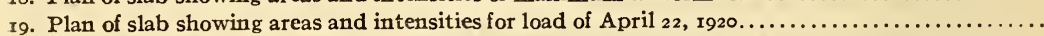

20. Distribution of compressive deformations across top of control slab No. $1 \ldots \ldots \ldots \ldots \ldots \ldots \ldots \ldots$.

21. Distribution of compressive deformations across top of control slab No. $2 \ldots \ldots \ldots \ldots \ldots \ldots \ldots \ldots$

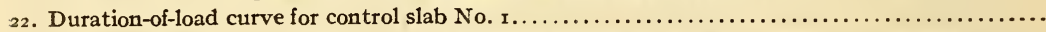

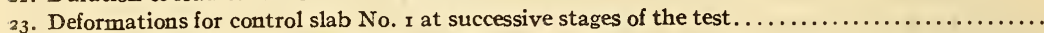

24. Load-deformation curves for control slab No. 2 .

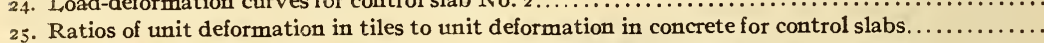

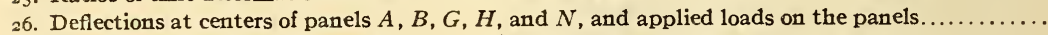

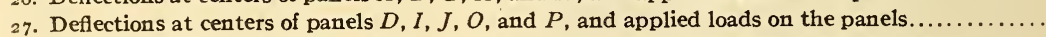

28. Deflections at centers of panels $E, F, K, L, Q$, and $R$, and applied loads on the panels..........

29. Panel $F$ resting on auxiliary posts..

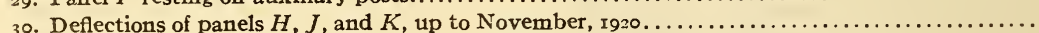

3r. Load-deflection curves for girders.

32. Coefficients of negative moment with maximum uniform load in place 55 to 73 days............ 
Page.

33. Coefficients of negative moment for interior panels $\ldots \ldots \ldots \ldots \ldots \ldots \ldots \ldots \ldots \ldots \ldots \ldots \ldots \ldots, \quad 76_{3}$

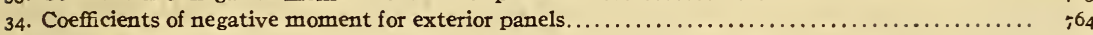

35. Coefficients of positive moment for interior and exterior panels $\ldots \ldots \ldots \ldots \ldots \ldots \ldots \ldots \ldots \ldots, \quad 766$

36. Stresses in reinforcement in cantilevers and in slab opposite cantilevers $\ldots \ldots \ldots \ldots \ldots \ldots \ldots \ldots, \quad 767$

37a. Points of zero stress for negative reinforcement in direction of short span $\ldots \ldots \ldots \ldots \ldots \ldots \ldots, \quad 77 x$

37b. Points of zero stress for negative reinforcement in direction of long span $\ldots \ldots \ldots \ldots \ldots \ldots \ldots \ldots \ldots \ldots$

38. Plan of slab showing cracks in under surface with maximum uniform load in place 2 to 21 days; also sectional areas of beam reinforcement...................................... $\quad 775$

39. Plan of slab showing cracks in under surface with maximum uniform load in place 55 to 73 days. 776

40. Plan of slab showing cracks in under surface with load of April 22 in place................ 777

4r. Load-deformation curves for steel and concrete for positions of negative moment in square panels. $\quad 778$

42. Load-deformation curves for steel and concrete for positions of negative moment in intermediate panels..

43. Load-deformation curves for steel and concrete for positions of negative moment in long panels.

44. Load-deformation curves for steel at positions of positive moment in panels $H, A, M, I, J, P, K$, $F$, and $R$.

45. Distribution, along edges of square panels, of deformation in negative reinforcement............ 46. Distribution, along edges of intermediate panels, of deformation in negative reinforcement.....

47. Distribution, along edges of long panels, of deformation in negative reinforcement..............

48. Distribution, along center lines of all panels, of deformations in positive reinforcement for maxi-

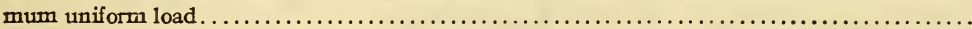

49. Distribution, along center lines of all panels, of deformation in positive reinforcement for load

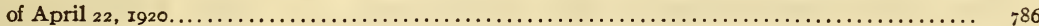

50. Distribution of deformation in concrete along edges of square panels $\ldots \ldots \ldots \ldots \ldots \ldots \ldots \ldots \ldots, \quad 78$,

51. Distribution of deformation in concrete along edges of intermediate panels............... $\quad 788$

52. Distribution of deformation in concrete along edges of long panels........................ $; \varepsilon g$

53. Final load in place from November, 1920 to date (Oct. I, I92I); view from south....(facing).... 790

\section{INTRODUCTION.}

The purpose of the test herein reported was to obtain data which would afford a basis for the design of a concrete and hollow tile floor reinforced in two directions. The test was planned to obtain information on: (r) The effect of variation in the ratio of length to width of panels upon the bending moments in two directions at right angles to each other, (2) the relation of maximum negative moment to maximum positive moment in a given panel, (3) distribution of tensile and compressive stresses at sections of maximum negative and maximum positive moment, (4) the amount of deflection of the slab and girders under different loadings, (5) the length of reinforcement required to give proper anchorage beyond points of support, and (6) the extent to which the tiles share in resisting the compressive stresses and the shearing stresses in the slab.

For the purpose of obtaining the data desired, a large floor slab, consisting of 18 panels, was constructed at Waynesburg, Ohio, in 1919. Approximately 900 gauge lines for measurement of deformations were established in the reinforcement, 500 gauge lines in the concrete, and 75 gauge lines in the tiles of the slab. Deflections were observed in 40 places.

The test was made for J. J. Whitacre, of Waynesburg, Ohio, under the direction of Mr. Slater, representing the Bureau of Stand- 
ards, with the cooperation of Prof. R. H. Danforth, of the Case School of Applied Science, Cleveland, Ohio. The slab was constructed under the supervision of Mr. Anthes. The tiles used were furnished by the Whitacre Fireproofing Co. of Waynesburg, Ohio. The observations used in the report were made by Messrs. Anthes, Hagener, and G. G. Scofield, all experienced observers in this kind of investigation. R. R. Zipprodt, of the bureau, assisted during the concreting of the slab and its preparation for test and in organizing the work of testing.

\section{MATERIALS, CONSTRUCTION, AND TESTING.}

\section{MATERIALS.}

Tests of the materials used in the slab were made in the laboratory of the Case School of Applied Science, Cleveland, Ohio, under the direction of Prof. R. H. Danforth.

(a) REINFORCEMENT.- -Six specimens of the reinforcement used in the slab and three specimens of the reinforcement used in

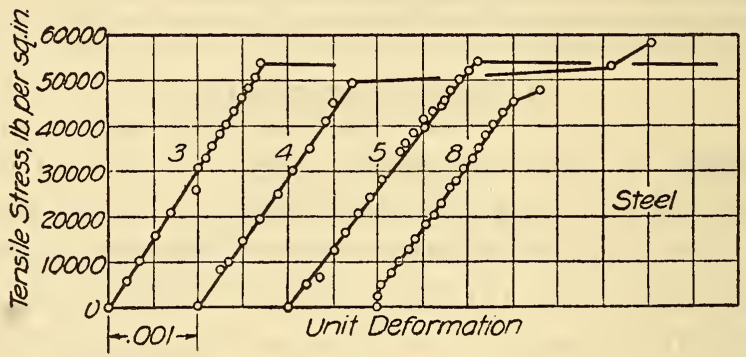

FIG. I.-Stress-deformation curves for control specimens of reinforcing steel.

the girders were tested. The results of these physical tests are given in Table $\mathrm{I}$. The stress-deformation curves for the reinforcement are given in Figure I.

(b) CONCRETE.-The aggregate which consisted of sand and gravel taken from a near-by stream contained a considerable amount of soft material.

Tests were made at the Structural Materials Research Laboratory, Lewis Institute, Chicago, on concrete containing I part of Portland cement made up of a mixture of five brands purchased in Chicago, 2 parts of this sand, and 4 parts of the gravel from which the material passing a No. 4 sieve had been rejected. The sand was graded from dust to about one-fourth inch and the gravel up to about $\mathrm{I}$ inch. The average strength of four 4 by 8 inch cylinders tested at 7 days was $890 \mathrm{lbs}$./in. ${ }^{2}$, and that of two cylinders tested at 28 days was I, $630 \mathrm{lbs}$./in. ${ }^{2}$. 
TABLE 1.-Tests of Slab and Girder Reinforcement. REINFORCEMENT USED IN SLAB.

\begin{tabular}{|c|c|c|c|c|}
\hline Reference number. & $\begin{array}{l}\text { Diameter } \\
\text { of bar. }\end{array}$ & $\begin{array}{l}\text { Yield } \\
\text { point. }\end{array}$ & $\begin{array}{l}\text { Ultimate } \\
\text { strength. }\end{array}$ & $\begin{array}{l}\text { Modulus of } \\
\text { elasticity. }\end{array}$ \\
\hline 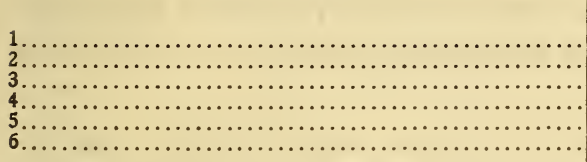 & $\begin{array}{r}\text { Inch. } \\
0.50 \\
.50 \\
.50 \\
.50 \\
.50 \\
.50\end{array}$ & $\begin{array}{r}\text { Lbs./in. }{ }^{2} \\
54,280 \\
53,880 \\
52,710 \\
52,890 \\
54,400 \\
53,200\end{array}$ & $\begin{array}{r}\text { Lbs./in. }{ }^{2} \\
86,490 \\
86,680 \\
88,690 \\
86,240 \\
88,400 \\
86,850\end{array}$ & $\begin{array}{c}\text { Lbs./in.2 } \\
\ldots \ldots \ldots . . \\
\ldots 32,100,000 \\
28,500,000 \\
27,800,000 \\
\ldots \ldots \ldots . .\end{array}$ \\
\hline Average. & & 53,560 & 87,220 & $29,500,000$ \\
\hline
\end{tabular}

REINFORCEMENT USED IN THE GIRDERS.

\begin{tabular}{|c|c|c|c|c|}
\hline \multirow{2}{*}{ 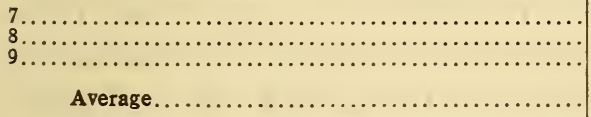 } & \multirow{2}{*}{$\begin{array}{l}0.875 \\
1.00 \\
1.125 \\
\\
\ldots \ldots \ldots\end{array}$} & $\begin{array}{l}49,100 \\
45,800 \\
44,100\end{array}$ & $\begin{array}{l}74,800 \\
78,800 \\
74,500\end{array}$ & $\begin{array}{r}29,350,000 \\
\ldots \ldots \ldots \ldots\end{array}$ \\
\hline & & 46,300 & 76,000 & $29,350,000$ \\
\hline
\end{tabular}

TABLE 2.-Compression Tests of Concrete.

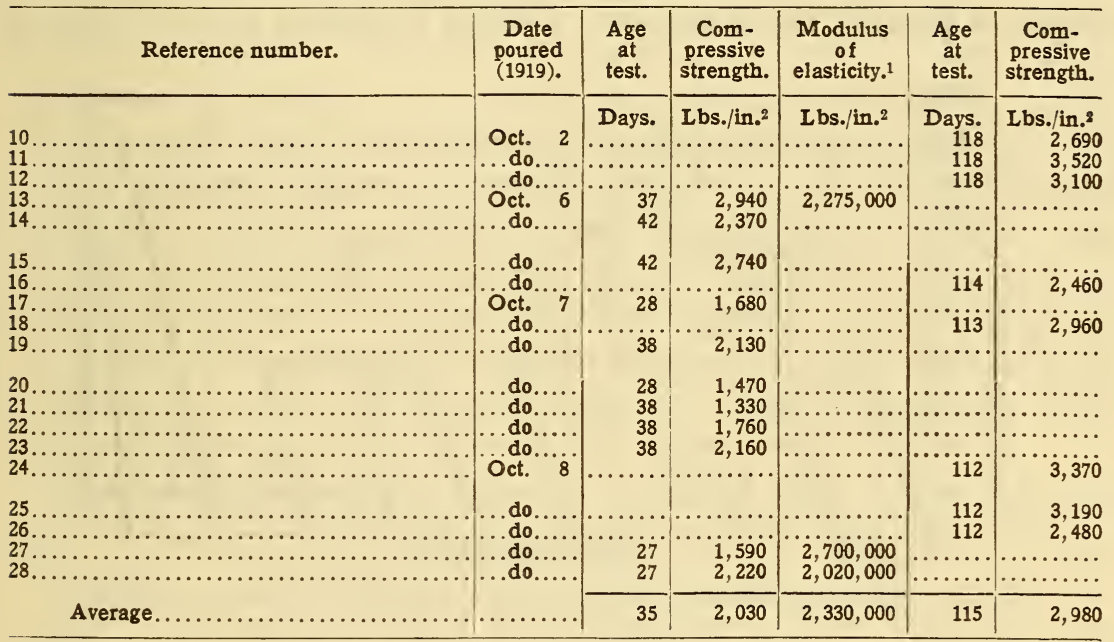

1 The initial modulus of elasticity is given.

TABLE 3.-Strength and Initial Modulus of Elasticity of 6 by 12 by 12 inch Clay Tiles.

\begin{tabular}{|c|c|c|c|c|c|}
\hline \multirow{2}{*}{ Reference number. } & \multicolumn{2}{|c|}{$\begin{array}{l}\text { Load applied on open } \\
\text { end of tile. }\end{array}$} & \multirow{2}{*}{$\begin{array}{c}\text { Refer- } \\
\text { ence } \\
\text { number. }\end{array}$} & \multicolumn{2}{|c|}{$\begin{array}{l}\text { Load applied perpen- } \\
\text { dicular to axis of } \\
\text { cells on } 6 \text { by } 12 \text { inch } \\
\text { face. }\end{array}$} \\
\hline & $\begin{array}{c}\text { Com- } \\
\text { pressive } \\
\text { strength. }\end{array}$ & $\begin{array}{l}\text { Modulus } \\
\text { of elas- } \\
\text { ticity. }\end{array}$ & & $\begin{array}{c}\text { Com- } \\
\text { pressive } \\
\text { strength. }\end{array}$ & $\begin{array}{l}\text { Modulus } \\
\text { of elas- } \\
\text { ticity. }\end{array}$ \\
\hline 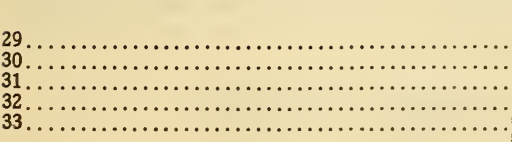 & $\begin{array}{r}\text { Lbs./in. } .^{2} \\
3,425 \\
4,850 \\
5,500 \\
4,570 \\
5,040\end{array}$ & $\begin{array}{r}\text { Lbs./in .2 } \\
5,500,000 \\
\ldots, 900,000 \\
4,900 \\
5,300,000\end{array}$ & $\begin{array}{l}37 \ldots \ldots \\
38 \ldots \ldots \\
39 \ldots \ldots \\
40 \ldots \ldots \\
41 \ldots \ldots\end{array}$ & \begin{tabular}{r|} 
Lbs./in. \\
3,290 \\
3,580 \\
4,700 \\
4,660 \\
3,050
\end{tabular} & $\begin{array}{r}\text { Lbs./in.2 } \\
\ldots \ldots, \ddot{2}, 360,000 \\
\ldots, 800,0000 \\
\ldots \ldots \ldots \ldots\end{array}$ \\
\hline 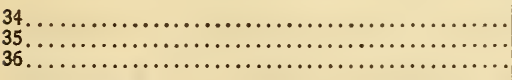 & $\begin{array}{l}5,080 \\
5,040 \\
5,880\end{array}$ & $\cdots, 100,000$ & $42 \ldots \ldots \ldots$ & $\begin{array}{r}4,820 \\
\cdots \cdots \cdots \cdots \\
\cdots \cdots \cdots\end{array}$ & $\begin{array}{r}6,100,000 \\
\cdots \cdots \cdots \cdots \\
\cdots \cdots \cdots\end{array}$ \\
\hline Average. . & 4,920 & $5,200,000$ & .. & 4,010 & $4,420,000$ \\
\hline
\end{tabular}

1 The compressive strength is the total load divided by the area of the tile walls cut by a section through the cells parallel to the bearing surfaces. 
The concrete used in constructing the slab contained I part cement and 5 parts of the mixed aggregate. The concrete used near the centers of spans of the girders contained a small percentage of aggregate as large as 2 or 3 inches in greatest diameter. For the concrete used in the slab the aggregate coarser than I inch was screened out.

All the concrete was mixed in a drum mixer which was set up near the northeast corner of the slab. The concrete was transported in wheelbarrows to the place where it was to be used. Placing of the concrete began on October 2, 1919, and was completed on October 9. The length of time consumed by the actual work of placing the concrete was about four and one-half days. R. R. Zipprodt, representing the bureau, was present during all the work of placing the concrete. Control cylinders ( 6 by 12 in.) of

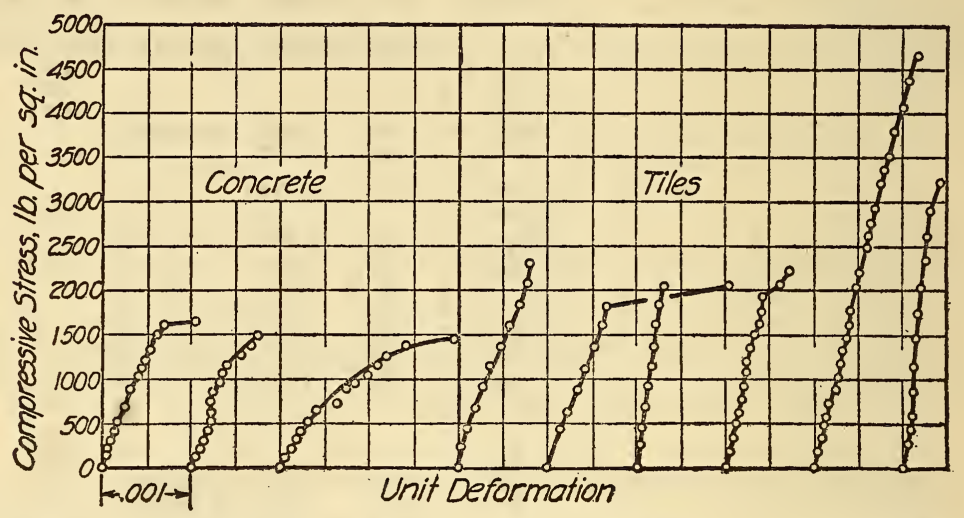

FIG. 2.-Stress-deformation curves for control specimens of concrete and tiles.

the concrete were taken from such parts of the work as would make them representative of the concrete in the structure, and were subsequently tested in compression. Stress-deformation curves for the concrete cylinders are given in Figure 2. The strength and modulus of elasticity are given in Table 2.

(c) TILES.-The tiles were of the six-cell type, 6 by I 2 by I 2 inches in size, and weighed approximately 30 pounds each. Test results for the tiles are given in Table 3. The stress-deformation curves for the tiles are given in Figure 2.

\section{DESIGN AND CONSTRUCTION OF SLAB.}

The test slab had less reinforcement than would be required by most existing standards for the design of fioors for even the smallest live loads specified in building codes. Certain tests which had already been made on slabs of similar construction in- 
dicated strengths great enough to point to the desirability of using very light reinforcement in the test slab. The general features of the design were: (I) Continuity of all portions of the structure; (2) a span as large as possible considering the expense of construction and of testing; (3) panels of three different ratios of length to width, I, I.2, and I.4; (4) slab thickness equal to one thirty-second of the short span center to center of supports; (5) reinforcement which was very small in amount ( 0.26 per cent) and which was the same for positive as for negative moment; and (6) girders heavy enough to carry a maximum load considerably greater than that which a rational analysis indicates that the slabs would carry.

An analysis of the structure indicates that on the basis of the recommendations of the final (IgI6) report of the Joint Committee on Concrete and Reinforced Concrete ${ }^{1}$ the interior panels of the slab would be suitable for total live and dead working loads of about 83,67 , and $48 \mathrm{lbs} . / \mathrm{ft}^{2}{ }^{2}$ for the square, intermediate, and long panels, in the order given. ${ }^{2}$ Taking the weight of the slab at $50 \mathrm{lbs}$. $/ \mathrm{ft}^{2}{ }^{2}$, it will be seen that under these recommendations the design live loads would be $33, \mathrm{I} 7$, and minus 2 lbs./ft. ${ }^{2}$, respectively. More exact analysis by rational methods ${ }^{3}$ would give design loads not greatly different from those stated here.

This general statement has been made in order to give a basis for comparing the loads carried by the slab with those to be expected on the basis of ordinary standards for design.

The slab was II 7 feet 6 inches long by 50 feet wide and was divided into 18 panels. Six of these panels were 16 feet square, six were 16 feet by 19 feet 3 inches, and six were 16 feet by 22 feet 6 inches. These panel dimensions were measured from center to center of supporting columns. The panels were supported by reinforced concrete girders, the stems of which were generally $\mathrm{r} 2$ inches wide, making the clear spans about $\mathrm{I} 2$ inches less than the dimensions given above. The slab was made of 6 by $\mathrm{I} 2$ by $\mathrm{I} 2$ inch clay tiles arranged in rows at right angles to each other and separated in both directions by ribs of concrete

\footnotetext{
1 Transactions A. S. C. E., 81, p. rror; r9I7.

${ }^{2}$ As recommended by the joint committee report the negative moment was taken as $\left(\frac{l}{b}-0.5\right) \frac{w b^{2}}{12}$ in the direction of the short span and $\left(\mathrm{I} .5-\frac{l}{b}\right) \frac{w l^{2}}{I^{2}}$ in the direction of the long span, and the positive moment was taken the same as the negative moment. Here $w$ is the uniform load per unit of area. $l$ is the long span, and $b$ is the short span. The values of $l$ and $b$ were taken as the clear spans between edges of girders.

${ }^{3}$ Westergaard and Slater, "Moments and stresses in slabs," Proc. Am. Concrete Inst., 17, Figs. 7 and 8 , p. 435 and 436 , respectively; I92 I.
} $108191^{\circ}-22-2$ 
4 inches wide and 6 inches deep. The tiles throughout the slab were laid with the cells running in the north-and-south direction. The ends of the tiles were left open allowing a small amount of concrete (from I 5 to 20 per cent of the volume of the cells) to enter, making the tiles form an integral part of the slab. The outer walls of the tiles were $3 / 4$ inch thick and the partition walls were $5 / 8$ inch thick. The outer surface was scored with grooves
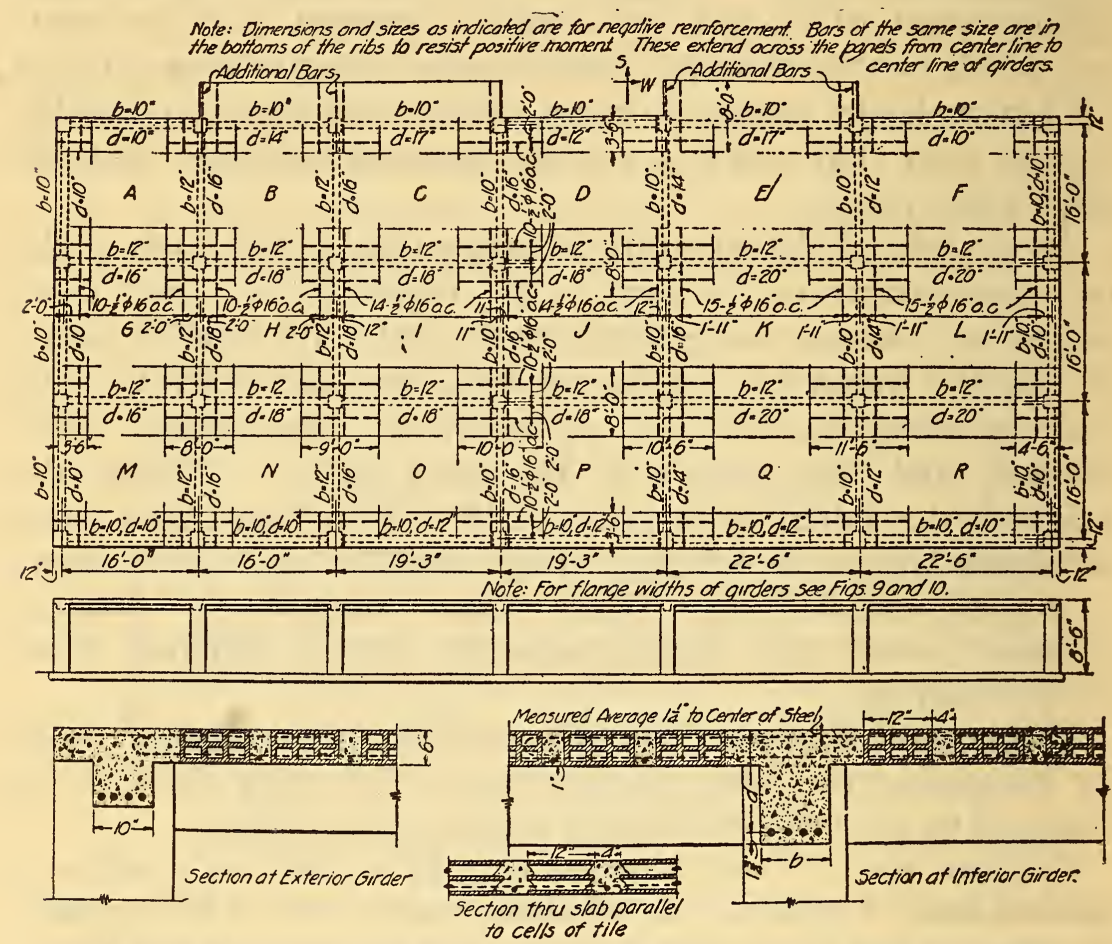

Frg. 3.-Plan and section of slab showing reinforcement.

$3 / 10$ inch deep and about $1 / 2$ inch wide extending in the direction of the cells.

Each concrete rib between rows of tiles was reinforced in the bottom with one $1 / 2$ inch plain round bar extending the full length of the rib, and in the top with one $1 / 2$ inch plain round bar at each end, which extended from a point one-fourth of the span length from the end of the rib through the top of the supporting girder one-fourth of the span length into the rib on the opposite side of the girder. The centers of the bottom bars were $I$ inch and $I I / 2$ inches from the bottom surface of the rib in the short and in the long spans, respectively. The centers of the top bars were $\mathrm{I} I / 4$ inches below the top of the ribs. The top bars were hooked at their ends to prevent slipping. Figure 3 shows the detail design 
Technologic Papers of the Bureau of Standards, Vol. 16.

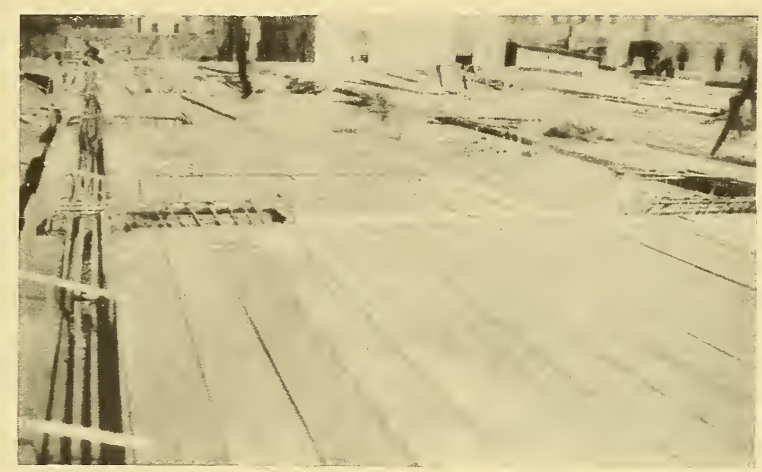

Fig. 4.-Girder reinforcement in place.

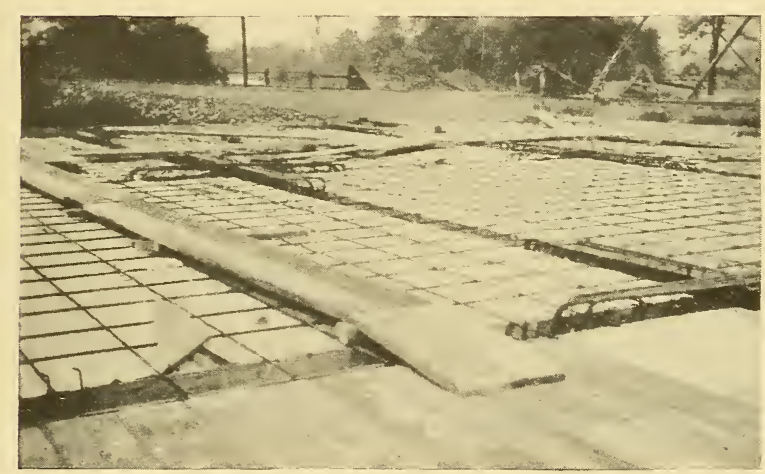

FIG. 5.-Slab reinforcement in place.

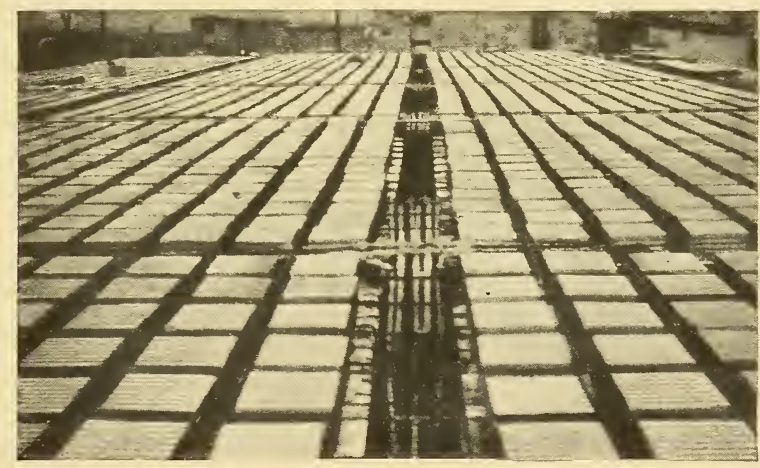

FIG. 6.--Tiles in place ready for concreting. 


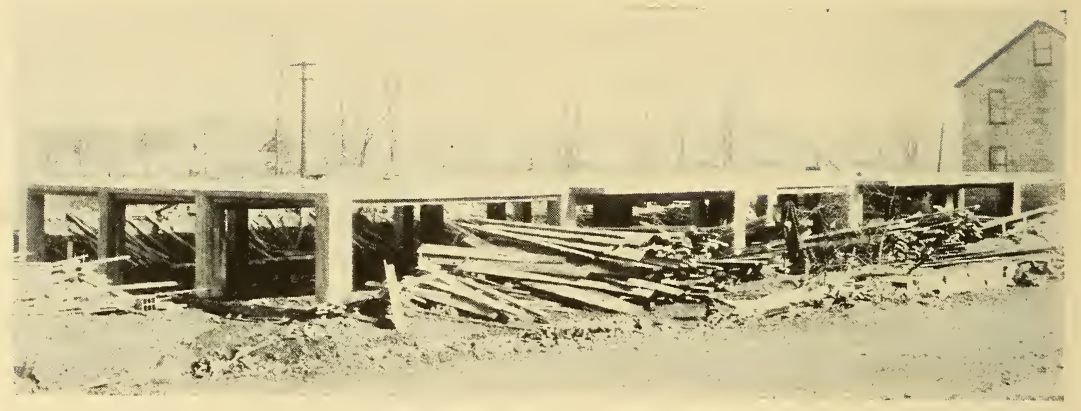

Fig. 7.-General view of completed slab.

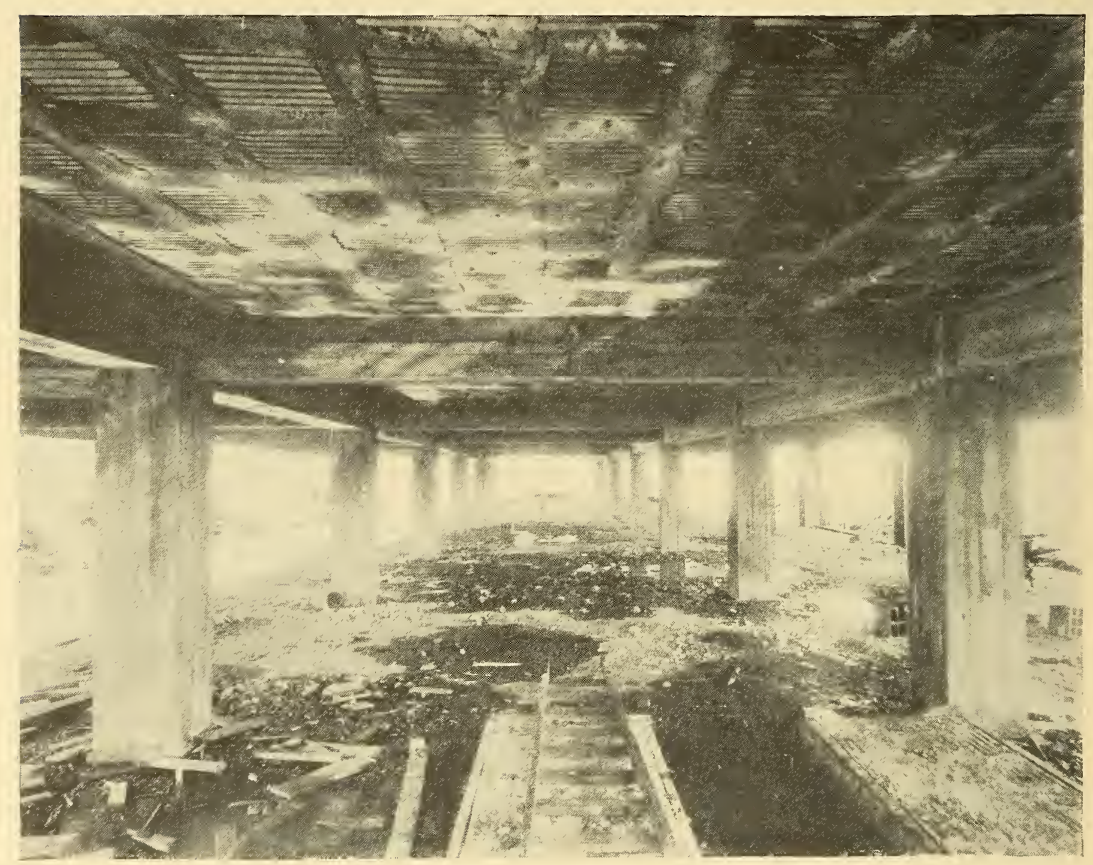

FIG. 8.-View of slab from below. 
of the slab, except that the areas of the tension reinforcement for the girders are shown in Figure 38 and the widths ofthe concrete flanges of the girders-that is, the distance from the center lines of the girders to the edge of the first row of tiles-are shown in Figures 9 and ro. Figures 4, 5, and 6 are views of the slab during construction. Figures 7 and 8 are views of the completed slab.

In order to avoid any chance of settlement of the footings, a continuous flat slab foundation was constructed. This foundation was 12 inches thick. The areas in the interior portions of the panels were of reinforced concrete and hollow tile construction. An area 9 feet by 9 feet 8 inches immediately surrounding each interior column was entirely of reinforced concrete.

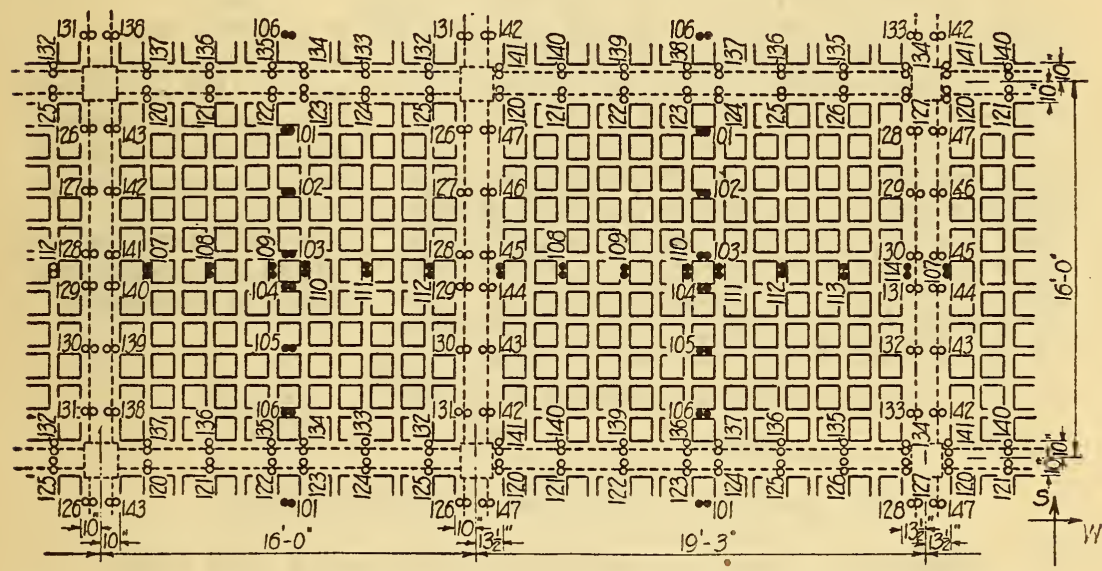

FIG. 9.-Layout of gauge lines for typical square and intermediate panels.

Work on the footings began July 26 , I9I9. The footings were poured between August 23 and September 2. The columns were poured on September 25 up to the soffits of the girders. The slab was poured between October 2 and I0, I919.

\section{TESTING.}

(a) Observations.-Figures 9 and ro give the layout of the gauge lines on the reinforcement and concrete of the slab for positions of positive moment and for positions of negative moment for a typical panel of each of the three sizes. In addition to the gauge lines indicated in Figures 9 and Io, gauge lines were also established in the reinforcement in the tops of the girders at the edges of the columns and in the reinforcement in the bottoms of the girders at the centers of the spans. Gauge lines were also 
placed at intervals on certain bars in the tops of the ribs in order to locate the points of zero stress and also in some of the tiles in the top and some in the bottom of the slab at points of maximum stress. For location of gauge lines to determine points of zero stress, see Figure 38 . The deformations in the reinforcement and in the concrete under the applied loads were observed with a Berry strain gauge ${ }^{4}$ having a gauge length of 4 inches and in the tiles with a strain gauge having a gauge length of 8 inches.

Deflection observations were made at the centers of the panels and at the centers of certain girders.

(b) LoAdING.-Radial chimney bricks of the type shown in Figure 14 were used as loading material. The bricks were of two

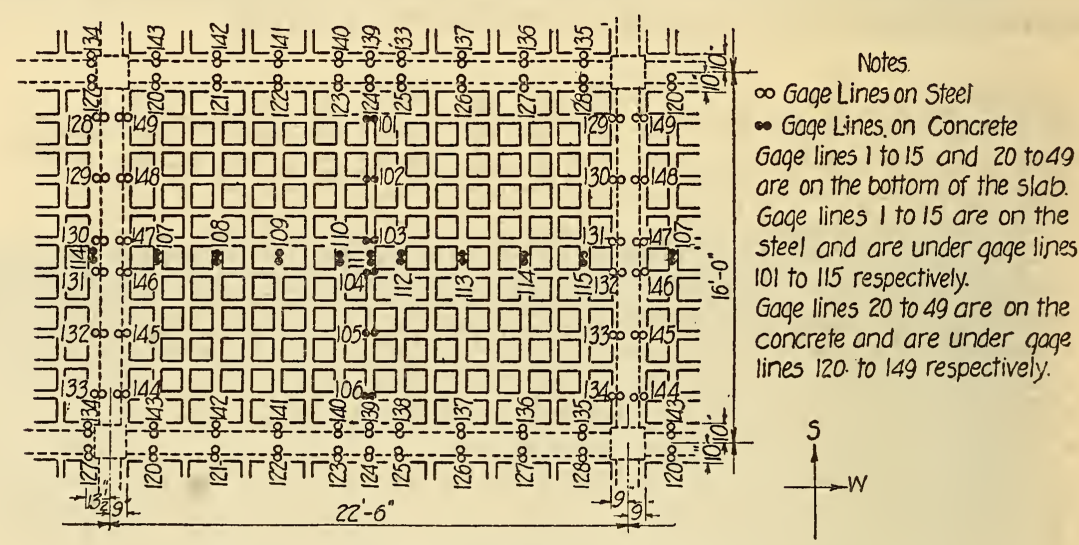

FIG. Io.-Layout of gauge lines for typical long panel.

sizes, weighing $\mathrm{I} 2$ and Io pounds, respectively, per brick. To prevent arching of the load and to secure accessibility to all of the gauge lines on top of the slab, the load on each panel was divided into four stacks as shown in Figure r8. This left an aisle 18 inches wide over each girder and along the center line of each panel in the direction of each pair of sides of the panel.

In forming stacks bricks of like size were placed in a layer. The I 2 -pound bricks gave a load of approximately $25 \mathrm{lbs}$./ $/ \mathrm{ft}{ }^{2}$ per layer on the square panels and $27.5 \mathrm{lbs}$. $/ \mathrm{ft}^{2}$ per layer on the intermediate and long panels. The Io-pound bricks gave a load of approximately $23 \mathrm{lbs} / \mathrm{ft}^{2}{ }^{2}$ per layer on the square panels and $25 \mathrm{lbs}$. $/ \mathrm{ft}^{2}$ per layer on the intermediate and long panels. The method of computing the load per square foot is stated in section II, 4 .

"W. A. Slater and H. F. Moore, "Use of the strain gauge in the testing of materials," Proc. Amer. Soc. Test. Mat., 13, p. rorg; rgr3. A. N. Talbot and W. A. Slater, "Tests of reinforced concrete buildings under load," Bulletin 64, Univ. of Illinois Engineering Experiment Station; rgr3. 
To avoid difficulty in stacking the bricks, due to slight irregularities in the surface of the slab, sand cushions $I / 2$ inches thick were laid before any bricks were placed. The sand was retained in place by wooden frames which defined the sizes of the piles and the location of the aisles and served as screeds for leveling off the sand cushions.

The first series of loadings began on December 20, 1919, and continued at intervals up to February 5, I920. The loaded areas and the intensities of the load on the latter date are given in Figure I8. This load is referred to throughout the paper as the "maxi-

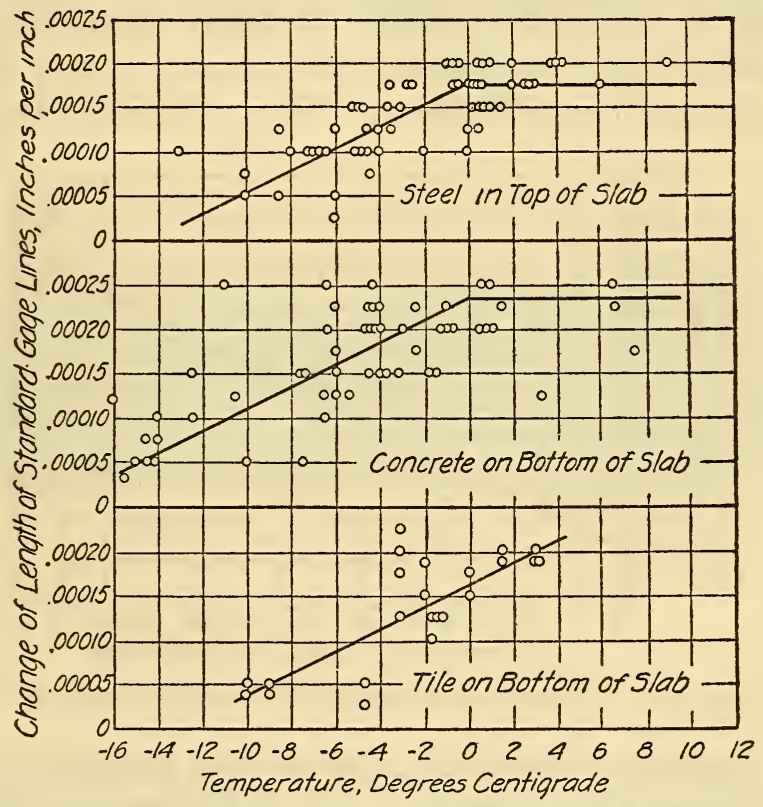

FIG. II.-Temperature-deformation curves for small unstressed slabs for January and February, 1920 .

mum uniform load." A view of the load is given in Figure $\mathrm{I}_{3}$. For this total amount of load no other practicable distribution would have produced a higher negative moment. The term uniform here applies to the distribution of the load over panels of the same size. The only exception to the uniformity of load for all panels of the same size was in the case of the corner square panels. (See Fig. I8.)

The maximum uniform load was left in place until April 3, 1920. Shifting of the load from one part of the slab to another was then begun and was continued up to April 22, 1920. The load was shifted with the purpose of maintaining as nearly as pos- 
sible a constant stress in the reinforcement resisting the negative moments, and at the same time of increasing the stress in the reinforcement resisting positive moment in typical panels. The loaded areas and the intensities of the load on April 22, 1920, are given in Figure 19. Views of that load are given in Figures I4 and $\mathrm{I}_{5}$.

Table 4 gives a record of the loading from December 20, I9I9, to April 22, 1920.

The load remained as shown in Figure 19 from April 22, 1920, until late in the summer of 1920 , when practically all the load was removed from the panels $R, L$, and $Q$. No further changes were made until in November, I920. Between November 4 and 9 the remaining load was shifted again so as to give the loading shown in the last line of Table 4. The loads placed on panels $H$,

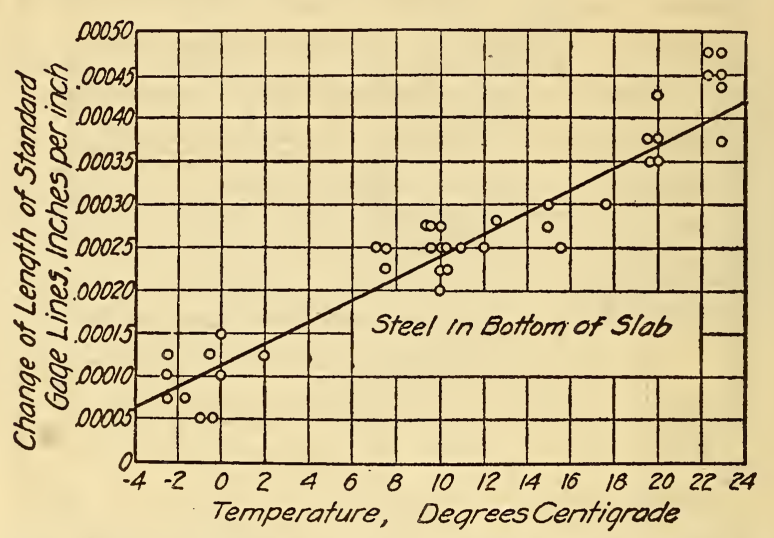

FIG. I2.-Temperature-deformation curves for small unstressed slabs for A pril, Iوzo.

$J$, and $K$ between November 4 and 9 have remained in position until the present time (October I, I92 I), but most of the live load from all other panels was removed from the slab shortly after November 9.

To furnish loading material for the three panels tested November 4 to 9 , bricks were taken from adjoining panels. The stacks shown in Figure I 2 were carried as high as seemed practicable and then a layer of 2 -inch planking was placed on the top of them. The layer of planking was necessary in order to insure stability of the stacks. For the sake of safety for the men who were working on top of the stacks and in order to secure maximum loads with the least height, the stacks above the planking were made solid; that is, no aisles were provided as in the stacks below the planking. In spite of the effort made to avoid arching it is 
Technologic Papers of the Bureau of Standards, Vol. 16.

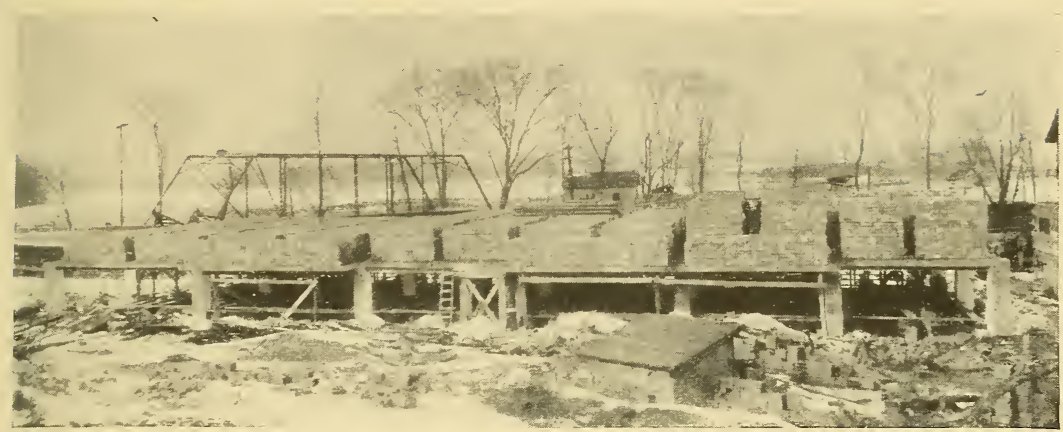

FIG. I3.-View of maximum uniform load.

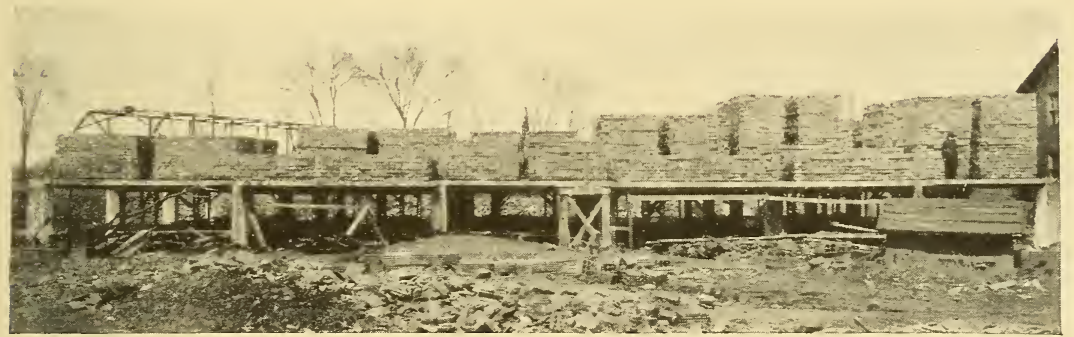

FIG. I4.-Load of A pril 22, I920; general view.

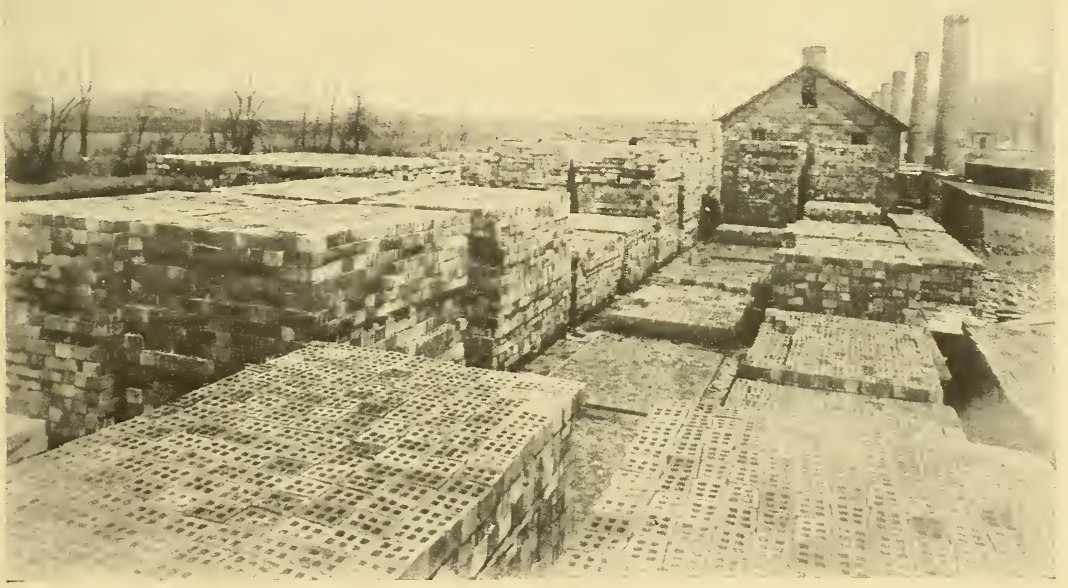

FIG. 15.-Load of A pril 22, 1920; close view showing form of loading bricks. 
Technologic Papers of the Bureau of Standards, Vol. 16.

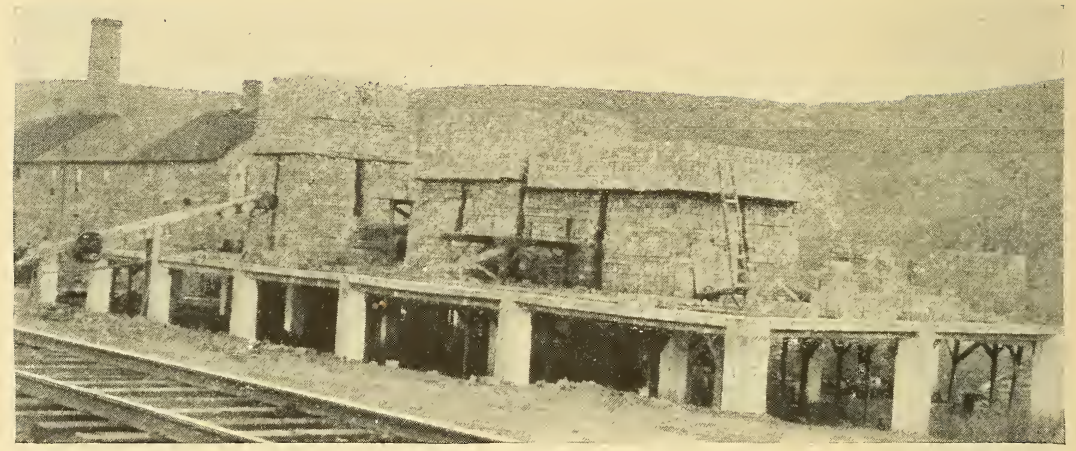

Fig. I6.-Final load on panels $H, J$, and $K$; view from northwest.

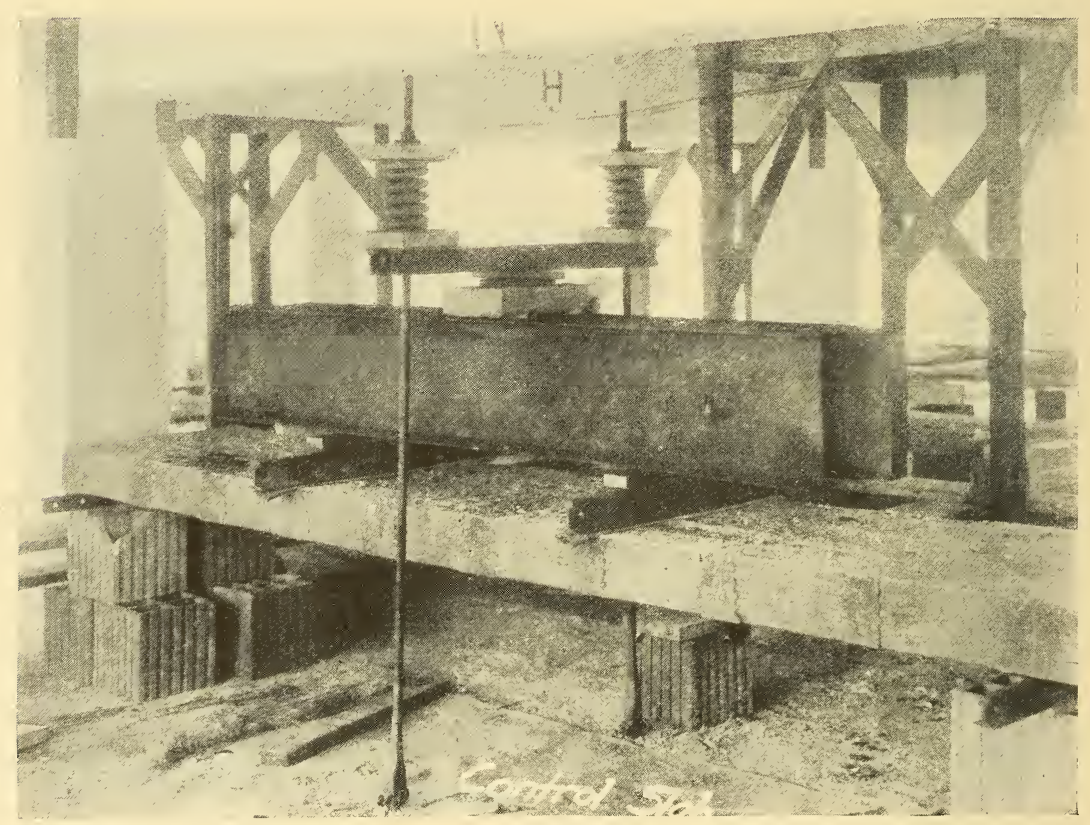

FIG. 17.-View of control slab under test. 
recognized that the conditions for the greatest loads were such that some arching was present. It is not known how important this arching effect was, but in any case the conclusions regarding the intensity of the shearing stresses and moment coefficients would remain unchanged. Arching would not reduce the shear, and the moment coefficients reported apply to the loads which were distributed in four stacks per panel, with which no appreciable arching can have occurred. ${ }^{5}$

Figure 16 also shows that at one time there was considerable load on other paneis besides $H, J$, and $K$. In spite of the pre-

\begin{tabular}{|c|c|c|c|c|c|c|c|c|c|c|c|}
\hline \multicolumn{2}{|c|}{$\begin{array}{l}\text { Loods ore qiven } \\
\text { in lopersqutt }\end{array}$} & \multicolumn{2}{|c|}{242} & \multicolumn{2}{|c|}{259} & \multicolumn{2}{|c|}{$I+W$} & \multicolumn{2}{|c|}{250} & \multicolumn{2}{|c|}{$\begin{array}{c}\text { All interior alsles } \\
18 \text { in wide }\end{array}$} \\
\hline 372 & 372 & 397 & 397 & 280 & 280 & 280 & 280 & 230 & 230 & 230 & $230^{1}$ \\
\hline & 372 & 397 & 397 & 280 & 280 & 280 & 280 & 230 & 230 & 230 & 230 \\
\hline 397 & 397 & 397 & 397 & 280 & 280 & 280 & 280 & 230 & 230 & 230 & 230 \\
\hline 397 & 397 & 397 & $3 \overline{97}$ & 280 & 280 & 280 & 280 & 230 & 230 & 230 & 230 \\
\hline 372 & 372 & 397 & 397 & 280 & 280 & 280 & 280 & 230 & 230 & 230 & 230 \\
\hline $21:-372$ & 372 & 397 & 397 & 280 & 280 & 280 & 280 & 230 & 230 & 230 & 230 \\
\hline s 16 & & & & & & & & & & & \\
\hline
\end{tabular}

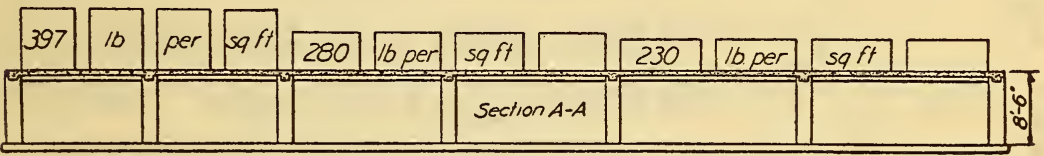

FIG. 18.-Plan of slab showing areas and intensities of maximum uniform load.

caution taken to secure maximum loads with minimum heights it was not practicable to carry the loads high enough to cause failure of the slab in any of the panels.

(c) Control Stabs. - Control observations included the measurement of deformations in standard gauge lines in the reinforcement, in the concrete, and in the tiles of unstressed slabs of small area, which were of the same thickness and of the same general makeup as the large slab. Readings on these slabs were taken at frequent intervals during the taking of the strain readings on the test slab. Observations of the atmospheric temperature were taken at the same time.

Two slabs termed control slabs, 2 feet, 6 inches wide, I 2 feet long, 6 inches thick, and similar in form of construction to the

\footnotetext{
5 Under date of June, $x_{922}$, it is reported that the loads shown in the last line of Table 4 are causing progressive deflections and opening of cracks in the oblong panels and that complete failure may be approaching, but that the loaded square panel is in good condition.
} 


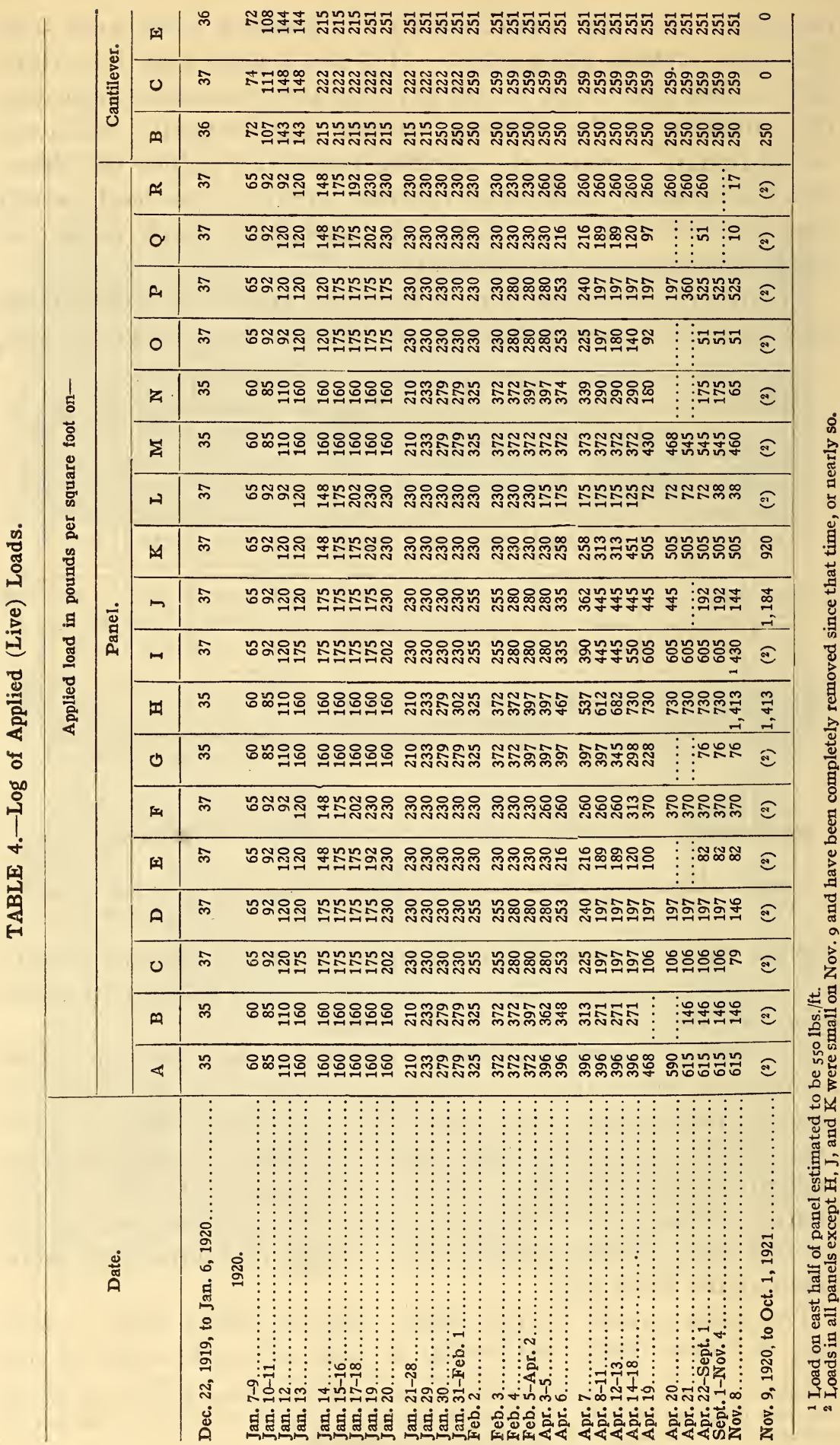


large slab, were provided in order to determine the effectiveness of the tiles in resisting compressive stresses in this type of construction. Figure $\mathrm{I}_{7}$ is a view of one of these slabs under load. The load was applied by the reaction of two springs which had been previously rated in a testing machine. In the slab test the amount of closure of the springs was measured and the corresponding load was determined therefrom.

The central concrete rib in each of the control slabs was reinforced in the bottom with three $5 / 8$-inch round bars. This gave a much higher percentage of reinforcement than was used in the large

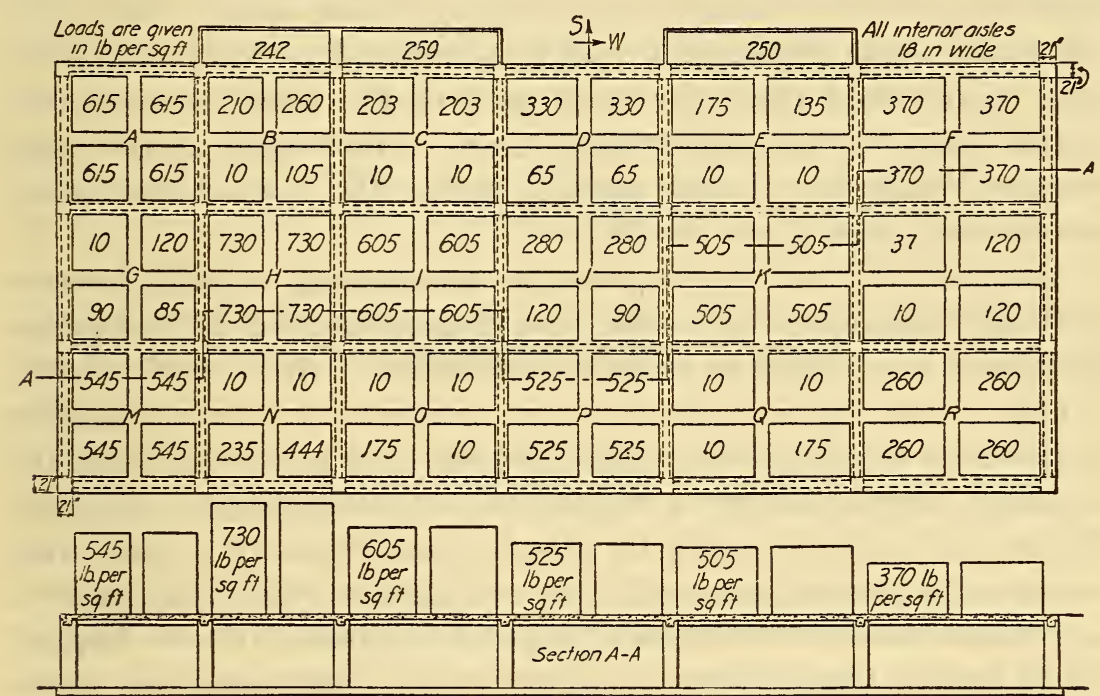

Fig. I9.-Plan of slab showing areas and intensities for load of A pril 22, 1920.

test slab. This high percentage was necessary in order to obtain large deformations in the tiles and concrete before failure.

The axes of the cells of all the tiles were parallel to the span in control slab No. I. Those of the tiles at mid span in control slab No. 2 were perpendicular to the span. Control slab No. I was tested at the same time as the large slab, under loads giving stresses in the reinforcement as nearly as possible the same as the stresses in the negative reinforcement in the large slab. The test of control slab No. I extended over a period of 84 days. Figures 22 and 23 show the length of time that the slab was held under successive loads and indicate that with the yielding of the slab the load and the tensile deformation decreased, while the compressive deformations increased slightly. Control slab No. 2 was tested to failure in one day, April I5, I920, observations being made under different loads before failure. 


\section{TEST DATA.}

The intensities of the load per square foot given throughout this paper were obtained by dividing the total panel load by the area inclosed by the faces of the supporting girders; that is, by the product of the clear spans. The moment coefficients based upon these loads and the measured stresses are about 8 per cent too low because the centers of gravity of the loaded areas fell closer to the supports than the one-fourth point of the clear span. For computing moment coefficients, therefore, a load 8 per cent smaller than that found in this way has been used. This gives about the same results as would be obtained by basing the intensity of the load upon the total area of the panel between the center lines of the supporting girders. The weight of the sand cushion inside the frames used to define the size of the loaded areas was taken as ro $1 \mathrm{bs} . / \mathrm{ft}^{2}{ }^{2}$

Considerable study was given to determining a basis for correcting the strain gauge readings for changes in the length of gauge lines due to changes in weather conditions. As a result of this study, it was decided that the most satisfactory basis for making corrections in the strain gauge readings was to assume that the readings varied directly in proportion to the temperature changes. All of the readings taken in January and February, 1920, were corrected in accordance with this assumption when the observed air temperatures were below $0^{\circ} \mathrm{C}$., and no correction was applied when the air temperature was above zero. This procedure seems to be logical in view of the fact that during that period the slab was at all times covered by ice and snow and for this reason the temperature of the slab itself would not rise above $o^{\circ} \mathrm{C}$. even though the air temperature should reach a higher point.

All of the observations taken in April, 1920, were reduced to those which should have been found at $0^{\circ} \mathrm{C}$. in accordance with the assumption that readings varied directly in proportion to the changes in air temperature.

Figures II and I 2 show the relation between the observed air temperature and the change in length of standard gauge lines in the reinforcement, concrete, and tiles of the unstressed slabs. The slope of the inclined portion of the mean lines fitted to the points in both figures represents fairly closely the coefficient of expansion of the materials.

Since the side pieces of the strain gauges used were of invar steel, it was assumed that no changes requiring corrections occurred in those instruments. 
Figures $4 \mathrm{I}$ to 44 give the load-deformation curves for all panels. On these diagrams tension is plotted to the right and compression is plotted to the left. The open circles indicate deformations in the steel and the solid circles indicate deformations in the concrete.

Figures 45 to 47 give the distribution of deformations in the slab reinforcement in the top of the slab which took stress due to negative moment across the edges of all girders of all panels under the maximum uniform load. The points connected by the broken lines are readings taken after the load had been in place less than three weeks; the solid lines connect readings taken after the load had been in place about nine weeks. Stresses beyond the yield point have been assumed to be the same as the yield-point stress of $54,000 \mathrm{lbs}$. $/$ in. $^{2}$ This stress corresponds to a unit deformation of 0.0018 , and for all gauge lines where the yield point was exceeded the unit deformation is shown as 0.0018 . To have plotted the full deformation for the gauge lines where the yield point had been exceeded would have led to serious confusion in interpreting the diagram.

Reference to Figure I shows that in order to reach a stress appreciably higher than the yield point a very large unit deformation would have been required. In all but a few gauge lines, which were located in panel $R$, the maximum unit deformations were less than 0.003 . In those few gauge lines the deformations were so large as to be beyond the range of the strain gauge. Even if the stress was considerably beyond the yield point in those gauge lines, they were so few in number that the conclusions from the test would not be changed.

Figure 48 gives the distribution of deformation at the centers of the spans for the maximum uniform load. Figure 49 gives the distribution of deformation at the centers of typical spans for the load of April 22, the intensity of which is shown in Figure I9.

Figures 50 to 52 give the distribution along the edges of girders of compressive deformations in the concrete due to negative moment in the slab next to the girders. Compressive deformations are plotted upward and tensile deformations are plotted downward.

\section{RELIABILITY OF RESULTS.}

Because of the unusually severe weather conditions in January and February, extreme precautions had to be taken to secure accurate strain gauge readings and to protect the observation points from damage. The gauge holes in the steel bars on top of the 
slab were protected by covering the bar with paper and filling the hole in the concrete above the paper with grease. This procedure generally prevented ice from coming in contact with the bar and avoided the possibility of doing injury to the gauge holes when removing the ice from the holes in the concrete preparatory to taking readings. There were indications that in some cases the steel plugs which were set in the concrete and in the tiles on the upper surface of the slab to provide suitable gauge holes for deformation readings were disturbed in the operation of removing the snow and the ice. This raised a question as to whether much reliance could be placed in the deformations observed in those places and, on this account, no use was made of those readings.

Extremely cold weather also made it difficult for the observers to secure readings in January and February. It required great persistence to obtain a satisfactory set of no-load strain gauge readings. Each observer took as many sets of readings as were necessary to secure satisfactory agreement between at least two consecutive series of readings. In some instances this required five or more series. In all the series of observations taken with the load on the slab check readings were frequently taken. In some series readings were taken for each gauge line twice, or even more times if necessary, to obtain satisfactory check readings.

The possible error in a recorded deformation is made up of the possible error of observation and the possible error in determining the temperature correction. The readings were recorded to the nearest one-half division of the strain gauge dial. It is believed that the error in reading was usually less than one division. It is believed also that the error in determining the temperature correction was in very few cases more than plus or minus two divisions of the dial and was in most cases less than plus or minus one division. One division of the instrument with a 4 -inch gauge length corresponds to a unit deformation of 0.00005 , equivalent to a stress of $\mathrm{I}, 500 \mathrm{lbs} / \mathrm{in}^{2}{ }^{2}$ in the reinforcement. It is believed, furthermore, that the sum of the error of observation and the error in applying the temperature correction for the readings taken in January and February seldom exceeded plus or minus three divisions of the instrument and that, for the majority of cases, the total error was much less than this.

Due to the more favorable weather in April, it is believed that the error in readings taken at that time was considerably less than the error in the readings taken in January and February. 
The total error in the corrected observations probably did not often exceed plus or minus one division of the instrument, which is equivalent to a stress of $\mathrm{I}, 500 \mathrm{lbs}$. $/$ in. $^{2}$ in the reinforcement.

Obviously the stresses reported in this paper must be based upon the average unit deformation measured in a gauge length of 4 inches. Since in general the unit deformation is not uniform over the gauge length the actual stresses will be somewhat greater than those reported. The lack of uniformity of deformation will be due mainly to variation of moment over the gauge length and to the occurrence of cracks within the gauge length. The error due to the first of these causes will be relatively small. The error due to the fact that the stress is larger at a crack than elsewhere within the gauge length will be more important. The proportionate amount of the error so introduced will depend upon the size of the bar, the bond resistance between the concrete and the bar, the length of the gauge line, and the intensity of the stress in the bar. With a $1 / 2$-inch bar and a 4 -inch gauge length the error might be 20 per cent or more when the observed average unit deformation corresponds to a stress of $10,000 \mathrm{lbs} . /$ in. $^{2}$ or less. With an observed stress of $40,000 \mathrm{lbs}$. $/$ in. ${ }^{2}$ or more the error may be as much as 5 per cent and probably not more than Io per cent. The effect of such error will be to make the stress appear less than it is.

\section{RESULTS OF TESTS.}

\section{DEFORMATIONS IN TILES, CONTROI SLABS, AND LARGE TEST SLAB.}

Figures 20 and $2 \mathrm{I}$ give the deformations for each gauge line in the tiles and in the concrete in control slabs I and 2, respectively, under different total loads and show that the tiles resisted an important part of the compressive stresses. At a given load the longitudinal deformation in the concrete rib was somewhat greater than that at a position immediately adjoining it in the tile. From that point outward to the edge of the slab the longitudinal deformation was approximately uniform. This was true of both control slabs. The first load applied caused cracks in the under surface of the slab. The total load shown on each curve in Figures 20 and $2 \mathrm{I}$ is the sum of the weight of the slab and the applied load.

Figures 23 and 24 show the average tensile deformation in the reinforcement and the average compressive deformation in the concrete and the tiles for control slabs I and 2, respectively, 
under different applied loads. The ratio of the deformation in the tiles to the deformation in the concrete was computed from these averages and is shown in Figure 25. The numbers attached to the points in Figures 22 and 25 indicate the order in which the observations were made.

The results for the tests on the two control slabs were very consistent. The average ratio of deformation in the tiles to the deformation in the concrete for all applied loads was 0.727 for slab No. I and 0.74 I for slab No. 2. The ratios for different ap-

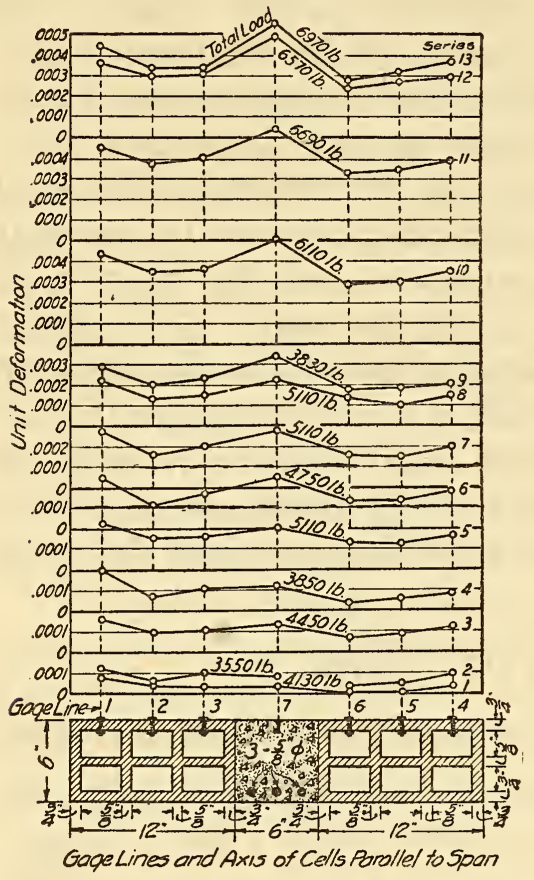

FIG. 20.-Distribution of compressive deformations across top of control slab No.I.

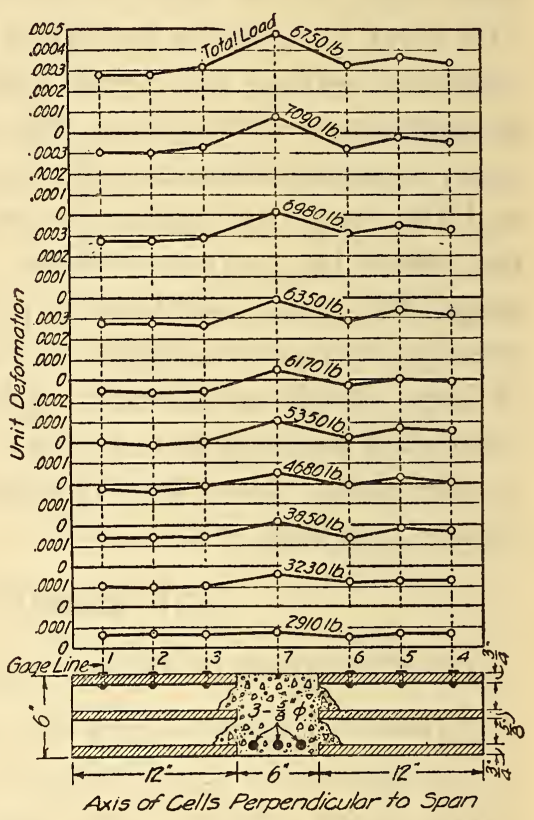

FIG. 21.-Distribution of compressive deformations across top of control slab No.2.

plied loads are more nearly uniform for control slab No. 2 than for slab No. I, due probably to the fact that for slab No. 2 all observations were made on the same day. The ratios obtained for control slab No. I were, in general, lower after the applied load had remained on the slab for a considerable length of time than the ratios obtained from observations taken immediately after the load was applied.

For the large slab, data for the comparison of the deformations in the tiles with the deformations in the concrete were available for two loads. The comparison can not be made directly, how- 
ever, since the gauge lines on the concrete in the large slab were located near the edge of the girders while those in the tiles were at least 7 inches farther from the point of the maximum negative

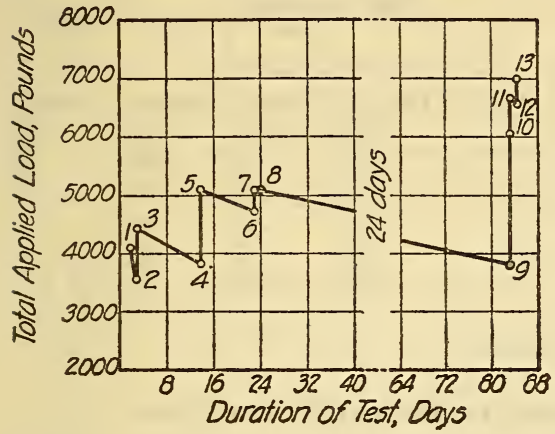

FIG. 22.-Duration-of-load curve for control slab No. I.

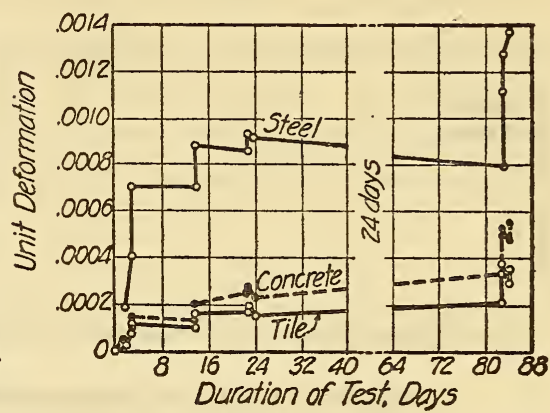

FIG. 23.-Deformations for control slab No. $I$ at successive stages of the test.

moment. Assuming that the unit deformation at any point in an element of the large slab was directly proportional to the distance from the point of zero stress, the deformations in the concrete

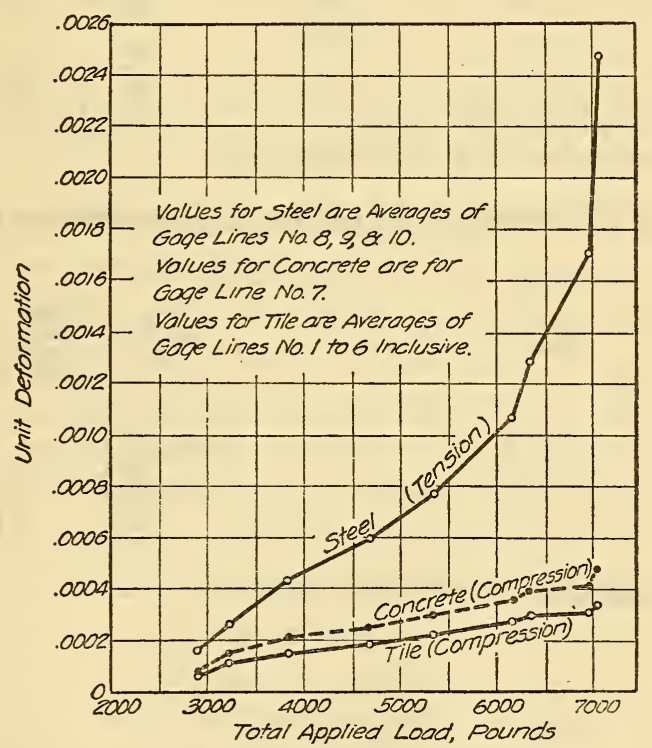

FIG. 24.-Load-deformation curves for control slab No. 2.

were corrected so as to make them comparable with the observed deformations in the tiles. Using the available data for the two loads, the ratio of the mean deformation in the tiles to the corrected mean deformation in the concrete was found to be 0.717 . 
TABLE 5.-Deflection in Square Panels under Constant Load.

\begin{tabular}{|c|c|c|c|c|}
\hline \multirow{2}{*}{ Panel. } & \multirow{2}{*}{$\begin{array}{l}\text { Applied } \\
\text { load. }\end{array}$} & \multirow{2}{*}{$\begin{array}{l}\text { Time } \\
\text { under } \\
\text { constant } \\
\text { load. }\end{array}$} & \multicolumn{2}{|c|}{ Deflection. } \\
\hline & & & $\begin{array}{c}\text { After one } \\
\text { day. }\end{array}$ & Final. ${ }^{1}$ \\
\hline 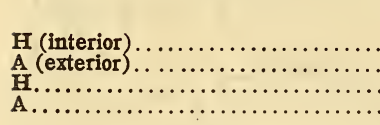 & \begin{tabular}{|r} 
Lbs./ft. 2 \\
160 \\
160 \\
210 \\
210
\end{tabular} & $\begin{array}{r}\text { Days. } \\
7 \\
7 \\
7 \\
7\end{array}$ & $\begin{array}{r}\text { Inches. } \\
0.00 \\
.08 \\
.00 \\
.12\end{array}$ & $\begin{array}{r}\text { Inches. } \\
0.00 \\
.10 \\
.00 \\
.12\end{array}$ \\
\hline 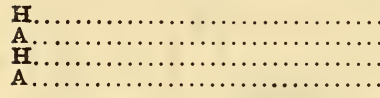 & $\begin{array}{l}397 \\
372 \\
730 \\
615\end{array}$ & $\begin{array}{l}52 \\
53 \\
30 \\
23\end{array}$ & $\begin{array}{r}.09 \\
.37 \\
.55 \\
1.36\end{array}$ & $\begin{array}{r}.22 \\
.70 \\
.68 \\
1.52\end{array}$ \\
\hline
\end{tabular}

1 At end of period indicated as "Time under constant load."

TABLE 6.-Deflection in Intermediate Panels under Constant Load.

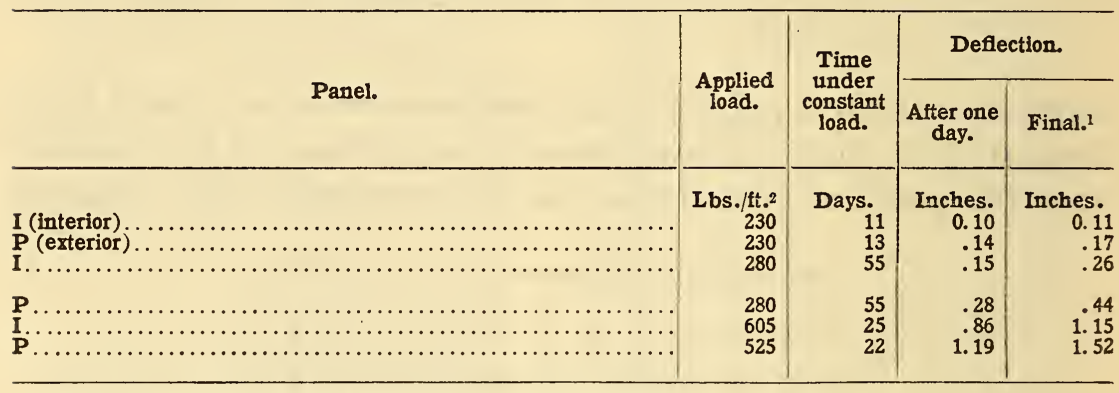

${ }^{1}$ At end of period indicated as "Time under constant load."

TABLE 7.-Deflections in Long Panels under Constant Load.

\begin{tabular}{|c|c|c|c|c|}
\hline \multirow{2}{*}{ Panel. } & \multirow{2}{*}{$\begin{array}{l}\text { Applied } \\
\text { load. }\end{array}$} & \multirow{2}{*}{$\begin{array}{l}\text { Time } \\
\text { under } \\
\text { constant } \\
\text { load. }\end{array}$} & \multicolumn{2}{|c|}{ Deflection. } \\
\hline & & & $\begin{array}{c}\text { After one } \\
\text { day. }\end{array}$ & Final. 1 \\
\hline 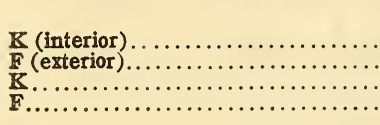 & $\begin{array}{r}\text { Lbs./ft. } 2 \\
230 \\
230 \\
505 \\
370\end{array}$ & $\begin{array}{r}\text { Days. } \\
69 \\
69 \\
25 \\
25\end{array}$ & $\begin{array}{r}\text { Inches. } \\
0.11 \\
.39 \\
1.04 \\
1.33\end{array}$ & $\begin{array}{r}\text { Inches. } \\
0.11 \\
.73 \\
1.32 \\
1.72\end{array}$ \\
\hline
\end{tabular}

${ }^{1}$ At end of period indicated as "Time under constant load." 
While this average agrees very closely with the ratio which was found between the deformations in the tiles and the deformations in the concrete in the control slabs, the variations between individual values for different parts of the slab were considerable.

The modulus of elasticity of the tiles was, in general, more than I.5 times the modulus of elasticity of the concrete. If the deformation in the tiles be taken as 0.70 times the simultaneous deformation in the adjoining concrete, the compressive unit stress in

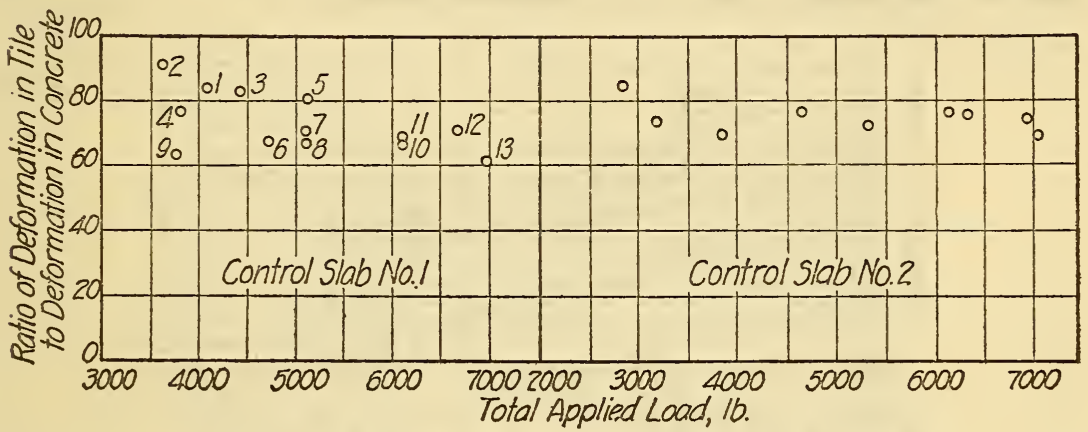

FIG. 25.-Ratios of unit deformation in tiles to unit deformation in concrete for control slabs.

the tiles must have been at least I.5 times 0.70 , or 1.05 times as great as the unit stress in the concrete.

\section{DEFLECTIONS FOR SQUARE PANELS.}

Figure 26 gives the deflections at the centers of the square panels and the loads which produced these deflections. In panel $A$ the deflection was 0.12 inch, or less than $r / r, 500$ of the clear span under an applied load of 2 ro $1 \mathrm{bs} . / \mathrm{ft} .{ }^{2}$, of which over twothirds had been in place for $I z$ days. Under the same unit load the deffections in the other square panels were less than this and in panel $H$ no deflection at all was detected.

There was, in general, a slight increase in deflection during the first day that the applied load of 2 Io $1 \mathrm{bs} . / \mathrm{ft}^{2}{ }^{2}$ was in place, but there was no further increase in deflection in any of the square panels due to that load remaining in place 6 days longer. As far as can be judged from the data available the slab behaved in the same manner under the loads of 160 and $35 \mathrm{lbs}$. $/ \mathrm{ft}^{2}{ }^{2}$ as for the load of 2 Io lbs. $/ \mathrm{ft}^{2}{ }^{2}$ No other load below the maximum uniform load was sustained long enough to give a basis for judging the effect of a continued static load on the deflections.

$$
108191^{\circ}-22 \longrightarrow 4
$$


For the loads exceeding 2 Io $\mathrm{lbs}$. $/ \mathrm{ft}^{2}{ }^{2}$ there appears to have been an increase in deflection as long as the load remained in place. It is not entirely certain that this is true since the readings of deflections were not taken with sufficient frequency in all of the panels to make certain that the entire amount of deflection did not take place soon after the load was applied. Of the square panels there was only one which may properly be termed an interior panel. The rate of deflection under constant load was less for this panel than for the exterior panels.

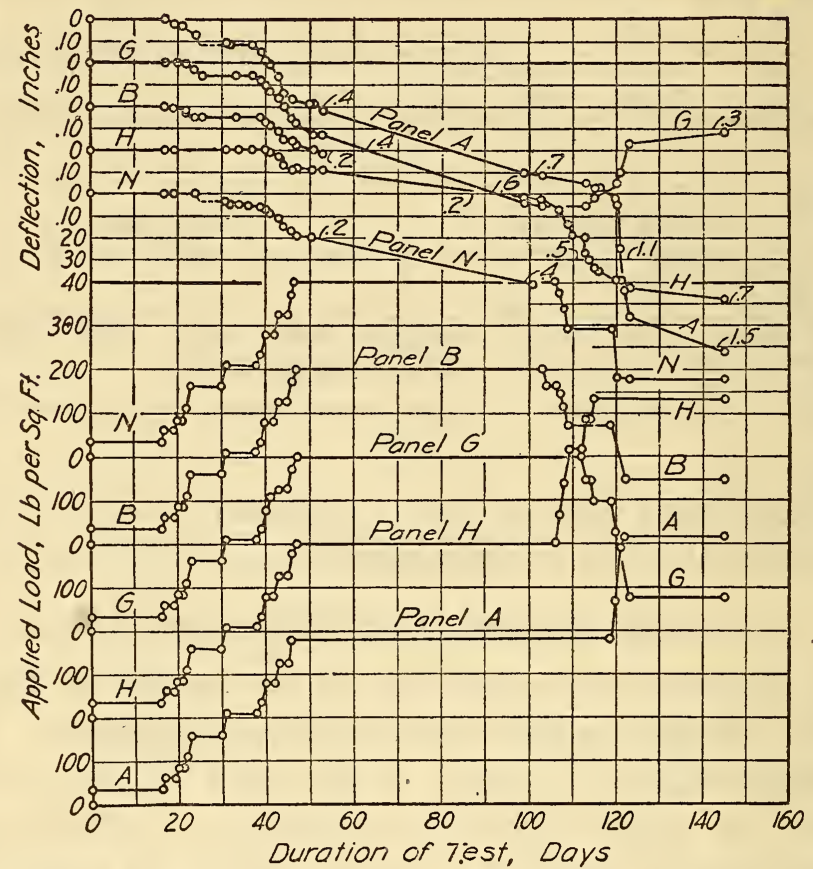

FIG. 26.-Deflections at centers of panels $A, B, G, H$, and $N$, and applied loads on the panels.

When load was shifted from panels $B, G$, and $N$ to panels $A$, $H$, and $M$, the deflections decreased in the former and increased in the latter until the greatest deflection reached in any square panel previous to the November loading occurred in panel $A$ (a corner panel) under a uniform live load of $615 \mathrm{lbs} . / \mathrm{ft}^{2}{ }^{2}$ This deflection was 1.36 inches after the load had been in place one day and $\mathrm{I} .52$ inches after the load had been in place 23 days. The maximum deflection for an interior square panel occurred in panel $H$ under a uniform live load of $730 \mathrm{lbs} . / \mathrm{ft}^{2}{ }^{2}$ This deflection increased from 0.55 inch within I day to 0.68 inch after the load 
had been in place for 30 days. Table 5 summarizes the principal deflections in the square panels. In Tables 5,6 , and 7 the deflection "after I day" is the deflection which was found after the load had been in place I day and the "final deflection" is that which was found at the end of the recorded "time under constant load."

\section{DEFLECTIONS FOR INTERMEDIATE-SIZE PANELS.}

Figure 27 gives the deflections at the center of the intermediatesize panels and the loads which produced these deflections.

Table 6 shows the effect of long-continued load on the deflections of typical panels.

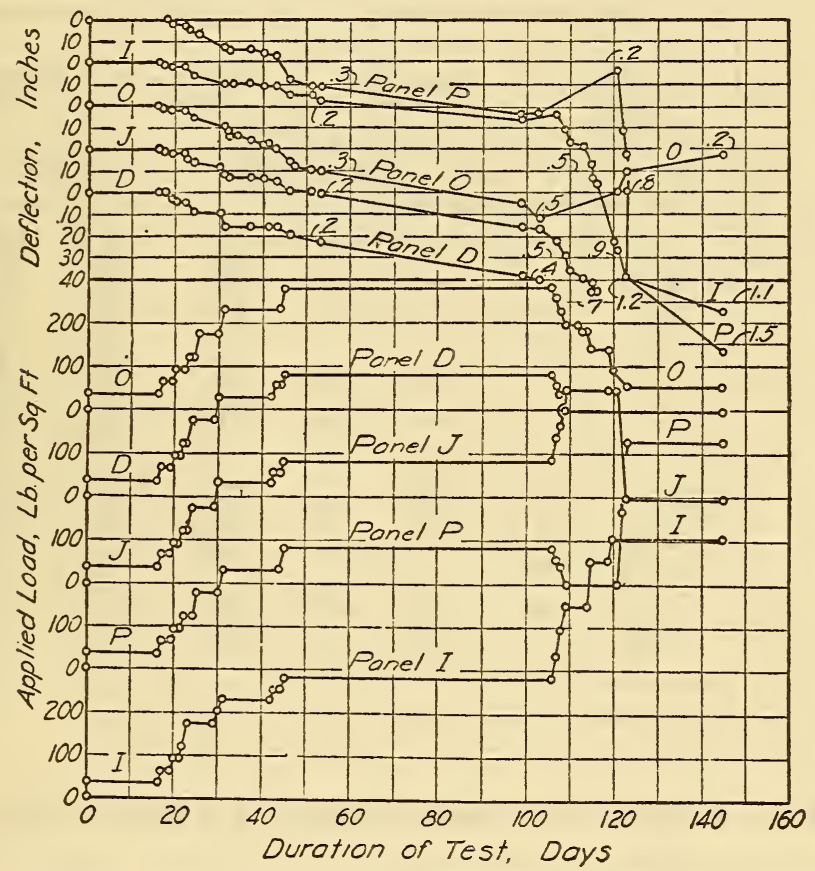

FIG. 27.-Deflections at centers of panels $D, I, J, O$, and $P$, and applied loads on the panels.

For the lower loads shown the increase in deflection under constant load was slight, even though the load was high in comparison with what in Section II, 2, are termed the design loads. For the larger loads the increase in deflection was considerably greater than for the smaller loads. The exterior panels showed a slightly greater rate of increase in deflection under constant load than the interior panels. The deflections shown for panels $I$ and $P$ under loads of 605 and $525 \mathrm{lbs} . / \mathrm{ft} .{ }^{2}$, respectively, were the largest deflections found for panels of the intermediate size. 
TABLE 8.-Recovery from Deflection upon Removal of Load from Exterior Panels.

\begin{tabular}{|c|c|c|c|c|c|c|c|}
\hline Panels. & $\begin{array}{c}\text { Applied } \\
\text { load. }\end{array}$ & $\begin{array}{c}\text { Defiec- } \\
\text { tion. }\end{array}$ & $\begin{array}{l}\text { Portion } \\
\text { load re }\end{array}$ & $\begin{array}{l}\text { of applied } \\
\text { moved. }\end{array}$ & $\begin{array}{l}\text { Recove } \\
\text { defie }\end{array}$ & $\begin{array}{l}y \text { from } \\
\text { tion. }\end{array}$ & $\begin{array}{l}\text { Recovery } \\
\text { per } 1 \text { per } \\
\text { cent load } \\
\text { removed. }\end{array}$ \\
\hline 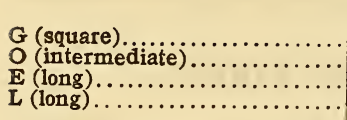 & $\begin{array}{r}\text { Lbs./ft. }{ }^{2} \\
397 \\
280 \\
230 \\
230\end{array}$ & $\begin{array}{r}\text { Inch. } \\
0.65 \\
.52 \\
.31 \\
.53\end{array}$ & $\begin{array}{r}\text { Lbs./ft. }{ }^{2} \\
321 \\
229 \\
148 \\
158\end{array}$ & $\begin{array}{r}\text { Per cent. } \\
81.0 \\
82.0 \\
64.0 \\
69.0\end{array}$ & $\begin{array}{r}\text { Inch. } \\
0.33 \\
.29 \\
.34 \\
.45\end{array}$ & $\begin{array}{r}\text { Per cent. } \\
51 \\
56 \\
110 \\
85\end{array}$ & $\begin{array}{r}\text { Per cent. } \\
0.63 \\
.68 \\
1.71 \\
1.24\end{array}$ \\
\hline
\end{tabular}

TABLE 9.-Distance from Surface of Slab to Surface of Slab Reinforcing Bars.

[Values (a) and (b) represent independent measurements at different places in the panel.]

\begin{tabular}{|c|c|c|c|c|c|c|c|c|}
\hline \multirow{3}{*}{ Panel. } & \multicolumn{4}{|c|}{ At positions of negative moment. } & \multicolumn{4}{|c|}{ At positions of positive moment. } \\
\hline & \multicolumn{2}{|c|}{$\begin{array}{l}\text { Over exterior } \\
\text { girders. }\end{array}$} & \multicolumn{2}{|c|}{$\begin{array}{l}\text { Over inierior } \\
\text { girders. }\end{array}$} & \multicolumn{2}{|c|}{$\begin{array}{c}\text { East-and-west } \\
\text { bars. }\end{array}$} & \multicolumn{2}{|c|}{$\begin{array}{l}\text { North-and-south } \\
\text { bars. }\end{array}$} \\
\hline & (a) & (b) & (a) & (b) & (a) & (b) & (a) & (b) \\
\hline $\begin{array}{l}\text { A... } \\
\text { B... } \\
\text { D... } \\
\text { E... }\end{array}$ & $\begin{array}{l}2.25 \\
1.12 \\
1.12 \\
1.87\end{array}$ & $\dddot{1} 1.75^{\circ}$ & 1.00 & & $\begin{array}{l}1.37 \\
1.00 \\
1.37 \\
1.43 \\
1.43\end{array}$ & $\begin{array}{l}1.25 \\
1.12 \\
1.37 \\
1.37 \\
1.37\end{array}$ & $\begin{array}{r}1.19 \\
.69 \\
.81 \\
.93 \\
.81\end{array}$ & $\begin{array}{l}0.75 \\
.69 \\
.81 \\
.87 \\
.87\end{array}$ \\
\hline $\begin{array}{l}\mathrm{F} . . . \\
\mathrm{G} \ldots \\
\mathrm{H} \ldots \\
\mathrm{J} . . .\end{array}$ & $\begin{array}{c}1.12 \\
\cdots \cdots \\
\cdots \cdots\end{array}$ & $\begin{array}{l}2.00 \\
\ldots \ldots \\
\ldots \ldots\end{array}$ & 1.25 & $\begin{array}{l}0.75 \\
1.00\end{array}$ & $\begin{array}{l}1.19 \\
1.25 \\
1.12 \\
1.19 \\
1.19\end{array}$ & $\begin{array}{l}1.31 \\
1.25 \\
1.19 \\
1.19 \\
1.37\end{array}$ & $\begin{array}{l}.87 \\
.75 \\
.56 \\
.75 \\
.93\end{array}$ & $\begin{array}{l}.75 \\
.69 \\
.69 \\
.87 \\
.87\end{array}$ \\
\hline 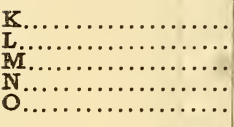 & $\begin{array}{l}1.30 \\
1.50\end{array}$ & $\begin{array}{r}1.025 \\
1.00\end{array}$ & $\begin{array}{r}1.00 \\
.87 \\
1.00 \\
\cdots \cdots\end{array}$ & $\begin{array}{r}1.00 \\
1.37 \\
.87 \\
\ldots \ldots \ldots \\
\ldots \ldots \ldots\end{array}$ & $\begin{array}{l}1.37 \\
1.25 \\
1.19 \\
1.25 \\
1.37\end{array}$ & $\begin{array}{l}1.43 \\
1.19 \\
1.12 \\
1.12 \\
1.19\end{array}$ & $\begin{array}{l}.93 \\
.69 \\
.69 \\
.75 \\
.75\end{array}$ & $\begin{array}{l}.75 \\
.62 \\
.81 \\
.81 \\
.81\end{array}$ \\
\hline 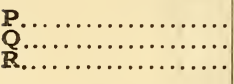 & $\begin{array}{l}1.62 \\
1.12 \\
1.12\end{array}$ & $\begin{array}{r}1.00 \\
\ldots \ldots \cdots \cdots \\
\cdots \cdots \cdots\end{array}$ & $\begin{array}{l}1.00 \\
1.25 \\
1.50\end{array}$ & $\begin{array}{r}1.00 \\
\ldots \ldots \ldots . \cdots \\
\ldots \ldots \ldots . .\end{array}$ & $\begin{array}{l}1.25 \\
1.69 \\
1.31\end{array}$ & $\begin{array}{l}1.19 \\
1.56 \\
1.56\end{array}$ & $\begin{array}{l}.81 \\
.93 \\
.93\end{array}$ & $\begin{array}{l}.69 \\
.93 \\
.75\end{array}$ \\
\hline Average........ & \multicolumn{2}{|c|}{1.42} & \multicolumn{2}{|c|}{1.04} & \multicolumn{2}{|c|}{1.29} & \multicolumn{2}{|c|}{0.80} \\
\hline
\end{tabular}

TABLE 10.-Values of $d$ and $j d$ Used in Computation of Moment Coefficients.

\begin{tabular}{|c|c|c|}
\hline Position or designation. & $d$. & $j d$. \\
\hline 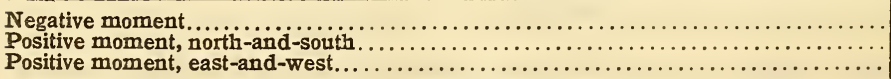 & $\begin{array}{l}4.75 \\
5.0 \\
4.5\end{array}$ & $\begin{array}{l}4.28 \\
4.50 \\
4.05\end{array}$ \\
\hline
\end{tabular}




\section{DERLECTIONS FOR LONG PANELS.}

Figure 28 gives the deflections at the centers of the long panels and the loads which produced these deflections.

Table 7 shows the effect on the deflections in certain panels of allowing the load to remain in position for a considerable length of time.

Approximately the same relation is seen between the deflections in long exterior panels and those in long interior panels

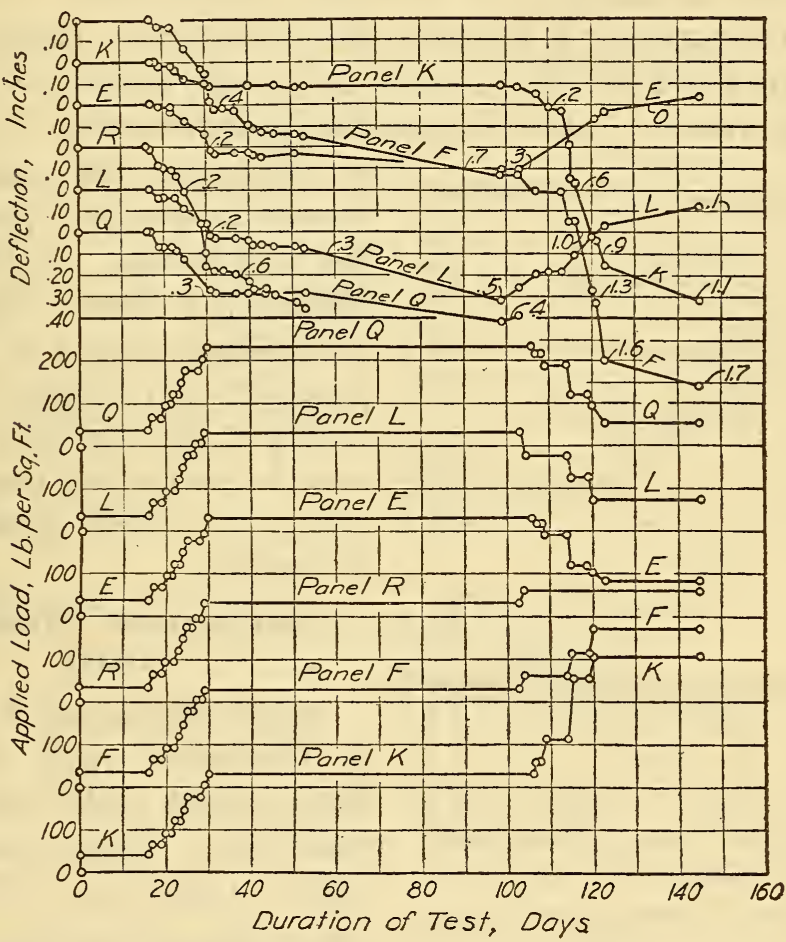

Fig. 28.-Deflections at centers of panels $E, F, K, L, Q$, and $R$ and applied loads on the panels.

as was found in the comparison of exterior and interior square and intermediate-size panels. The effect on long panels of standing under constant load was not greatly in excess of the effect for square and intermediate-size panels. When the fact is taken into account that the safe working load would be considerably different for the panels of different size, it does not appear that the effect of long-continued load was any greater for the long panels than for the others. 


\section{RECOVERY FROM DETLECTION UPON REMOVAL OF LOAD.}

Data on the effect of partial removal of load on deflection are available for a few panels. These data are given in Table 8 . The loads on these panels and surrounding panels before and after the load was changed are given in Figures 18 and 19.

The recovery in the panels referred to in Table 8 was assisted by the increase in load on the adjacent panels simultaneously with the decrease in load on panels, $G, O, E$, and $L$. The ratios of the loads on panels $G$. $O, E$, and $L$, respectively, to the loads on the corresponding heavily loaded adjacent panels do not vary so greatly but that a comparison of the amounts of recovery is of some value. Table 8 shows that proportionally the recovery
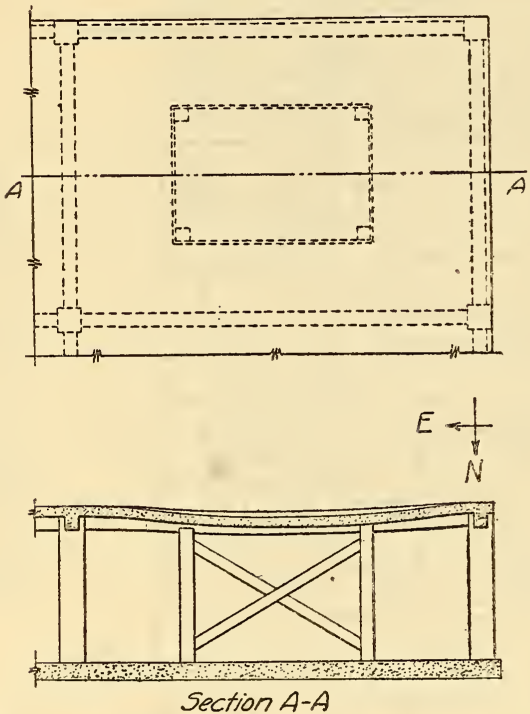

FIG. 29.-Panel $F$ resting on auxiliary posts. was least for the square panel reported upon and greatest for the long panels. A reference to Figure 39 shows that there were fewer cracks in the long panels $E$ and $L$ than in panels $G$ and $O$, and for that reason it may be expected that the recovery for these panels would be greater.

\section{б. DEFLECTION UNDER FINAL LOAD.}

Before the slab was first loaded in December, I919, four posts were placed under the slab in each panel. These posts were of such a length that their upper ends came within about 3 inches of the bottom of the slab. These posts were provided in order to insure safety in case complete failure should occur with the slab under load. Up to April 22, I920, the end of the first test, none of the panels had deflected sufficiently to cause the slab to rest upon the posts. Within a few weeks it was noted that the slab of panel $F$ had deflected so that it rested upon two of the posts. The other two posts were free of the slab. Figure 29 shows approximately in plan the position of the posts and in elevation the original and deflected positions of the slab. The locations of the posts in the other panels were approximately the same as those in panel $F$. 
After the completion of the April test the deflection apparatus had been removed and the further deflection of the slab could not be determined except by measurement of the curvature of its under surface, assuming that originally it was a plane surface. By this means the deflections shown in Figure 30 for November 4 and 8 were found just previous to the November test.

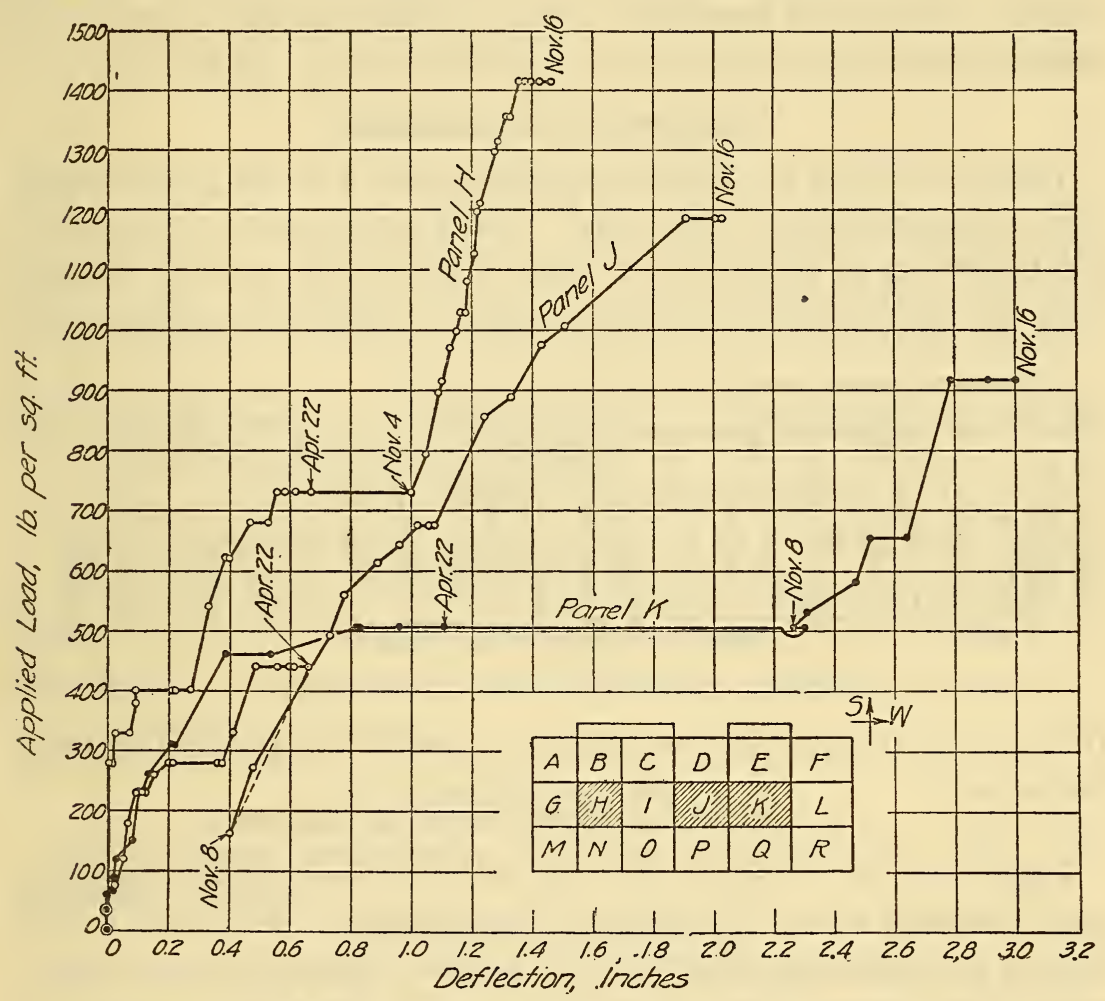

Fig. 30.-Deflections of panels $H, J$, and $K$, up to November, Igro.

Before the final loading (applied in November, I920) the thread and mirror apparatus for measuring deflections was replaced in the panels to which more load was applied and during the test additional deflections were observed. The error of these deflection readings is believed to be not more than plus or minus o.or inch. The error of determining the deflections by means of the curvature of the slab surface before the application of load in November, I 920 , may be as much as plus or minus O.I inch.

The deflections for panels $H, J$, and $K$ up to the middle of November are given in Figure 30. Apparently the deflection at the center of panel $H$ had increased from 0.68 inch at the end of 
the April test to about I.o inch at the beginning of the November test. The deflection in panel $J$ had changed very little, but that in panel $K$ had increased about I.2 inches between the April and the November tests. In view of the fact that the live load on the slab during this time was more than ro times as great as the "design loads" given in Section II, 2, this increase in deflection is small. For all the panels the rate of deflection with increase of load was about the same for the high load as for the low load.

\section{DEFLECTION OF GIRDERS.}

Figure 3 I gives the load-deflection curves for the girders upon which measurements were taken. These deflections are given for the period up to February I0, I920, when the maximum uniform load had been in place about two weeks. Deflection readings after

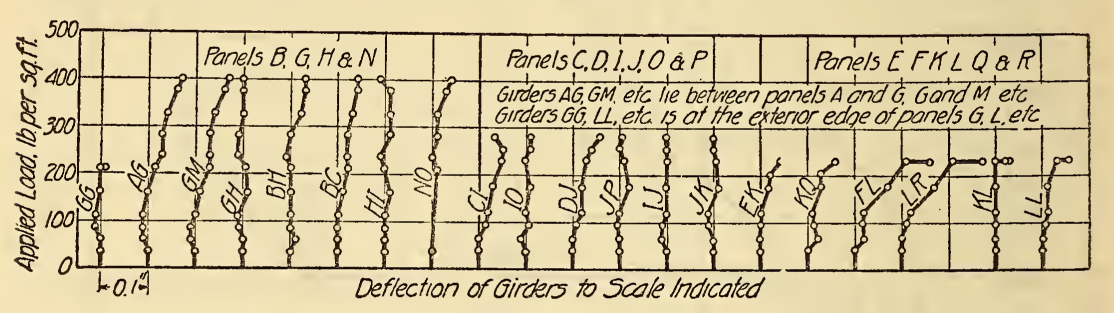

FIG. 3I.-Load-deflection curves for girders.

this time were not taken because the observation points had been disturbed.

\section{TORSIONAL RESISTANCE OF GIRDERS.}

Figures 45 to 47 show that the deformations in the negative reinforcement across the edges of the wall girders were very small. This is an indication that the wall girders twisted without giving much resistance to torsional moment. The fact that the negative moment coefficients (see Fig. 32) for the slab over the girders which were one panel length or width away from the wall girder were no greater, in general, on the edge of the girder toward the wall than on the edge farther from the wall, points toward the same conclusion. The torsional resistance of the girder is the only thing which should introduce any appreciable difference between the stresses at these two points and since the difference in stresses was too slight to be detected the torsional resistance of the girder could not have been large.

If there were no torsional resistance in the wall girders, the lack of fixity of the slab at the wall would be expected to be accompanied by high stresses due to positive moment at the middle of 
the wall span. The average stresses due to positive moment in the square and the long wall panels were greater than corresponding averages for interior panels, while in the intermediate size wall panels they were less than in the interior panels. The average, however, for wall panels of all sizes was almost the same as that for interior panels. This seems to be in contradiction to the indications of the preceding paragraph. Possibly the inconsistency is only apparent and is due to the fact that at positions of positive moment and at sections along the wall girders the stresses were generally so low that the concrete was not extensively cracked. This would vitiate a comparison of moments based upon measured steel stresses. That this may be the explanation is indicated by the fact that the greatest excess of stress due to positive moment in wall panels over that in interior panels is found by using panel $R$ in the comparison. The concreting was of a poorer quality in that panel than elsewhere, and such differences would be magnified.

\section{MEASURED DEPTH TO REINFORCEMENT.}

The depth from the tension surface of the slab to the surface of the reinforcement was measured in representative positions in various parts of the slab. The depths are shown in Table 9. The depths to the centers of the bars were used for the computations of resisting moment.

\section{MOMENT COEFFICIENTS.}

The moment coefficients, $K$, were computed by using the following relation:

$$
M=K W l=A f j d \text { where }
$$

$M=$ total resisting moment offered by the observed tensile stresses in the reinforcement which crossed one edge of the panel (for negative moment) or the center line of the panel (for positive moment).

$W=0.92$ of the sum of the live and dead load within the panel area (see Sec. II, 4); the dead load was taken as $50 \mathrm{lbs} . / \mathrm{ft}^{2}$;

$l=$ clear span in the direction of the short side (180 inches);

$A=$ total sectional area of reinforcement crossing an edge or a center line of the panel considered;

$f=$ observed tensile stress in the reinforcement plus an allowance of 2 per cent for the dead load stress in the reinforcement ${ }^{6}$;

$j d=$ moment arm of the resisting couple.

6 The stresses used in computing the average coefficients given in Table I 5 range probably from 30,000 to $50,000 \mathrm{lbs}$./in. ${ }^{2}$ Therefore, the stress allowed for dead-load ranges from 600 to $\mathrm{I}, 000 \mathrm{lbs}$./in. ${ }^{2}$ For a discussion of stresses before cracking of the concrete, see Westergaard and Slater, "Moments and stresses in slabs," Proc. Am. Concrete Inst., 17, p. 478; r921.

$108191^{\circ}-22-5$ 
For positions of negative moment the distance $d$ from the compression surface of the slab to the center of the reinforcement was determined from the average measurements taken at the edges of the girders in a number of places on the slab and was found to be $4.7 \mathrm{I}$ inches. The value used in computations was 4.75 inches.

The value used for $j$ was 0.9 and for $j d 4.28$ inches. This was obtained from the relation

$$
j d=d-\frac{1}{3} k d
$$

in which $k d$, the depth from the compression surface to the neutral axis, was determined by the ordinary methods from the measured deformations; that is, by assuming that the deformations varied directly with the distance from the neutral axis. This value of $j d$ represents the average for all panels for the positions where maximum deformations occurred in the reinforcement in the top of the slab and in the concrete below.

The moment coefficients given in this paper represent a measure of the moment resisted by the stress in the reinforcement. It is recognized that this stress will not account for all the moment in the slab. A study of the results of this test as a basis for an estimate of the total moments has been made elsewhere. ${ }^{7}$

The same considerations as those which in Section III, 16 , are stated as a reason for expecting the tiles to form an integral part of the slab in resisting the shearing stress, also constitute a reason for expecting an appreciable part of the moment to be carried in other ways than by tension in the reinforcement, just as has been found in other tests of concrete slabs. In the basing of coefficients for design upon the values here given account must be taken of this fact.

The values of the observed deformations after the load had been in place about nine weeks were used as the basis of the computations of $j d$. The value of $j d$ as computed from deformations observed after two weeks under load was 4.35 inches. The decrease in the value of $j d$ with long-continued loading will help to account for the corresponding increases in tensile stress in the reinforcement. However, it is probable that progressive cracking of the concrete played a more important part in causing the increase in the tensile stress than did the decrease in $j d$.

\footnotetext{
${ }^{7}$ Westergaard and Slater, "Moments and stresses in slabs," Proc. Am. Concrete Inst., 17, p. 495-500;
} I92I. 
The values of $d$ and $j d$ for positions of positive moment were determined similarly to those for negative moment. The values for both positions are given in Table Io. For both control slabs the value of $j d$ as computed from deformations for all loads was 4.35 inches.

Values for the stress, $f$, for use in the computations were obtained by drawing symmetrical curves which would conform as closely as possible to the points plotted to show the distribution of deformations under various loads. (See Figs. 45 to 49.) Each curve was fitted to the points in such a way that the area between the zero line of deformations and the curve which was fitted to the plotted points would be equal to the area between the zero line of deformations and the straight lines connecting the points. The methods of drawing the curves is illustrated in Figure 45. The stress represented by the vertex of each one of these curves was used as the $f$ of the resisting moment equation and is called the "weighted maximum stress". These weighted stresses are given in Tables I I and I3. Using the weighted maximum stress instead of the average stress to determine the moment $M$ gives a larger moment than the summation of the individual moments of the stresses in the respective reinforcing bars.

Coefficients of bending moment have not been computed from deformations observed in the concrete on account of uncertainty as to the intensity of the stress in the concrete. Numerous tests ${ }^{8}$ have shown that the deformations in concrete change enough, under long-sustained constant load, to make it impossible to determine a fixed value of the modulus of elasticity. Thus, the average deformations in the concrete in the sections of the slab indicated in Figures 50 to 52 showed increases varying from practically nothing to more than 200 per cent of the deformation at the beginning of the period.

It was found that the average increase in deformation in the concrete under long-continued load was considerably greater than the average increase in the deformation in the reinforcement during the same period.

${ }^{8}$ (a) F. R. McMillan, "Shrinkage and time effect in reinforced-concrete" Studies in Engineering, No. 3, Univ. of Minnesota; March, I9I5.

(b) Almon H. Fuller and Charles C. More, "Time tests of concrete," Proc. Am. Concrete Inst., 12, p. $302 ; 1916$.

(c) Earl B. Smith, "The flow of concrete under sustained loads," Proc. Am. Concrete Inst., 12, p. 317; 1916, and 13, p. 99, 1917. 


\section{NEGATIVE MOMENTS IN SLAB.}

The stresses in the negative reinforcement observed after the load had been in place about nine weeks were used as a basis for the calculations of moment coefficients. These stresses were considerably higher than those observed after the load had been in place about two weeks. The effect of the load remaining in place for the longer period was to increase the average of the weighted maximum stresses by 38 per cent for the square panels, 57 per cent for the intermediate-size panels, and 23 per cent for the long panels. In some places, as may be seen in Figures 45 to 47 , the yield point of the reinforcement had been reached.

Table II gives the moment coefficients as computed from the weighted maximum stresses in the reinforcement crossing the

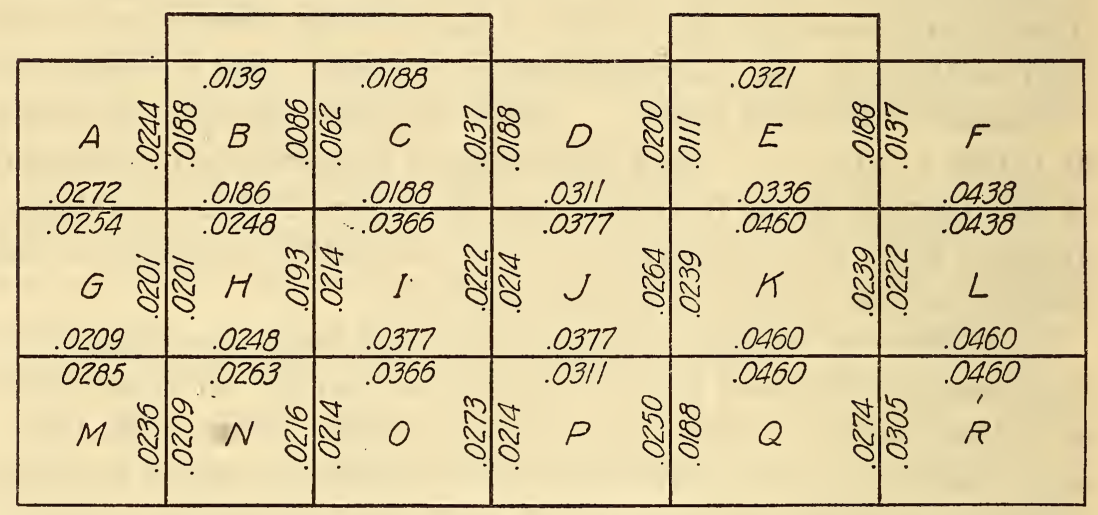

FIG. 32.-Coefficients of negative moment with maximum uniform load in place 55 to 73 days.

edges of the panels. These coefficients are shown in Figure 32 along the panel edges to which they apply.

In Table I I the coefficients are classified as for either interior or exterior panels. A moment is classified as for an exterior panel if it is computed from the stress across the edges of a girder one panel length (or width) removed from a wall girder. For this purpose a cantilever is considered as having the same effect as a panel.

In Figures 33 and 34 the coefficients of negative moment for the panels are shown as ordinates and the ratios of length to width of panels as abscissas. The broken lines in the figures represent mean coefficients for like edges. The averages of the 
TABLE 11.-Weighted Maximum Tensile Stresses in Slab Reinforcement and Resulting Coefficients of Negative Moment.

SQUARE PANELS.

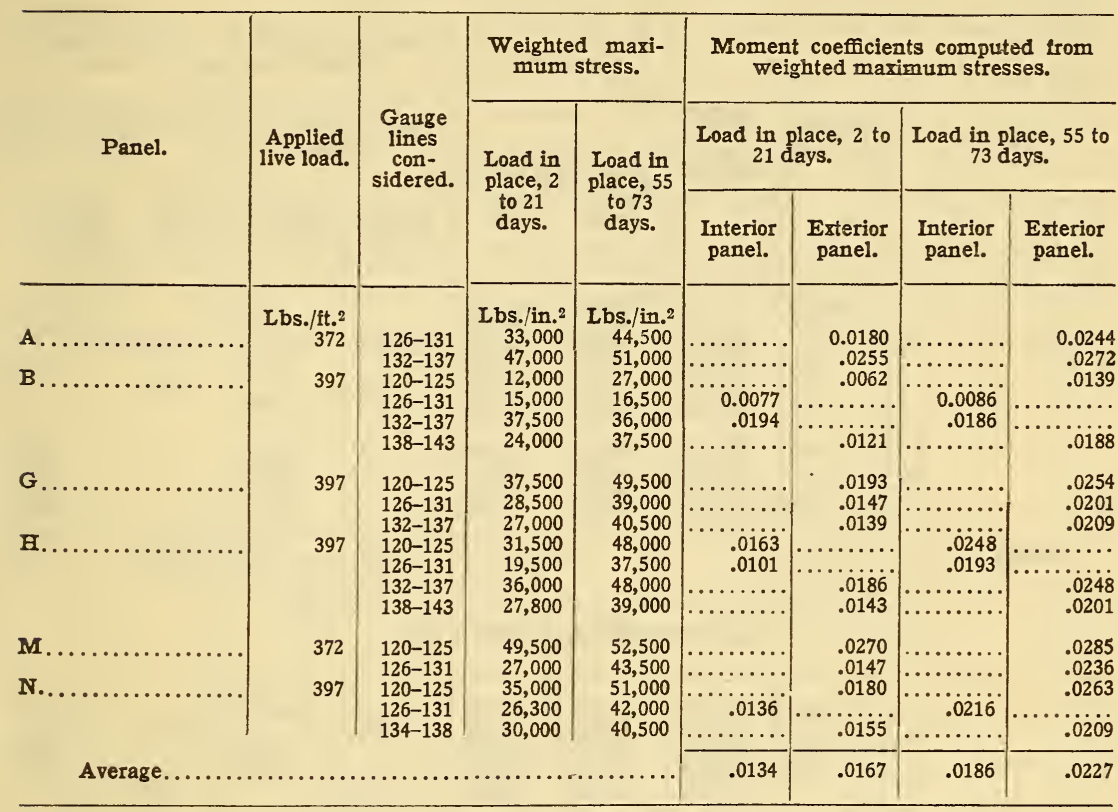

INTERMEDIATE PANELS-SHORT SPAN.

\begin{tabular}{|c|c|c|c|c|c|c|c|c|}
\hline $\begin{array}{l}\mathbf{C} \ldots \ldots \ldots \ldots \cdots \cdots \\
\mathbf{D} \ldots \ldots \cdots \cdots \cdots \cdots \cdots\end{array}$ & $\begin{array}{l}280 \\
280 \\
280\end{array}$ & $\begin{array}{l}120-127 \\
135-140 \\
135-140 \\
121-126 \\
135-140\end{array}$ & $\begin{array}{l}15,000 \\
19,500 \\
40,500 \\
31,500 \\
33,800\end{array}$ & $\begin{array}{l}25,500 \\
25,500 \\
42,000 \\
49,500 \\
51,000\end{array}$ & $\left|\begin{array}{r}0.0145 \\
.0233 \\
\cdots \\
\cdots\end{array}\right|$ & $\begin{array}{r}0.0111 \\
\cdots \cdots \\
.0300 \\
.0250\end{array}$ & $\mid \begin{array}{r}0.0188 \\
.0366 \\
\cdots\end{array}$ & $\begin{array}{r}0.0188 \\
\ldots \ldots .0311 \\
\ldots \ldots .0377\end{array}$ \\
\hline 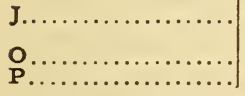 & $\begin{array}{l}280 \\
280 \\
280\end{array}$ & $\begin{array}{l}121-126 \\
135-140 \\
121-126 \\
121-126\end{array}$ & $\begin{array}{l}33,000 \\
37,500 \\
34,500 \\
30,000\end{array}$ & $\begin{array}{l}51,000 \\
51,000 \\
49,500 \\
42,000\end{array}$ & $\mid \begin{array}{c}\cdots \cdots \cdots \\
\cdots \cdots \cdots \\
\cdots \cdots \cdots \\
\cdots \cdots \cdots \\
\end{array}$ & $\begin{array}{l}.0247 \\
.0278 \\
.0255 \\
.0222\end{array}$ & 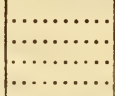 & $\begin{array}{l}.0377 \\
.0377 \\
.0366 \\
.0311\end{array}$ \\
\hline Average & & 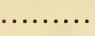 & & & .0189 & .0238 & .0277 & .0330 \\
\hline
\end{tabular}

INTERMEDIATE PANELS-LONG SPAN.

\begin{tabular}{|c|c|c|c|c|c|c|c|c|}
\hline 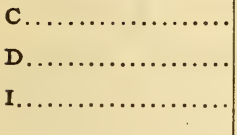 & $\begin{array}{l}280 \\
280 \\
280\end{array}$ & $\begin{array}{l}128-133 \\
142-147 \\
128-133 \\
142-147 \\
128-133 \\
142-147\end{array}$ & $\begin{array}{l}22,500 \\
12,000 \\
26,300 \\
18,000 \\
15,000 \\
18,000\end{array}$ & $\begin{array}{l}24,000 \\
28,500 \\
35,000 \\
33,000 \\
39,000 \\
37,500\end{array}$ & $\begin{array}{r}0.0128 \\
.0068 \\
.0150 \\
.0103 \\
.0086 \\
.0103\end{array}$ & 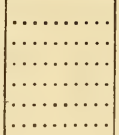 & $\begin{array}{l}0.0137 \\
.0162 \\
.0200 \\
.0188 \\
.0222 \\
.0214\end{array}$ & 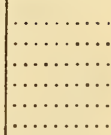 \\
\hline 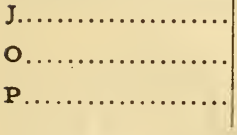 & $\begin{array}{l}280 \\
280 \\
280\end{array}$ & $\begin{array}{l}128-133 \\
142-147 \\
128-133 \\
142-147 \\
128-133 \\
142-147\end{array}$ & $\begin{array}{l}19,500 \\
34,500 \\
18,500 \\
25,500 \\
19,500 \\
28,200\end{array}$ & $\begin{array}{l}46,500 \\
37,500 \\
48,000 \\
37,500 \\
44,000 \\
37,500\end{array}$ & $\begin{array}{l}.0111 \\
.0197 \\
.0107 \\
.0146 \\
.0111 \\
.0161\end{array}$ & 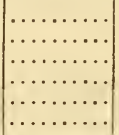 & $\begin{array}{l}.0264 \\
.0214 \\
.0273 \\
.0214 \\
.0250 \\
.0214\end{array}$ & 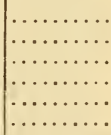 \\
\hline \multicolumn{5}{|l|}{ Average. } & .0123 & & .0213 & $\ldots$ \\
\hline
\end{tabular}


TABLE 11.-Weighted Maximum Tentile Stresses in Slab Reinforcement and Resulting Coefficients of Nagative Moment-Continued.

LONG PANELS-SHORT SPAN.

\begin{tabular}{|c|c|c|c|c|c|c|c|c|}
\hline \multirow{3}{*}{ Panel. } & \multirow{3}{*}{$\begin{array}{l}\text { Applied } \\
\text { live load. }\end{array}$} & \multirow{3}{*}{$\begin{array}{l}\text { Gauge } \\
\text { lines } \\
\text { con- } \\
\text { sidered. }\end{array}$} & \multicolumn{2}{|c|}{$\begin{array}{l}\text { Weighted maxi- } \\
\text { mum stress. }\end{array}$} & \multicolumn{4}{|c|}{$\begin{array}{l}\text { Moment coefficients computed from } \\
\text { weighted maximum stresses. }\end{array}$} \\
\hline & & & \multirow{2}{*}{$\begin{array}{l}\text { Load in } \\
\text { place, } 2 \\
\text { to } 21 \\
\text { days. }\end{array}$} & \multirow{2}{*}{$\begin{array}{c}\text { Load in } \\
\text { place, } 55 \\
\text { to } 73 \\
\text { days. }\end{array}$} & \multicolumn{2}{|c|}{$\begin{array}{l}\text { Load in place, } 2 \text { to } \\
21 \text { days. }\end{array}$} & \multicolumn{2}{|c|}{$\begin{array}{l}\text { Load in place, } 55 \text { to } \\
73 \text { days. }\end{array}$} \\
\hline & & & & & $\begin{array}{l}\text { Interior } \\
\text { panel. }\end{array}$ & $\begin{array}{l}\text { Exterior } \\
\text { panel. }\end{array}$ & $\begin{array}{l}\text { Interior } \\
\text { panel. }\end{array}$ & $\begin{array}{l}\text { Exterior } \\
\text { panel. }\end{array}$ \\
\hline $\begin{array}{l}\text { E. } \\
\text { F. } \\
\text { IK. }\end{array}$ & $\begin{array}{r}\text { Lbs./ft. } 2 \\
230 \\
230 \\
230\end{array}$ & $\begin{array}{l}120-128 \\
135-143 \\
135-143 \\
120-128 \\
135-143\end{array}$ & $\begin{array}{c}\text { Lbs./in. }{ }^{2} \\
36,000 \\
36,000 \\
44,300 \\
44,500 \\
46,500\end{array}$ & $\begin{array}{r}\text { Lbs./in. }{ }^{2} \\
37,500 \\
40,500 \\
51,000 \\
53,500 \\
53,500\end{array}$ & $\begin{array}{l}0.0309 \\
.0380\end{array}$ & $\begin{array}{l}0.0309 \\
\ldots .0379 \\
.0379 \\
.0399\end{array}$ & $\begin{array}{l}0.0336 \\
.0460 \\
.0460\end{array}$ & $\begin{array}{l}0.0321 \\
\ldots .0438 \\
\ldots .030 \\
.0460\end{array}$ \\
\hline $\begin{array}{l}\mathbf{L} \ldots \ldots \ldots \ldots \\
\mathbf{Q} \ldots \ldots \ldots \ldots \ldots \\
\mathbf{R} \ldots \ldots \ldots \ldots \ldots\end{array}$ & $\begin{array}{l}230 \\
230 \\
230\end{array}$ & $\begin{array}{l}120-128 \\
135-143 \\
120-128 \\
120-128\end{array}$ & $\begin{array}{l}38,500 \\
52,500 \\
42,000 \\
48,000\end{array}$ & $\begin{array}{l}51,000 \\
53,500 \\
53,500 \\
53,500\end{array}$ & & $\begin{array}{l}.0330 \\
.0450 \\
.0360 \\
.0411\end{array}$ & & $\begin{array}{l}.0438 \\
.0460 \\
.0460 \\
.0460\end{array}$ \\
\hline Average. . & & & & & .0344 & .0376 & .0398 & .0434 \\
\hline
\end{tabular}

IONG PANELS-LONG SPAN.

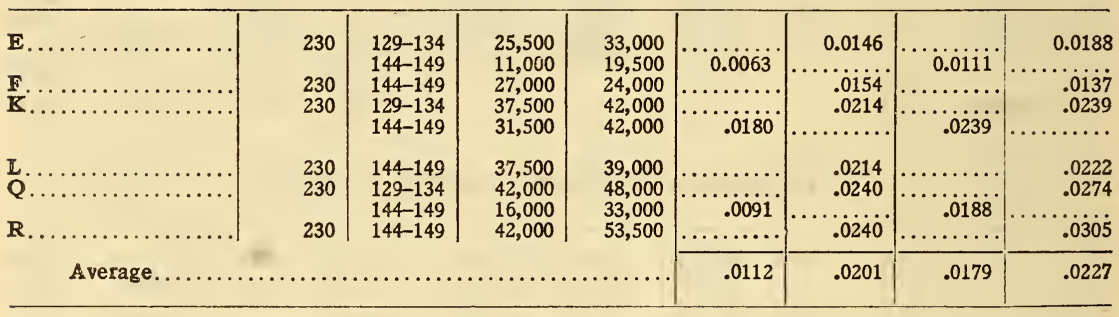

coefficients for interior and exterior panels for the square, intermediate, and long panels are given in Table 16 . The coefficients of negative moments for the short span showed a marked increase with the increase in ratio of length to width of panel, while the coefficients for the long span changed only slightly with the increased ratio of length to width.

The average moment coefficient for exterior panels was greater in all cases than the corresponding coefficients for interior panels. The ratios of the negative bending moments due to the observed stresses for exterior panels to those for interior panels are given in Table $\mathrm{I} 2$.

An examination of the data shows that without exception the negative moments accounted for by the stress in the steel even for the square panels were greatest in the north-and-south direction. The average of all the moment coefficients given in Table 
II for the north-and-south direction is 27 per cent greater than the average for the east-and-west direction. It is not known whether this difference should be taken to indicate that a larger proportion of the load was carried to the girders on the north-andsouth margins of the panels or that the concrete and the tiles assisted less in carrying the tensile stresses in the north-and-south direction than in the east-and-west direction. The tiles in all panels were laid with the axes of their cells extending in the north-and-south direction, and the participation of the tiles in resisting tensile stresses in that direction would come mainly through adhesion between the tile and the concrete. For the

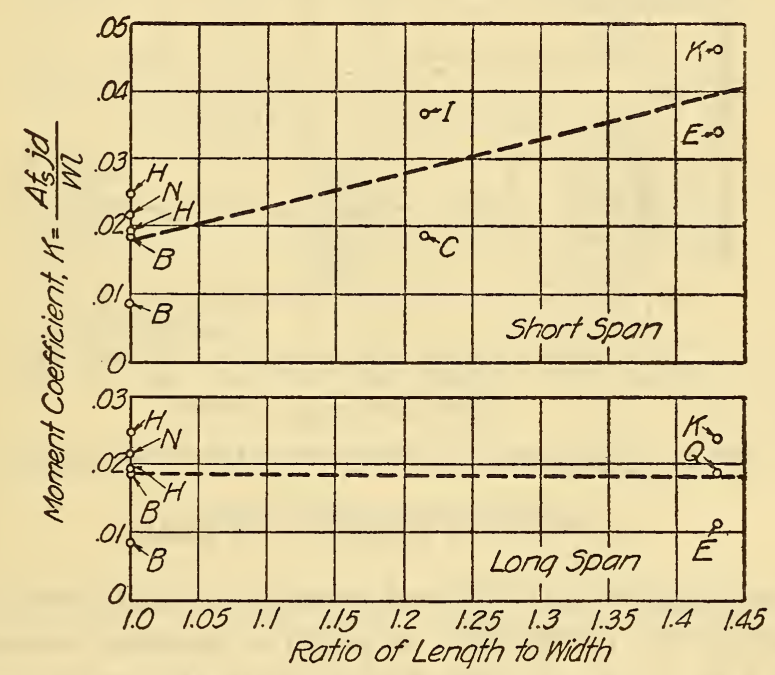

FIG. 33.-Coefficients of negative moment for interior panels.

east-and-west direction the adhesion would probably be less effective, but due to the flow of concrete into the cells of the tiles there is an interlocking which should assist in transferring tensile stresses into the tiles.

A similar relation between positive moments in the two directions is shown in Table $\mathrm{I} 3$, but the excess of the moments in the north-and-south direction over those in the east-and-west direction is only about ro per cent, and the number of cases for which comparisons can be made is smaller than for positions of negative moment. The difference in depth to the center of the reinforcement for the two directions as shown in Table ro and the distribution of loads (see Fig. 19) were such as to make an excess of stress 
in the north-and-south direction appear reasonable. Furthermore, even if the stresses were the same in the two directions the greater moment arm for the north-and-south direction would be sufficient to account for the difference in moments.

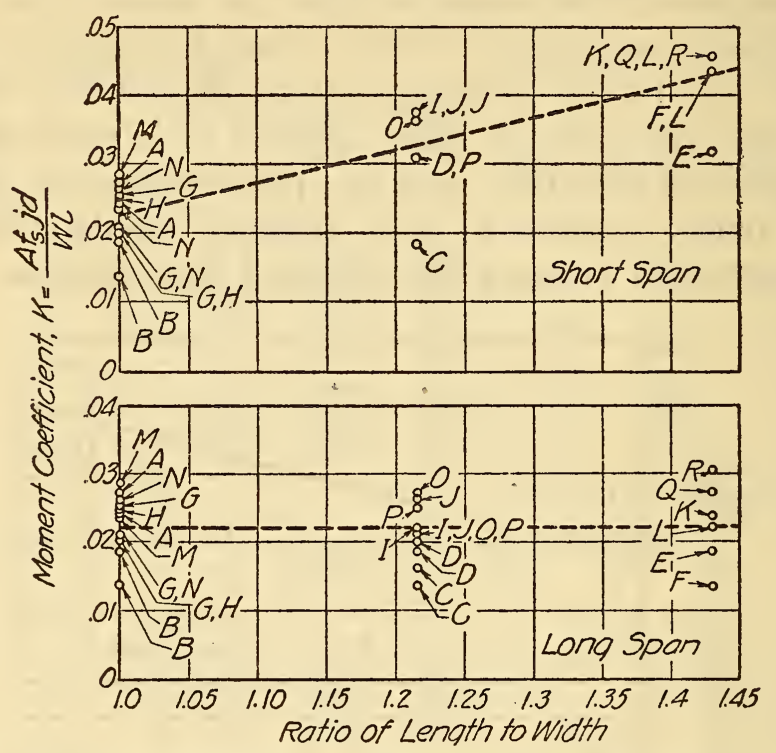

FIG. 34-Coefficients of negative moment for exterior panels.

\section{POSITIVE MOMENTS IN SLAB.}

The stresses in the positive reinforcement, which formed the basis for computing the coefficients of positive bending moment, were developed by loading typical panels until the under surfaces of those panels were cracked to some extent and the stress in the reinforcement was generally beyond $30,000 \mathrm{lbs}$./in. ${ }^{2}$

TABLE 12.-Ratios of Negative Moments in Exterior Panels to Negative Moments in Interior Panels.

\begin{tabular}{|c|c|c|c|}
\hline Size of panel between gircers. & $\begin{array}{l}\text { Ratio of } \\
\text { length to } \\
\text { width. }\end{array}$ & $\begin{array}{l}\text { Clear } \\
\text { span. }\end{array}$ & $\begin{array}{l}\text { Ratios of } \\
\text { moments, } \\
\text { exterior to } \\
\text { interior. }\end{array}$ \\
\hline 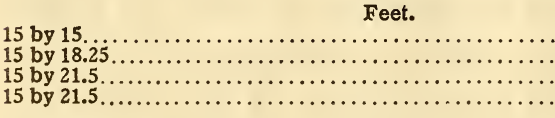 & $\begin{array}{l}1.0 \\
1.22 \\
1.43 \\
1.43\end{array}$ & $\begin{array}{l}\text { Feet. } \\
15 \\
15 \\
15 \\
21.5\end{array}$ & $\begin{array}{l}1.22 \\
1.19 \\
1.09 \\
1.27\end{array}$ \\
\hline Average... & & & 1.19 \\
\hline
\end{tabular}


TABLE 13.-Weighted Maximum Stresses in Slab Reinforcement and Resulting Coefficients of Positive Moment. SQUARE PANELS.

\begin{tabular}{|c|c|c|c|c|c|}
\hline \multirow{2}{*}{ Panel. } & \multirow{2}{*}{$\begin{array}{l}\text { Applied } \\
\text { live load. }\end{array}$} & \multirow{2}{*}{$\begin{array}{l}\text { Gage } \\
\text { lines } \\
\text { consid- } \\
\text { ered. }\end{array}$} & \multirow{2}{*}{$\begin{array}{c}\text { Weighted } \\
\text { maximum } \\
\text { stresses. }{ }^{1}\end{array}$} & \multicolumn{2}{|c|}{$\begin{array}{l}\text { Moment coefficients } \\
\text { computed from, } \\
\text { weighted maxi- } \\
\text { mum stresses. }\end{array}$} \\
\hline & & & & $\begin{array}{c}\text { Interior } \\
\text { parel. }\end{array}$ & $\begin{array}{c}\text { Exterior } \\
\text { panel. }\end{array}$ \\
\hline 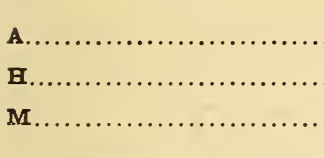 & $\begin{array}{r}\text { Lbs./ } \text { ft. }^{2} \\
615 \\
730 \\
545\end{array}$ & $\begin{array}{l}1-6 \\
7-12 \\
1-6 \\
7-12 \\
1-6 \\
7-12\end{array}$ & \begin{tabular}{|r|} 
Lbs./in. ${ }^{2}$ \\
33,000 \\
30,000 \\
30,000 \\
33,000 \\
32,000 \\
32,000
\end{tabular} & $\begin{array}{r}0.0084 \\
.0102 \\
\ldots \ldots \\
\cdots\end{array}$ & $\begin{array}{r}0.0108 \\
.0109 \\
\ldots .6 . \\
\cdots .0117 \\
.0130\end{array}$ \\
\hline Average..... & & - & & .0093 & .0116 \\
\hline
\end{tabular}

INTERMEDIATE PANELS-SHORT SPAN.

\begin{tabular}{|c|c|c|c|c|c|}
\hline 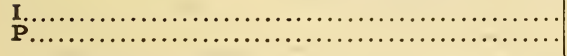 & $\begin{array}{l}605 \\
525\end{array}$ & $\begin{array}{l}7-14 \\
7-14\end{array}$ & $\begin{array}{l}39,000 \\
39,000\end{array}$ & $\begin{array}{r}0.0154 \\
\cdots \cdots \cdots\end{array}$ & 0.0176 \\
\hline
\end{tabular}

INTERMEDIATE PANELS-LONG SPAN.

\begin{tabular}{|c|c|c|c|c|c|}
\hline 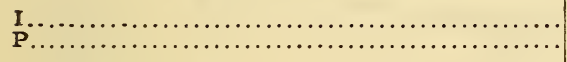 & $\begin{array}{l}605 \\
525\end{array}$ & $\begin{array}{l}1-6 \\
1-6\end{array}$ & $\begin{array}{l}16,500 \\
38,000\end{array}$ & $\begin{array}{r}0.0046 \\
.0119\end{array}$ & \\
\hline Average .. & . & & & .0083 & $\ldots$ \\
\hline
\end{tabular}

LONG PANELS-SHORT SPAN.

\begin{tabular}{|c|c|c|c|c|c|}
\hline 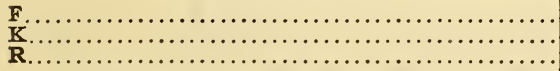 & $\begin{array}{l}370 \\
505 \\
260\end{array}$ & $\begin{array}{l}7-15 \\
7-15 \\
7-15\end{array}$ & $\begin{array}{l}40,000 \\
44,000 \\
33,000\end{array}$ & 0.0200 & $\begin{array}{r}0.0241 \\
\cdots .0269\end{array}$ \\
\hline Average ......... & $\ldots \ldots$ & & & .0200 & .0255 \\
\hline
\end{tabular}

LONG PANELS-LONG SPAN.

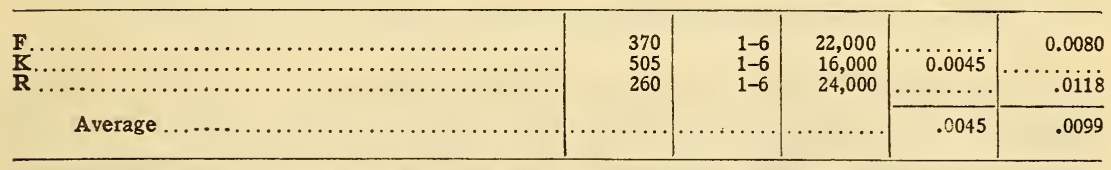

${ }_{1}$ Stresses shown are from those observed on Apr. 22, 1920. See Fig. I9 and Table 4 for loads. 
For the loads of April 22 on the typical panels, the adjacent panels were partially, and in some cases almost entirely, unloaded. This loading was used in the effort to produce the highest practicable positive moment.

Table $I_{3}$ gives the coefficients of positive moment as computed from the weighted maximum stresses in the reinforcement at the centers of the spans. In Figure 35 these values of $K$ are plotted as ordinates and the ratios of length to width of panel as abscissas.

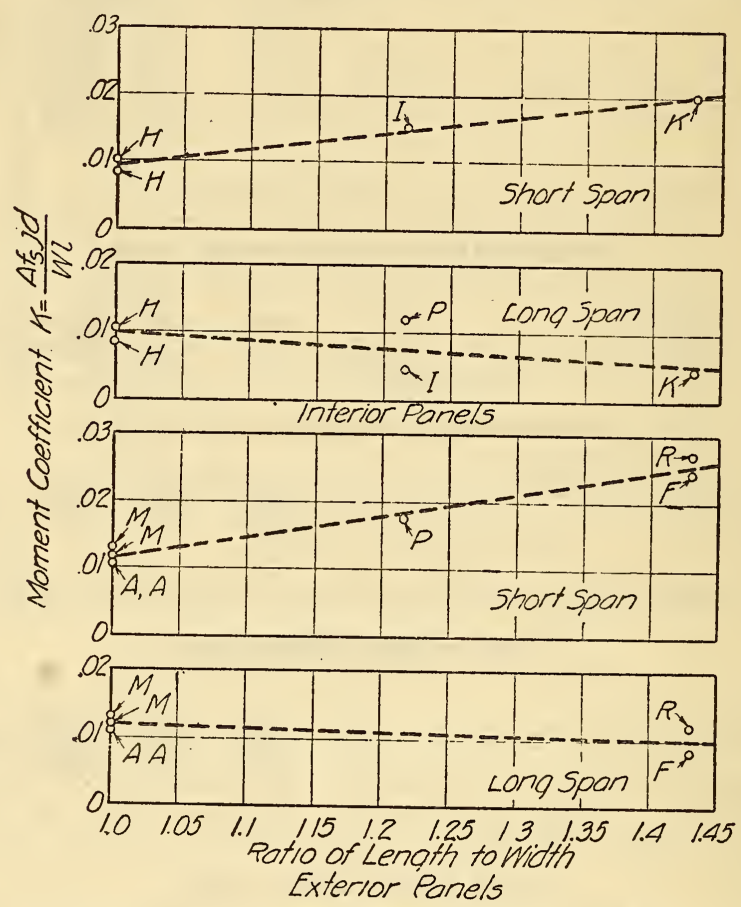

FIG. 35.-Coefficients of positive moment for interior and exterior panels.

The average coefficients of positive moment for exterior panels were in all cases greater than the corresponding coefficients for interior panels. The ratios of the average positive moments for exterior panels to the average positive moments for interior panels of the same size are given in Table I4.

A comparison of Table 12 with Table 14 shows that the excess of the moment for the exterior panels over that for the interior panels was slightly greater for positive moment than for negative moment one panel-length away from the wall.

The average coefficient of the positive bending moment for all panels with load as shown in Figure 19 is given in Table 16 as 50 per 
cent of the average coefficient of negative bending moment for all panels with the uniform loads shown in Figure I8.

In Section II, 3, of this paper it was stated that the purpose of the arrangement of the load of April 22, I920, was to increase the positive moments with as little increase as possible in the negative moments. In spite of the effort to avoid increasing the negative moments the stress in the negative reinforcement passed the yield point in a number of places before the loading of April 22 was completed. The manner of distribution of the final load and the reaching of the yield point in positions of negative moment are factors both of which would tend toward producing a high positive moment in relation to negative moment. For these reasons it seems that the values given represent as high ratios of positive to negative moment as could be obtained under any practical conditions.

\section{MOMENTS IN CANTUEVERS.}

Without the cantilevers shown in Figure 3 there would have been no section of negative moment at a greater distance in the

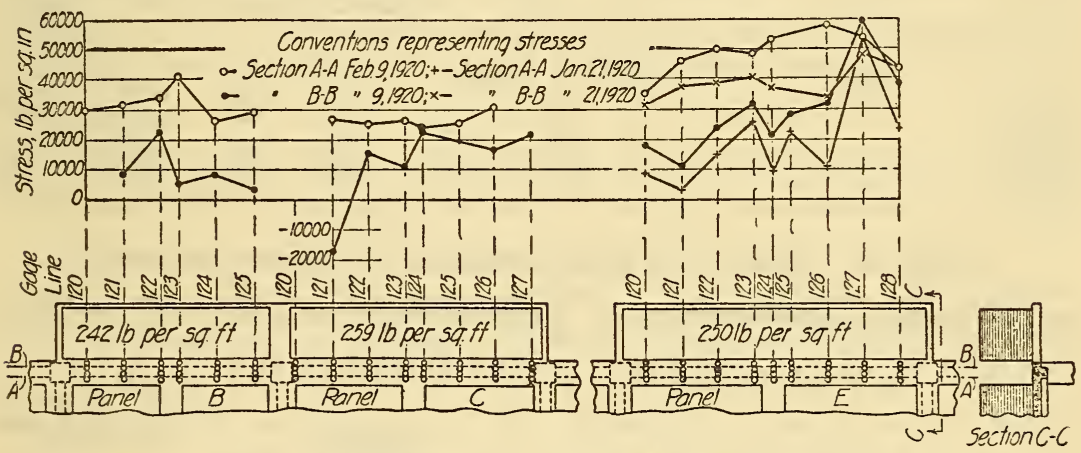

FIG. 36.-Stresses in reinforcement in cantilevers and in slab opposite cantilevers.

direction of the short span from the edge of the slab than one span length. Most building regulations provide that moments at such sections be taken somewhat greater than those for interior panels. With the cantilevers added the sections between panels $B$ and $H$, $C$ and $I$, and $E$ and $K$, respectively, were further removed from the influence of wall panels. It was to give information on this feature that the cantilevers were added.

As shown in Figure 36, the stresses in the reinforcement of the cantilevers at section $B-B$ were considerably greater than the stresses in the slab at section $A-A$ for all three panels $B, C$, and $E$. This is somewhat unexpected in view of the indications, stated 
TABLE 14.--Ratios of Maximum Positive Moment in Exterior Panels to Maximum Positive Moment in Interior Panels.

[Ratios are obtained from average coefficients given in Table 13 and apply to load of Apr. 22, 1920. See Fig. 19 and Table 4 for loads.]

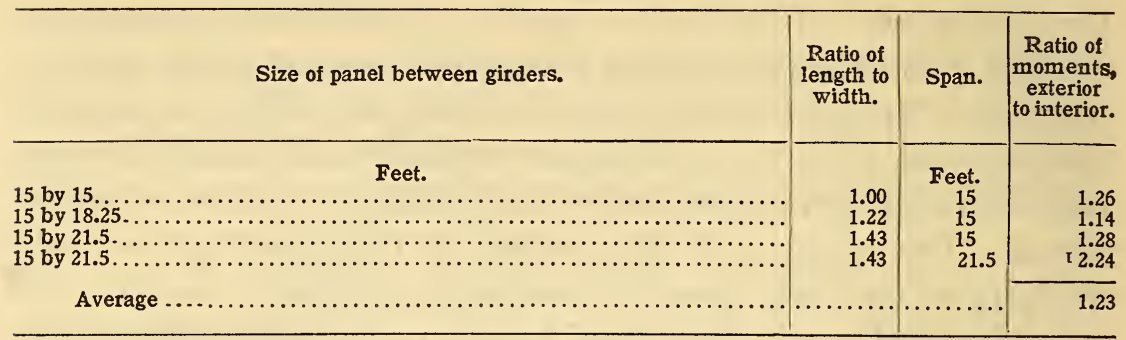

1 Not included in average.

TABLE 15.-Summary of Average Moment Coefficients.

[Values given are averages taken from Tables 13 and 14. Negative moment is for maximum uniform load; positive moment is for load of Apr. 22, 1920.]

\begin{tabular}{|c|c|c|c|c|c|c|}
\hline \multirow{3}{*}{ Size of panel. } & \multirow{3}{*}{$\begin{array}{c}\text { Ratio of } \\
\text { length to } \\
\text { width. }\end{array}$} & \multirow{3}{*}{ Span. } & \multicolumn{4}{|c|}{ Moment coefficients. } \\
\hline & & & \multicolumn{2}{|c|}{ Negative. } & \multicolumn{2}{|c|}{ Positive. } \\
\hline & & & $\begin{array}{l}\text { Interior } \\
\text { panel. }\end{array}$ & $\begin{array}{c}\text { Exterior } \\
\text { panel. }\end{array}$ & $\begin{array}{l}\text { Interior } \\
\text { panel. }\end{array}$ & $\begin{array}{c}\text { Exterior } \\
\text { panel. }\end{array}$ \\
\hline 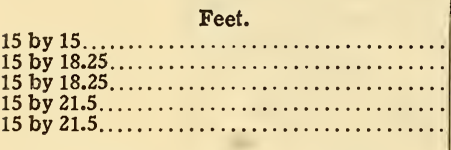 & \begin{tabular}{l|}
1.0 \\
1.22 \\
1.22 \\
1.43 \\
1.43
\end{tabular} & $\begin{array}{l}\text { Feet. } \\
15 \\
15 \\
18.25 \\
15 \\
21.5\end{array}$ & $\begin{array}{r}0.0186 \\
.0277 \\
.0213 \\
.0398 \\
.0179\end{array}$ & $\begin{array}{r}0.0227 \\
.0330 \\
.0434 \\
.0227\end{array}$ & $\begin{array}{r}0.0093 \\
.0154 \\
.0083 \\
.0200 \\
.0045\end{array}$ & $\begin{array}{r}0.0116 \\
.0176 \\
.0255 \\
.0099\end{array}$ \\
\hline
\end{tabular}

TABLE 16.-Comparison of Positive Moments with Negative Moments.

[Negative moment is for maximum uniform load. Positive moment is for load of Apr. 22, 1920. See Figs. 18 and 19.]

\begin{tabular}{|c|c|c|c|c|}
\hline \multirow{2}{*}{ Size of panel between girders. } & \multirow{2}{*}{$\begin{array}{l}\text { Ratio of } \\
\text { length to } \\
\text { width. }\end{array}$} & \multirow{2}{*}{ Span. } & \multicolumn{2}{|c|}{$\begin{array}{l}\text { Ratio of positive } \\
\text { moment to nega- } \\
\text { tive moment. }\end{array}$} \\
\hline & & & $\begin{array}{l}\text { Interior } \\
\text { panel. }\end{array}$ & $\begin{array}{l}\text { Exterior } \\
\text { panel. }\end{array}$ \\
\hline 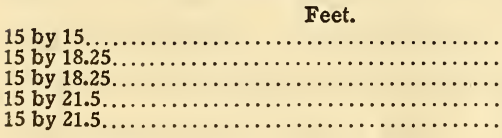 & \begin{tabular}{l|}
1.0 \\
1.22 \\
1.22 \\
1.43 \\
1.43
\end{tabular} & $\begin{array}{l}\text { Feet. } \\
15 \\
15 \\
18.25 \\
15 \\
21.5\end{array}$ & $\begin{array}{r}0.50 \\
.56 \\
.39 \\
.50 \\
1.25\end{array}$ & $\begin{array}{r}0.51 \\
\cdot 54 \\
\ldots . .6 \% \\
.59 \\
.44\end{array}$ \\
\hline Average... & & & .49 & .52 \\
\hline
\end{tabular}

${ }^{1}$ Not included in average. 
elsewhere, that the girders resisted very little moment by torsion, and the reason for the discrepancy is not apparent. The bending moments in pound-feet per foot of width at section $B-B$ under the live load shown in Figure 36 plus the weight of the slab (50 lbs./ft. $\left.{ }^{2}\right)$ were 2,900 at panel $B, 3,070$ at panel $C$, and 2,980 at panel $E$. The loads given in Figure 36 are based upon the areas loaded. If the moments at the two sections be assumed to be proportional to the observed stresses at the sections, it is found by multiplying the moments above stated by the ratios of stresses at section $A-A$ to stresses at $B-B$ that the moments at section $A-A$ were 9ro, I,590, and I,570 lb.-ft. per foot of width at panels $B, C$, and $E$, respectively. Stating these moments in terms of the live and dead load $w$ per square foot and the clear short span the moments found on section $A-A$ at the edges of panels $B, C$, and $E$ are $0.0098 w l^{2}, 0.023 w l^{2}$, and $0.0267 w l^{2}$, respectively.

These values afford an independent and fairly satisfactory check on the values given in Figure 32 for the same positions. The difference between stresses on sections $A-A$ and $B-B$ rather unsettles, however, the question of torsional resistance of the girders. The cantilevers do not seem to have a distinguishable effect on the moments one span length away from the cantilever support.

At section $B-B$ the moments of the stresses observed in the reinforcement were approximately $0.53,0.48$, and 0.69 of the moment of the cantilever loads opposite panels $B, C$, and $E$, respectively, about the same section. These ratios are based on stresses observed on January 2I, I 920, at panel $E$ and February 9 at panels $B$ and $C$, which was shortly after the load had been placed on the cantilevers. By February 9 the stresses in the cantilever at panel $E$ had increased so that the moment of the stresses in the reinforcement was 0.86 of the external bending moment. For cantilevers $B$ and $C$ deformations were not measured after the load had been in place longer than about a week.

\section{MOMENTS IN GIRDERS.}

The beams were designed on the assumption that the load from an area bounded by intersecting lines drawn from the corners of the panels at $45^{\circ}$ with the sides of the panels would be carried by the girders which extend across the ends of the panel. The load on the remaining trapezoidal area of each panel was assumed to be equally divided between the girders on the sides of the panel. 
Measurements of deformations in the reinforcement of the girders were taken at various stages of the test in the effort to determine as to whether this method of design is approximately correct or whether the somewhat smaller moment coefficients which apply for uniform load could be used instead. The stresses observed were quite erratic and therefore seemed less reliable than those in the reinforcement of the slab.

For the maximum uniform load shown in Figure i 3 the moment coefficients for the girders computed from the observed stresses averaged much less than the coefficients determined analytically from the trapezoidal load distribution assumed, but on account of the erratic distribution of the stresses the correctness of the coefficients determined from them is subject to question. The higher load of April 22 (see Figs. I4 and I9) gave higher coefficients just as has been found in many other tests. ${ }^{9}$ Even in this case, assuming that the girders were fixed, the coefficients were lower than those given by analysis for trapezoidal and triangular distribution of load on the girders, but somewhat larger than the coefficients which would be obtained with the load distributed uniformly over the length of the girder. The stresses in the girders under the load of April 22, I920, were observed in only a few places, and it does not seem safe to base important conclusions on these computed coefficients, especially in view of the erratic nature of the stress distribution under the maximum uniform load.

Under the intensified loading of November, I920, in panels $H, J$, and $K$, with other panels partly loaded it seemed quite clear from the opening of a crack at the center of girder $J K$, that the yield point of the positive reinforcement in that beam had been reached. From the nature of the stress-strain curve for the reinforcement given in Figure I, it is clear also that with the deflections as small as they were the stress can not have been much greater than the yield point. The sectional area of the positive reinforcement was 2.59 square inches. Assuming that the stress was at the yield point, $46,300 \mathrm{lbs} . /$ in. $^{2}$, and using the depth $d$ of 16 inches to the reinforcement, as given in Figure 3, and assuming that the load on girder $J K$ was the total live and dead load, $W$, of 124,000 pounds within the area inclosed by four $45^{\circ}$ lines drawn from the ends of girder $J K$ the resisting moment is found to be $0.0714 \mathrm{Wl}$. This is somewhat greater than the

\footnotetext{
9 Westergaard and Slater, "Moments and stresses in slabs,"Proc. Am. Concrete Inst., 17, p. 47r; I92 I.
} 
maximum positive moment $(0.0625 \mathrm{Wl}$ ) in a fixed beam under a triangular distribution of load but much less than the maximum moment (o.1667 Wl) in a simple beam similarly loaded. The conditions of restraint are unknown, but the beam under the loads shown in the frontispiece and Figure I6 would seem to be more nearly like a simple beam than a fixed beam.

\section{ANCHORAGE REQUIRED FOR NEGATIVE REINFORCEMENT.}

In order to prevent slipping of the negative reinforcing bars, hooks were furnished at the ends of the bars. If in such a case

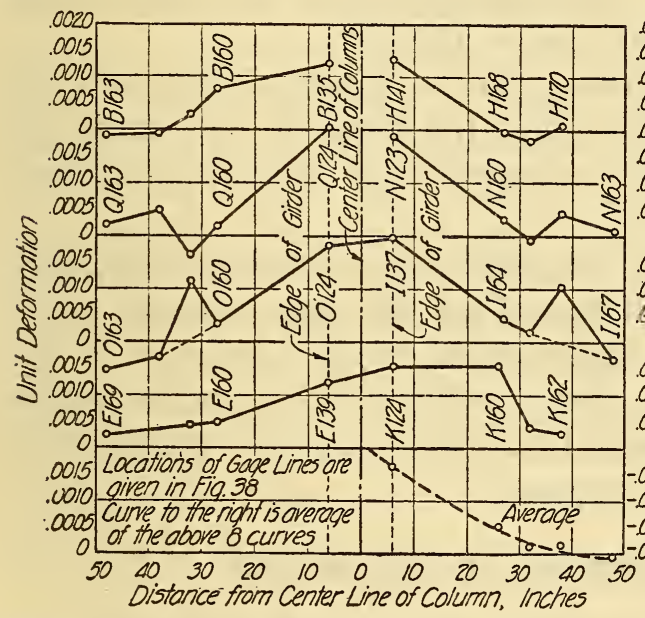

Fic. 37a.-Points of zero stress for negative reinforcement in direction of short span.

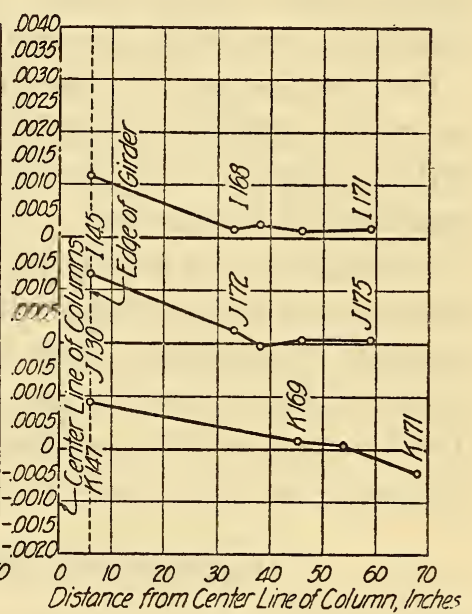

Fig. 37 b.-Points of zero stress for negative reinforcement in direction of long span.

the tensile stress is reduced to zero before reaching the end of the bar, at the same time that the stress in the negative reinforcement where it crosses the edge of the girder has reached the yield point, the hook is not needed. An effort to determine whether such anchorage was necessary was made by observing the stresses at several points along the negative reinforcing bars which lay on the center lines of the panels. The location of these gauge lines is shown in Figure 38.

In six of the eight bars included in Figure $37(a)$ a point of zero stress was reached within the length over which readings were taken. These bars extend in the north-and-south direction of the slab. Except for a few points, which seem erratic, the position of zero stress was consistent for the bars shown. The average 
curve shown in the lower right-hand portion of Figure $37(a)$ indicates that the point of zero stress occurred about 38 inches from the center line of the girders, or $3^{2}$ inches from the nearest edge of the girders. This distance from the edge of the girder is 0.I77 times the clear span of the slab

In two of the three cases shown in Figure $37(b)$ a point of zero stress was found within the distance over which measurements were taken. These bars extended in the direction of the longer span. For the long panel the point of zero stress was about 55 inches from the center of the girders, or 49 inches from the nearest edge of the girder. This distance from the edge of the girder is o.rgo times the clear span of the slab.

For the long span in the intermediate-size panels the results are somewhat erratic, but indicate that the point of zero stress lies within a distance not greater in proportion to the span than that found in the long panel.

The data on the position of the point of zero stress are somewhat scant, but it seems that with bars of the size used here and spans as great, or greater, a safe design would result if the sum of the bond and the anchorage provided is sufficient to reduce the tensile stress to zero within a distance from the edge of the girder equal to 0.20 of the clear span of the panel.

\section{SHEARING STRESSES IN RIBS OF SLAB.}

In the calculations of the shearing stresses in the ribs, use was made of the fact that the bending moments were found to be different in the two directions of the square panels. (See Sec. III, 2.)

It was assumed that the loads carried to the girders were proportional to the negative resisting moments. Using the average of the ratios of the negative moments in the north-and-south direction to those in the east-and-west direction as the basis for the determination, it was found that 56 per cent of the panel load was carried in the north-and-south direction and 44 per cent in the east-and-west direction of the square panels.

There is some uncertainty as to what section should be considered effective in resisting shearing stresses. The type of construction is such as to make the tile so nearly an integral part of the floor slab that it seems that it must participate in resisting any stresses which could be resisted by a monolithic concrete construction. The scoring of the tiles furnished a bond with the 
concrete, the pouring of the concrete on four sides of the tiles secured the tiles in place, and the partial filling of the cells with concrete insured the effective transmission of compressive stresses through the tiles. These considerations would lead one to expect that the ribs of the tiles in direct contact with the concrete would constitute a portion of the section which is effective in resisting shearing stresses.

The entire load within the portion of the panel area which is bounded by lines drawn through the ends of the ribs parallel to the sides of the panels must have been resisted by vertical shear in the ribs made up of concrete and the tile walls. In panel $H$ the sum of the live and dead loads from November 9, I920, to the date of writing (October I, I92I) has been I,463 lbs. $/ \mathrm{ft}^{2}{ }^{2}$ Assuming that equal loads were carried by all parallel ribs and that, as stated in a preceding paragraph, only 44 per cent of the load was carried in the east-and-west direction, the maximum shearing stress developed on each of those ribs was $405 \mathrm{lbs}$./in. ${ }^{2}$ It is likely, however, that the ribs which extended along the center lines of the panels carried larger loads, and consequently greater shearing stresses, than those near the edges. On the other hand, it is possible that the increase in resisting section caused by the flowing of the concrete into the cells of the tiles was of appreciable effect in increasing the shearing resistance of the rib.

In the north-and-south direction there were tile walls which probably assisted the concrete ribs materially in resisting the shearing stresses. Assuming that the remainder of the load (56 per cent) was carried in the north-and-south direction, the maximum computed shearing stress in the composite rib (made up of the concrete and the two ${ }^{10}$ tile walls in contact with it) was 375 lbs./in. ${ }^{2}$ There has been no sign of diagonal tension failure at that load. Assuming the entire shearing stress to have been resisted by the concrete without assistance from the tiles requires a shearing resistance of $500 \mathrm{lbs}$. $/$ in. ${ }^{2}$ in the concrete. Since tests have indicated that even with thorough end anchorage of the longitudinal reinforcement of beams which have no stirrups or bent-up bars, diagonal tension failure may generally be expected at shearing stresses not greater than $250 \mathrm{lbs}$. $/$ in. $^{2}$ for concrete such as was used in this test, it seems obvious that the tile walls must have been of considerable assistance in resisting the shearing stresses.

${ }^{10}$ As the shells of the tiles were not much cracked it is possible that the middle rib also contributed appre. ciably to the shearing strength. 
These conditions indicate that it is proper and safe to consider that the tile walls which are in contact with the concrete rib are capable of carrying a shearing stress which is not less per square inch of tile than the shearing strength per square inch of the concrete rib.

In view of the high shearing stress developed without failure in the ribs which had no tile walls in contact with them, a somewhat greater allowance for the shearing resistance of the concrete in those ribs than is generally recognized for concrete beams which have no web reinforcement would probably be justified.

If it be assumed that the loads carried in the two directions were equal and that the apparent difference in moments was due to tensile stresses in tiles and concrete, the shearing resistance would be about $325 \mathrm{lbs}$./in. ${ }^{2}$ in the ribs of concrete and tile in the north-and-south direction and $460 \mathrm{lbs} . / \mathrm{in} .{ }^{2}$ in the concrete ribs in the east-and-west direction, but the conclusions would not be far different from those already stated.

\section{SHEARING STRESSES IN GIRDERS.}

Assuming that only 44 per cent of the load in panel $H$ was transmitted in the east-and-west direction, the load applied to girder $H I$ (between panels $H$ and $I$ ) in the loading of November, I 920 , was 72,600 pounds. Adding 30,000 pounds assumed to be applied to girder $H I$ by panel $I$, the total load on girder $H I$ is found to be 103,000 pounds. The girder $H I$ was 12 inches in width and $15 \frac{1}{8}$ inches in depth from the center of the top reinforcement to the bottom of the girder. The end of the girder was reinforced with $U$-shaped stirrups made from $3 / 8$ inch round bars and spaced 3 inches apart in a horizontal direction. The stirrups were anchored at their ends and were inclined so that they made an angle of about $60^{\circ}$ with the horizontal.

The computed shearing stress based upon the load of 103,000 pounds is $342 \mathrm{lbs} . /$ in. $^{2}$ The computed tensile stress in the stirrups, using the formula $P=\frac{2}{3} \frac{V a}{j d}$, is $32,800 \mathrm{lbs}$./in. ${ }^{2}$ where $P$ is the total load carried by the stirrup and $a$ is the distance between stirrups at right angles to their direction. Diagonal tension cracks appeared in the girder at the highest load, but these were not large.

Assuming the load on girder $J K$ to be 124,000 pounds as indicated in Section III, I4, the shearing stress which that girder 
has had to carry for over a year ${ }^{11}$ is $467 \mathrm{lbs} /$ in. $^{2}$ The tensile stress in the stirrups computed by the formula $P=\frac{2}{3} \frac{V a}{j d}$ is 37,000 lbs./in. ${ }^{2}$ The web reinforcement was the same as for girder HI.

It is not known accurately how great was the maximum load carried by the girders on the long sides of the oblong panels. However, any reasonable assumption as to the amount of load carried by these girders gives a shearing stress which is considerably smaller than that computed for girder HI.

\section{CRACKS.}

Careful examination for cracks in the bottom of the slab was made at each of three stages of the test: (a) About February Io,

- Goge lines to determine point of zero stress

Numbers along beams indicate sectional areas $A_{s}$, of beam reinforcement

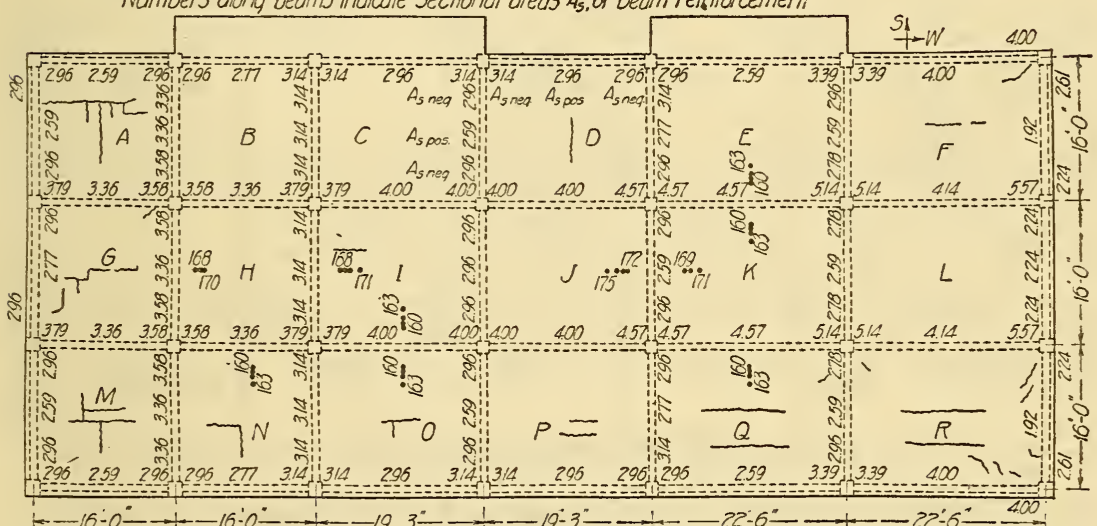

FIG. 38.-Plan of slab showing cracks in under surface with maximum uniform load in place 2 to $2 I$ day's; also sectional areas of beam reinforcement.

I920, after the maximum uniform load had been in place about two weeks; (b) April 2, after the maximum uniform load had remained in place about nine weeks; and (c) April 22, after the load on certain panels had been increased in order to increase the positive moment. This last examination was made only in the panels in which the load had been increased. Figures 38 to 40 give the location of cracks which were found at these three stages. The intensities of the load on various portions of the slab may be found in Table 4.

The presence of loading material on the top of the slab interfered with a thorough examination of the top surface. For this reason no crack diagrams for the upper surface are given. After the maximum uniform load had been in place about two weeks

11 See footnote 5, p. 739 . 
the stress in the positive reinforcement was still very low and correspondingly few cracks had developed. The largest crack was less than 0.005 inch wide. There were more cracks in the corner panels $A, M$, and $R$ than in any other panels, and correspondingly the measured stresses in the positive reinforcement were greater for these panels than for the other panels.

After the maximum uniform load had remained in place about nine weeks the number and size of the cracks had increased considerably. This increase was especially marked in the square panels and in the two long corner panels. The largest cracks at this time were less than o.or inch wide. However, in panels $E$ and $L$ no cracks could be found and in several other panels very

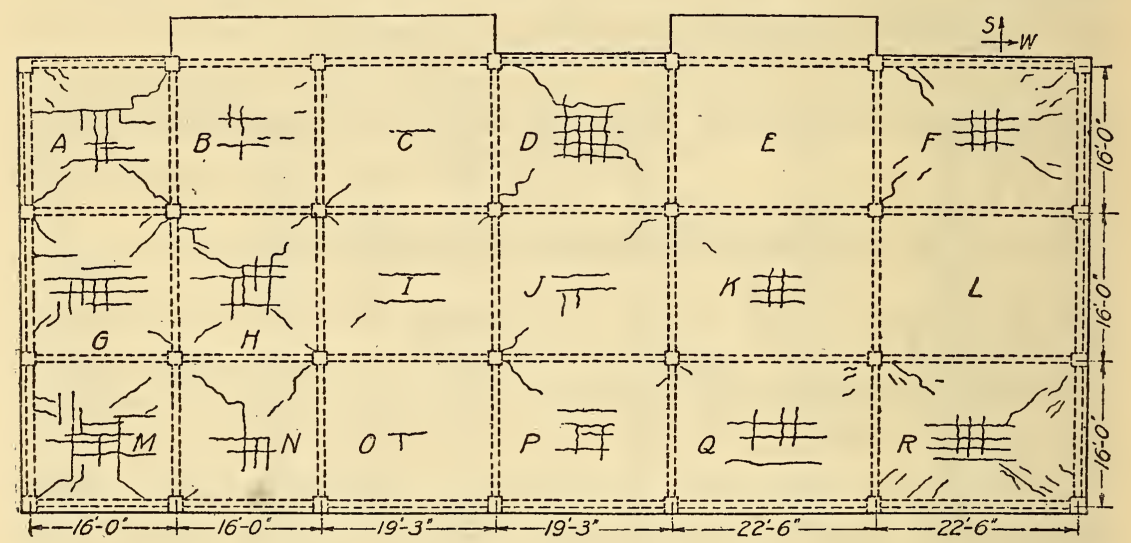

FIG. 39.-Plan of slab showing cracks in under surface with maximum uniform load in place 55 to 73 days.

few cracks were present. In general, the diagonal cracks occupied the corners of the panels. Cracks parallel to the panel edges occupied the central portions of the panels and usually followed along the edges of the tiles. For this reason they were somewhat difficult to detect and probably more cracks of this type were present than are shown. The regularity of the formation of the cracks in certain panels (see panels $D, F$, and $R$ in Fig. 39) was sufficient to give the location and outline of the tiles over a considerable area. The diagonal cracks generally crossed the tiles, but in a few cases they followed the edges of the tiles in a zigzag fashion.

When the load on certain panels was increased-that is, under the loading of April 22, I 920-the diagonal cracks extended farther toward the centers of the panels and increased considerably in size. The cracks parallel to the sides of the tiles increased in size 
but apparently not so much in extent as the diagonal cracks. The largest diagonal crack was 0.020 inch wide and was found in panel $A$. The largest crack parallel to the edges of the panel was 0.025 inch wide and was found in panel $K$. All other cracks in the under surface of the slab were less than 0.0 inch wide at this stage of the test. (See Fig. 40.) While it was evident that the cracks

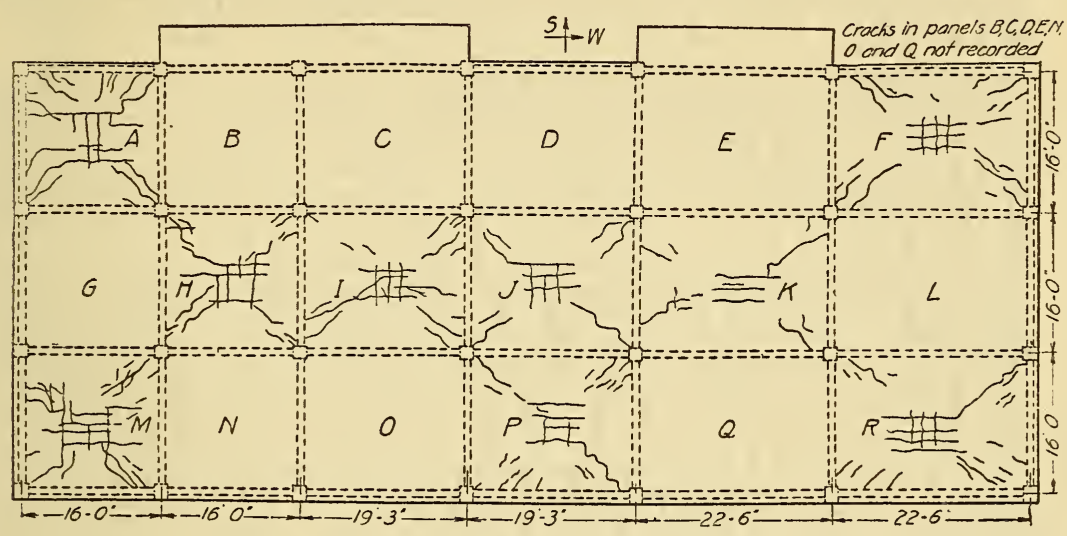

FIG. 40.-Plan of slab showing cracks in under surface with load of A pril 22 in place.

had opened slightly between the April and the November tests they were still generally quite small and no new cracks were found.

\section{FACTOR OF SAFETY.}

Many tests which have been made on slabs of buildings in service have been subjected to the criticism that because the test was not carried to the point of failure of the slab it did not furnish information as to the factor of safety of the structure, although at the loads applied the observed stresses were small. Important significance is given to this criticism by the fact that a simple beam having a small amount (say, 0.5 per cent) of reinforcement of structural grade steel may be expected to fail at a load about 30 per cent greater than the load which develops a measured stress of $16,000 \mathrm{lbs} . /$ in. $^{2}$ in the reinforcement. ${ }^{12}$

Further criticisms of building tests have been made on the ground that since only a small portion of the floor area was loaded, the loaded portion is materially assisted by the unloaded portion adjacent to it, and that in the tests the load is not left on the floor long enough to show the full extent of its effect on the slab.

\footnotetext{
12 Westergaard and Slater, "Moments and stresses in slabs," Proc. Am. Concrete Inst., 17, Figs. $31-34$. p. $478-481$; 1921 .
} 
In planning the test described in the foregoing pages, pains were taken to make the conditions so severe that any weakness suggested by the criticisms referred to would be fully exposed.

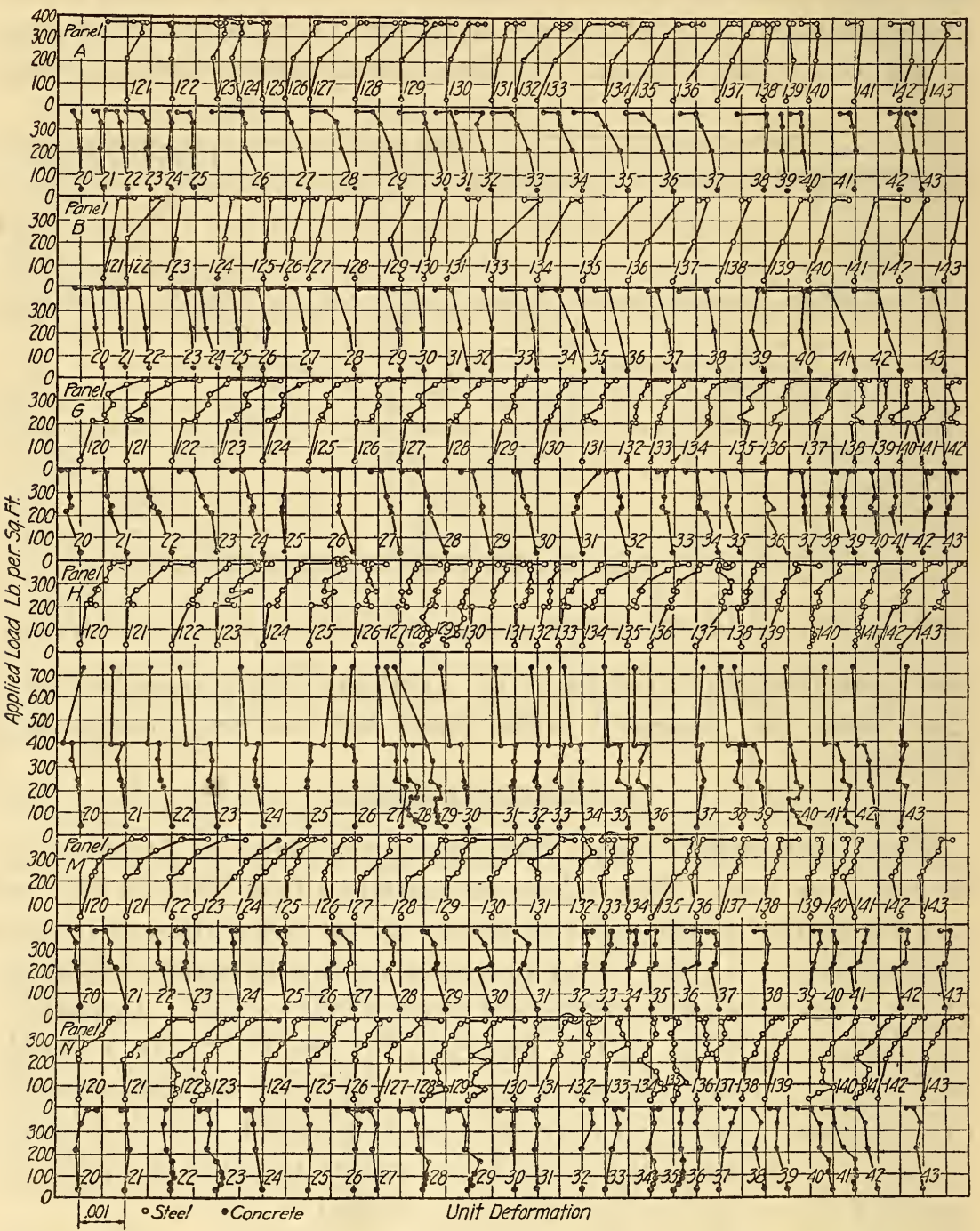

FIG. 4I.-Load-deformation curves for steel and concrete for positions of negative moment in square panels.

An effort was made to test the slab to failure with all panels loaded so as to determine the factor of safety for the panels of the various sizes.

Under the maximum uniform loading shown in Figure 18 the ratios of the live and dead loads to the "design loads" of Section 
II, 2, were $5.4,4.9$, and 5.8 for the square, intermediate, and long panels, respectively. It seemed that continuing to increase the load uniformly would make the conditions for negative moment so severe before high stresses due to positive moment were developed that dependable information on the ratio of positive to negative moment would not be obtained. This consideration together with the difficulty and expense of providing additional

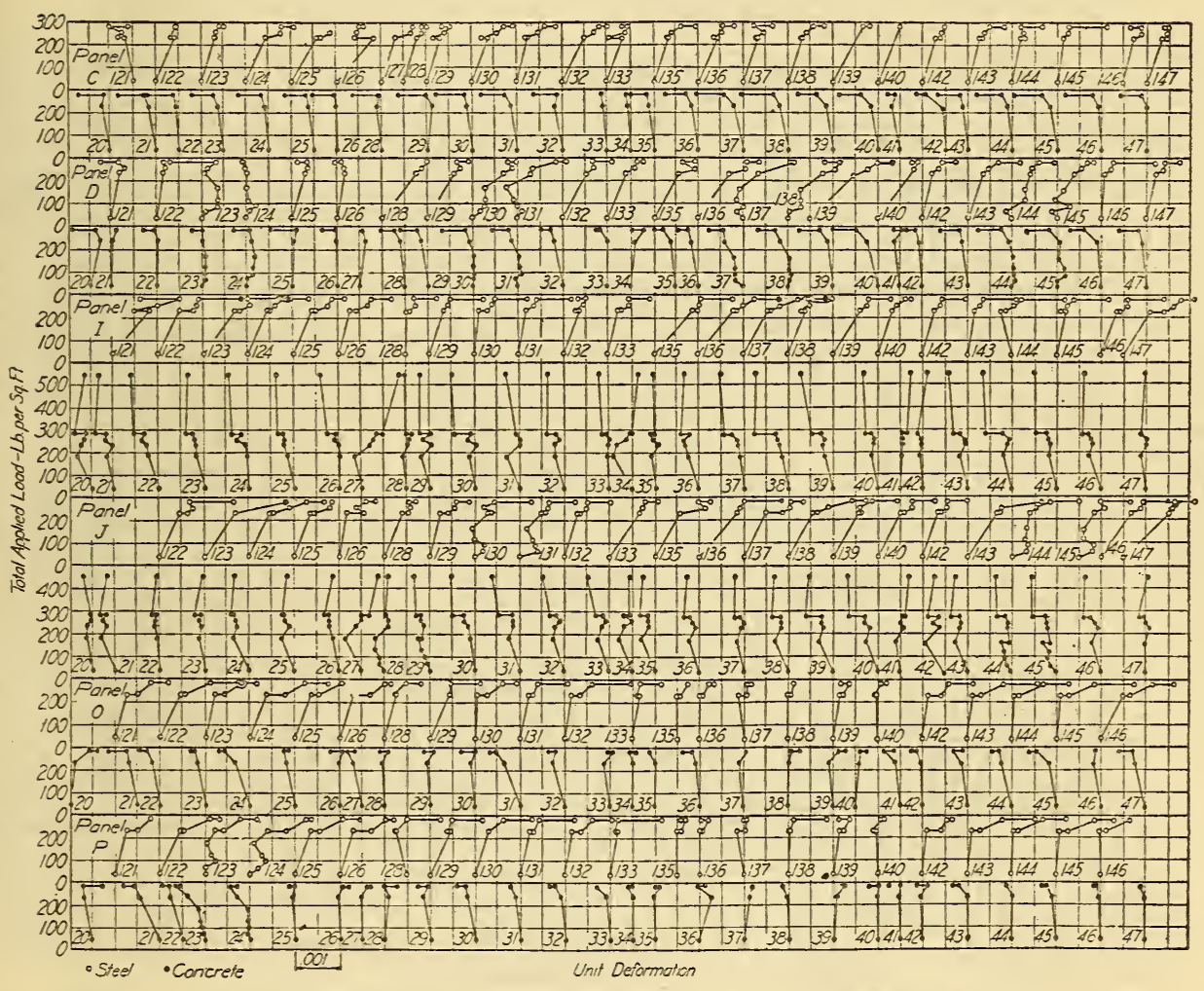

FIG. 42.-Load-deformation curves for steel and concrete for positions of negative moment in intermediate panels.

loading material led to the redistribution of load shown in Figure I 9. While it is believed that the factor of safety should be based upon a load uniformly distributed over all panels of the same size (since the design is based upon such a distribution and since such a loading would probably be the most severe) such a loading was not carried far enough to show what the factor of safety was. It is necessary, therefore, to make the best possible use of the information available. 
The condition of the slab after the load shown in Figure 19 had been in position six months was such as to indicate that loads of the maximum intensity there shown for each panel size could have been applied simultaneously over all the panels of that size without causing failure. This belief seems abundantly confirmed by the results of the test of November, I920.

While bearing in mind the qualifications here named it seems safe to assume that the factors of safety for the interior panels

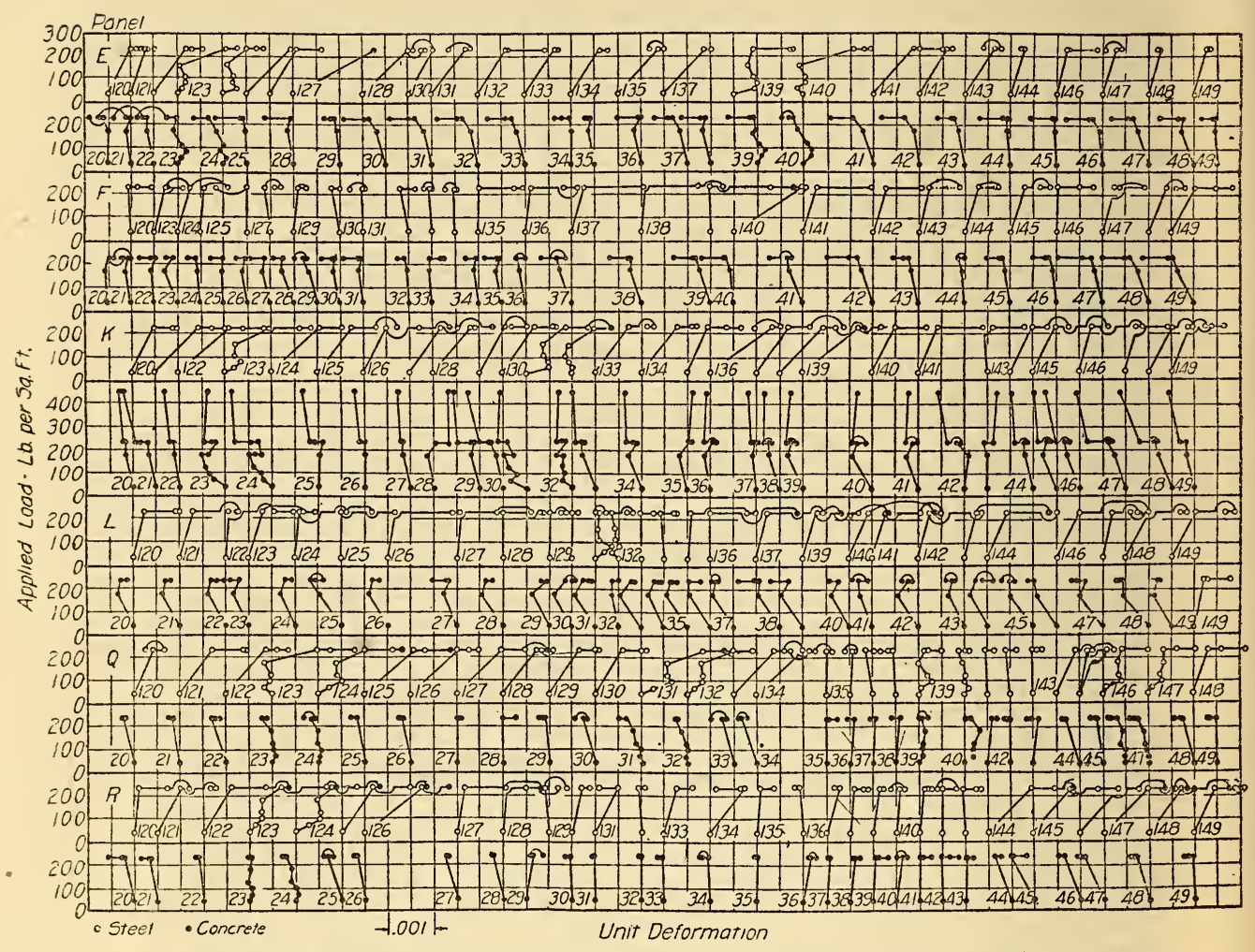

FIG. 43.-Load-deformation curves for steel and concrete for positions of negative moment in long panels.

of this test slab were not less than the ratios of the loads which were in place from April to November, 1920 (see Fig. 19), to the design loads stated in Section II, 2. These ratios are 8.7, 9.0, and 10.6 for the square, intermediate, and long panels, respectively.

Attention has been called to the fact that panel $F$ settled down upon the shores between April and November, 1920. After the shores were removed a period of 30 hours elapsed before any load was removed. During that time the deflections increased 0.04 
inch. It is obvious that the extension of the ratios above given to the case of a corner panel has not been justified.

The loads which have been in place from November 9 to the present date (October I, I92I) on certain panels give ratios of

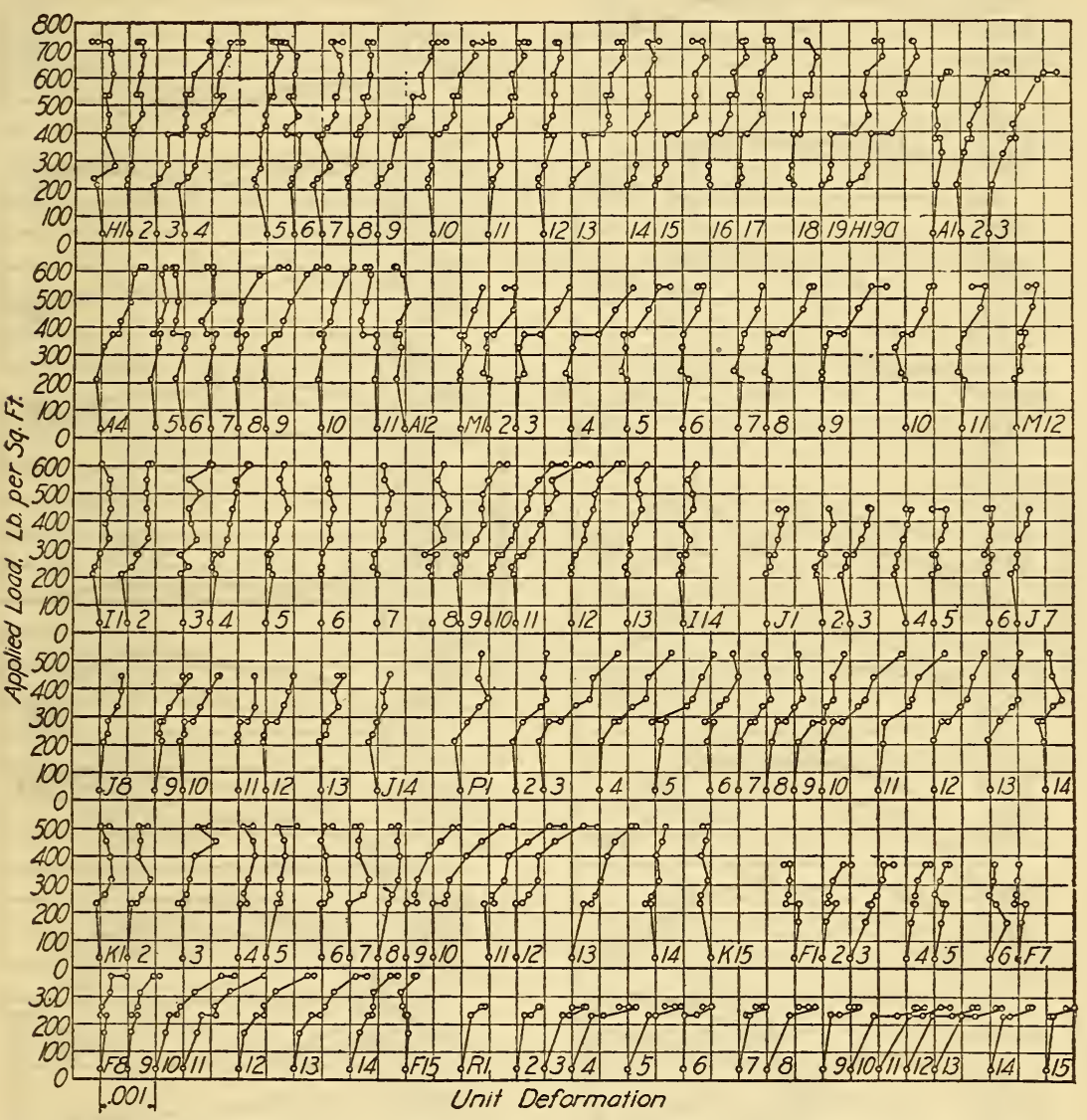

FIG. 44.-Load-deformation curves for steel at positions of positive moment in pancls $H, A, M, I, J, P, K, F$, and $R$.

test loads to design loads, computed in the same way, of $\mathrm{I} 6.2$, I 7.0, and 18.6 for the three sizes of panels.

In computing the above ratios the test load (sum of live and dead loads) was divided by the "design loads" given in Section II, 2. In order to place the ratios upon the basis of an equivalent uniform load the test loads used in computing these ratios were taken as 8 per cent less than those reported in this paper. 


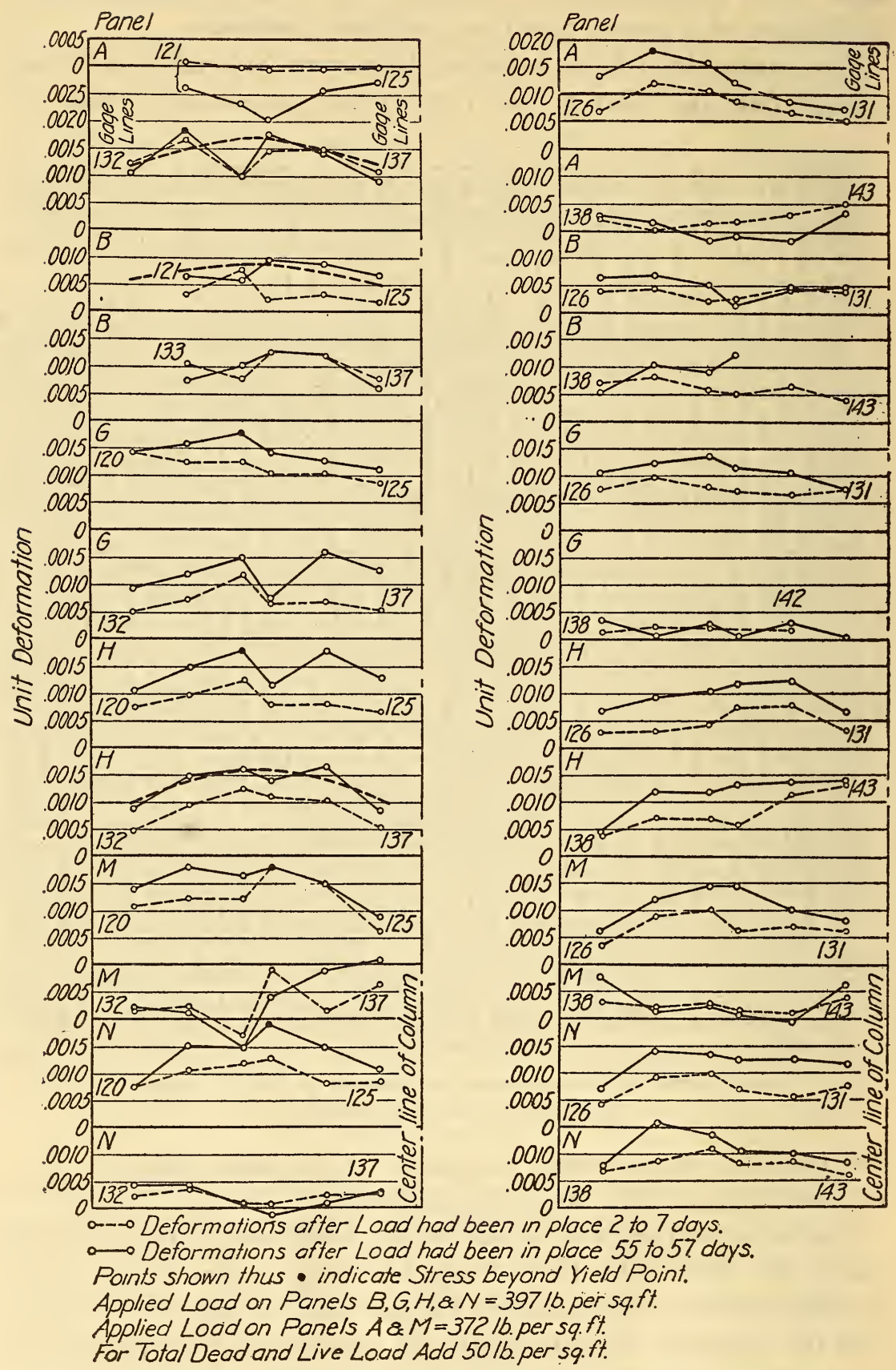

FIG. 45.-Distribution, along edges of square panels, of deformation in negative reinforcement. 


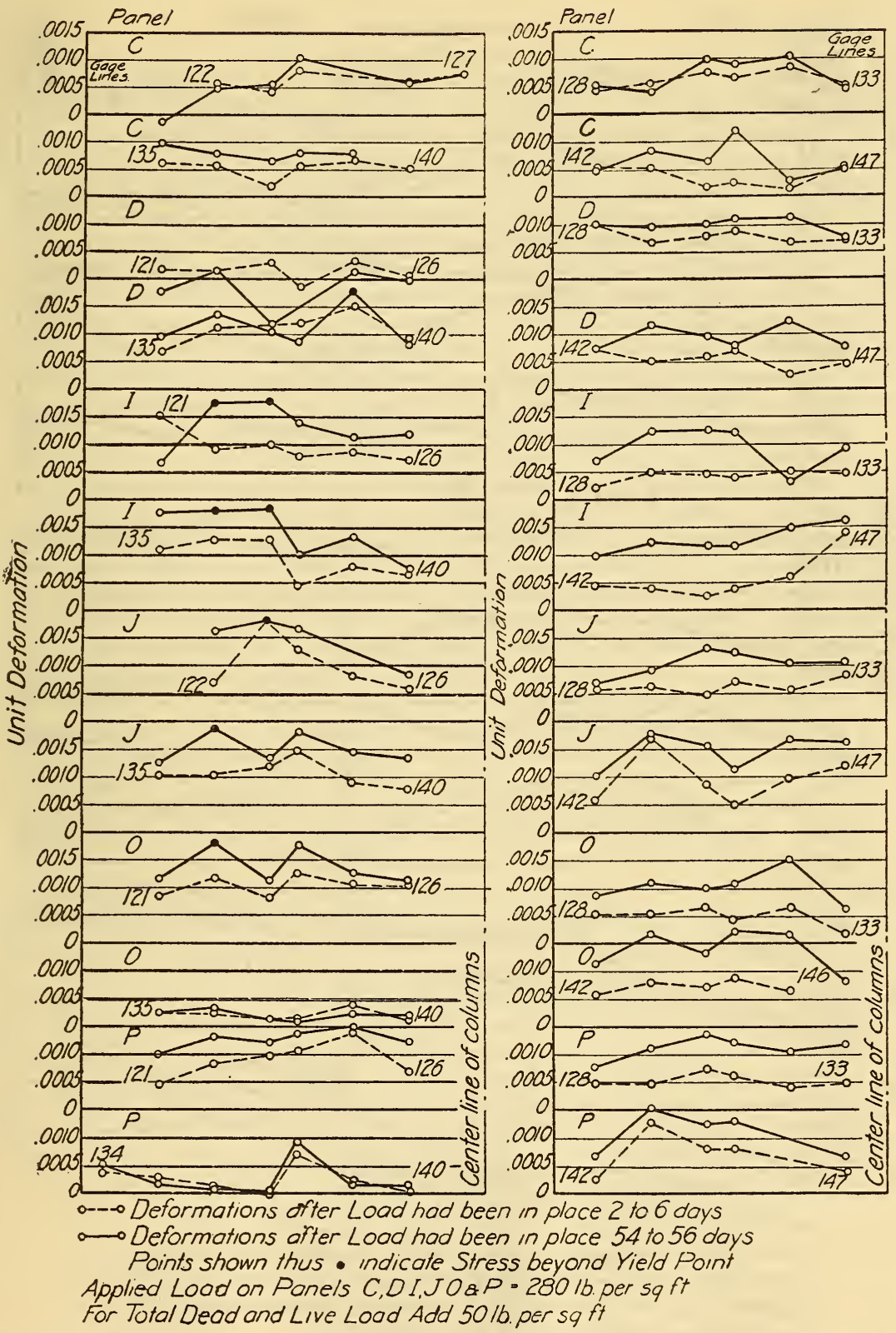

FIG. 46.-Distribution, along edges of intermediate panels, of deformation in negative reinforcement. 


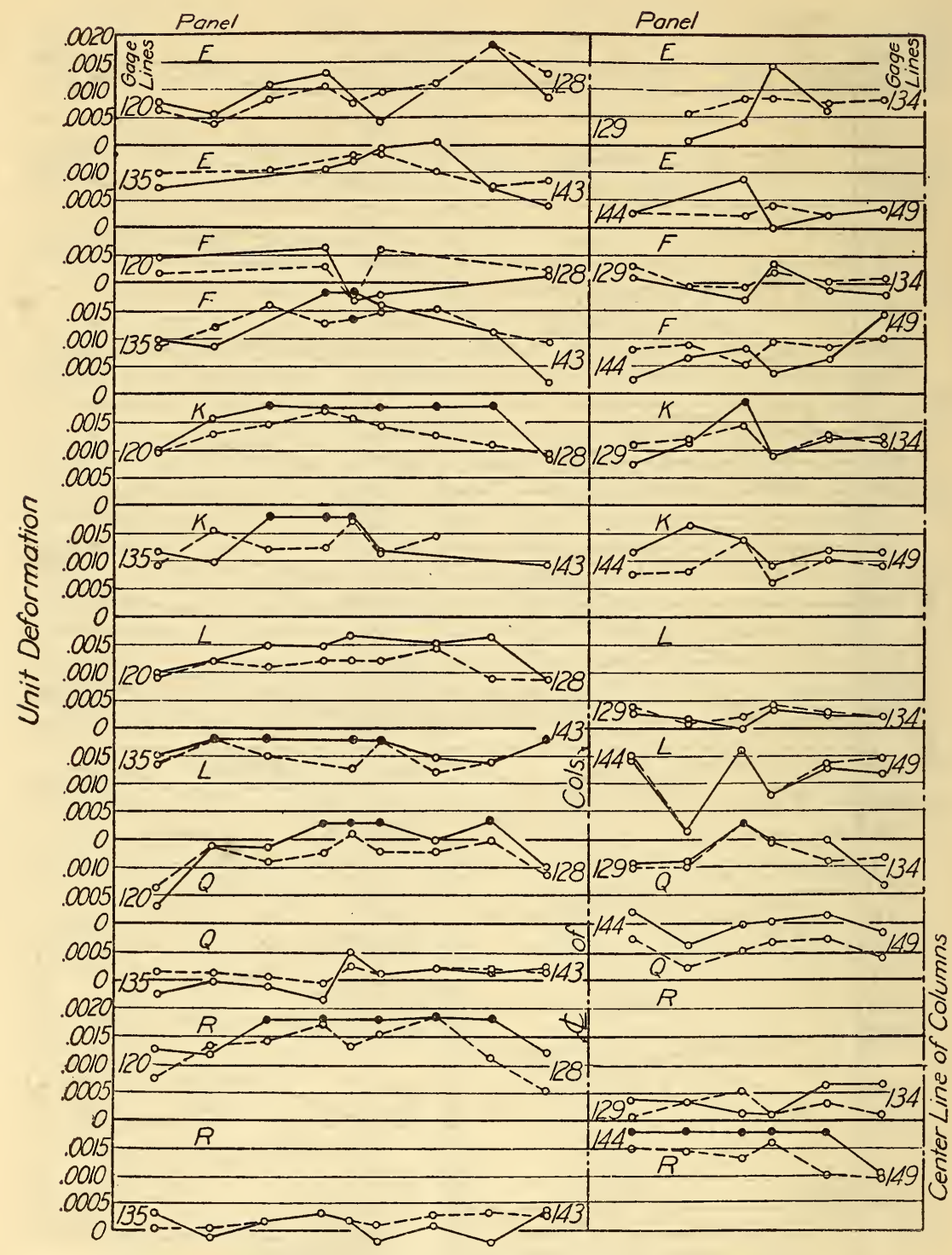

$\cdots$ Deformations after Lood hod been in place 17 to 21 doys.

- Deformations after Load had been in place 71 to 73 days.

Points shown thus - indicate Stress beyond Yield Point.

Apolied Lood on Panels E, F, K. L, Q \& R $=230 \mathrm{lb}$. persq. ft

For Total Dead and Live Lood Add $50 \mathrm{lb}$. per sq ft

FIG. 47.-Distribution, along edges of long panels, of deformation in negative reinforcement. 

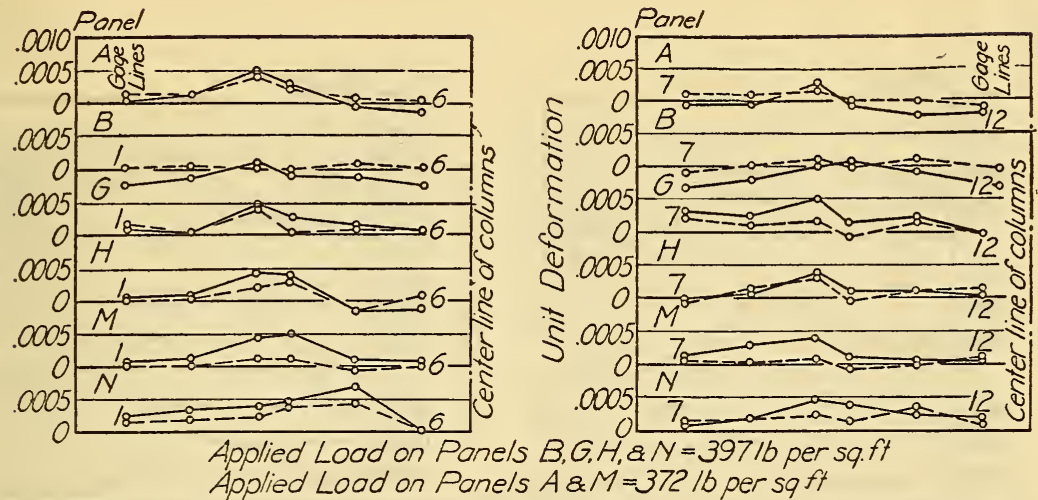

Applied Load on Panels B,G,H, \&N=397Ib per sq.f

Applied Load on Panels A \& M $=372 \mathrm{lb}$ per sq ft
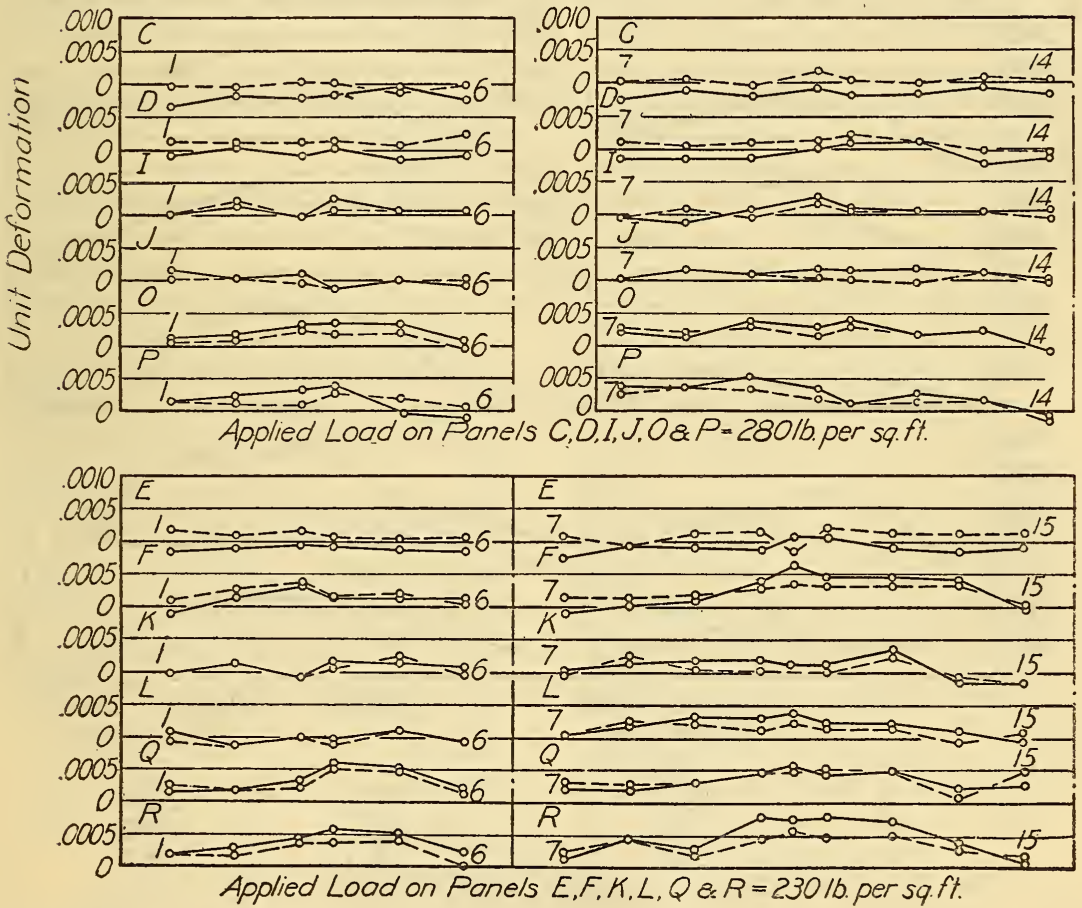

$\cdots$ Deformations after Lood had been in place 2 to 21 days.

- Deformations after Load had been in place 55 to 73 days For Total Dead and Live Load Add $50 \mathrm{lb}$. per sq.ft.

FIG. 48.-Distribution, along center-lines of all panels, of deformations in positive reinforcement for maximum uniform load. 


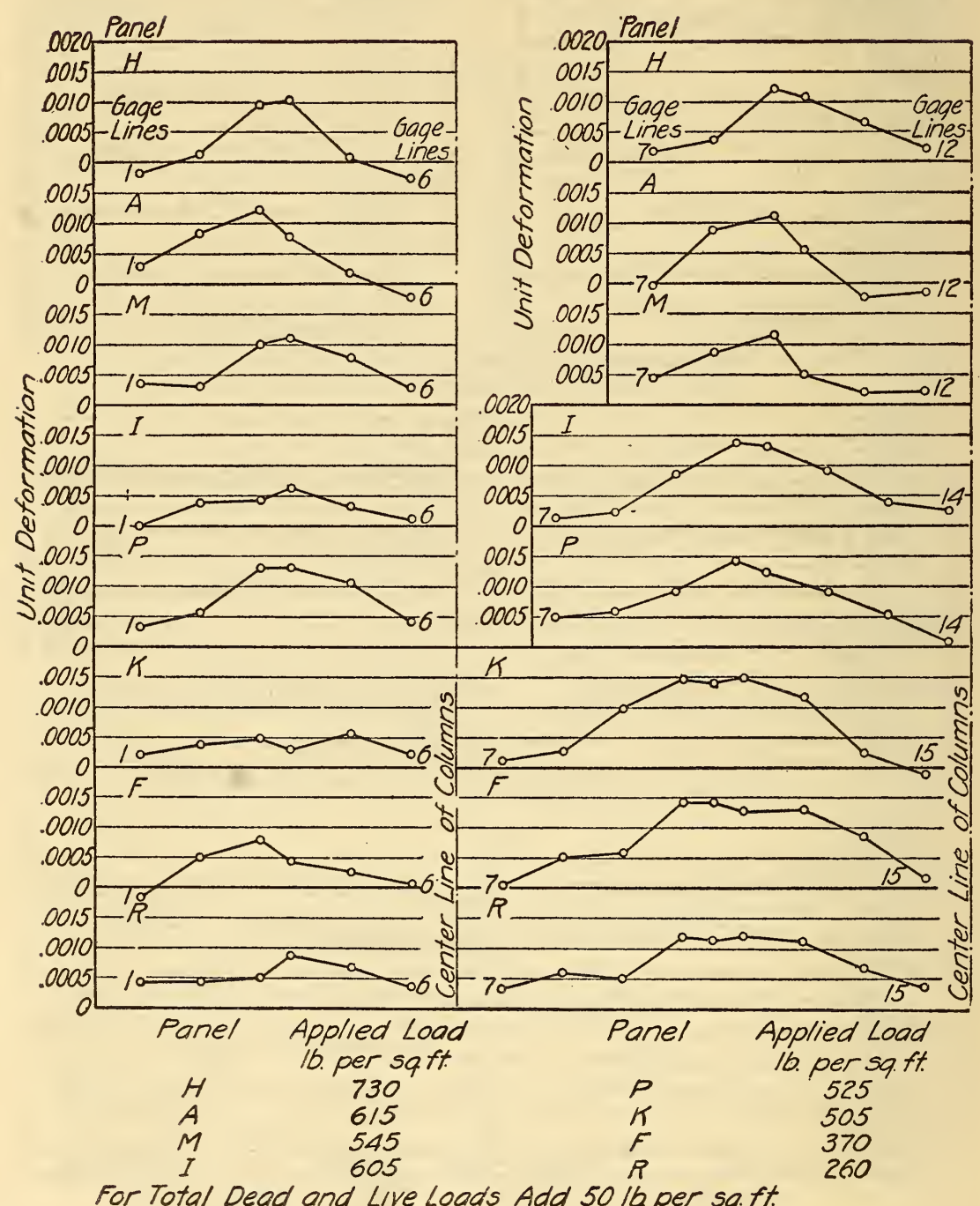

FIG. 49.-Distribution, along center-lines of all panels, of deformation in positive rein. forcement for load of A pril 22, 1920 . 


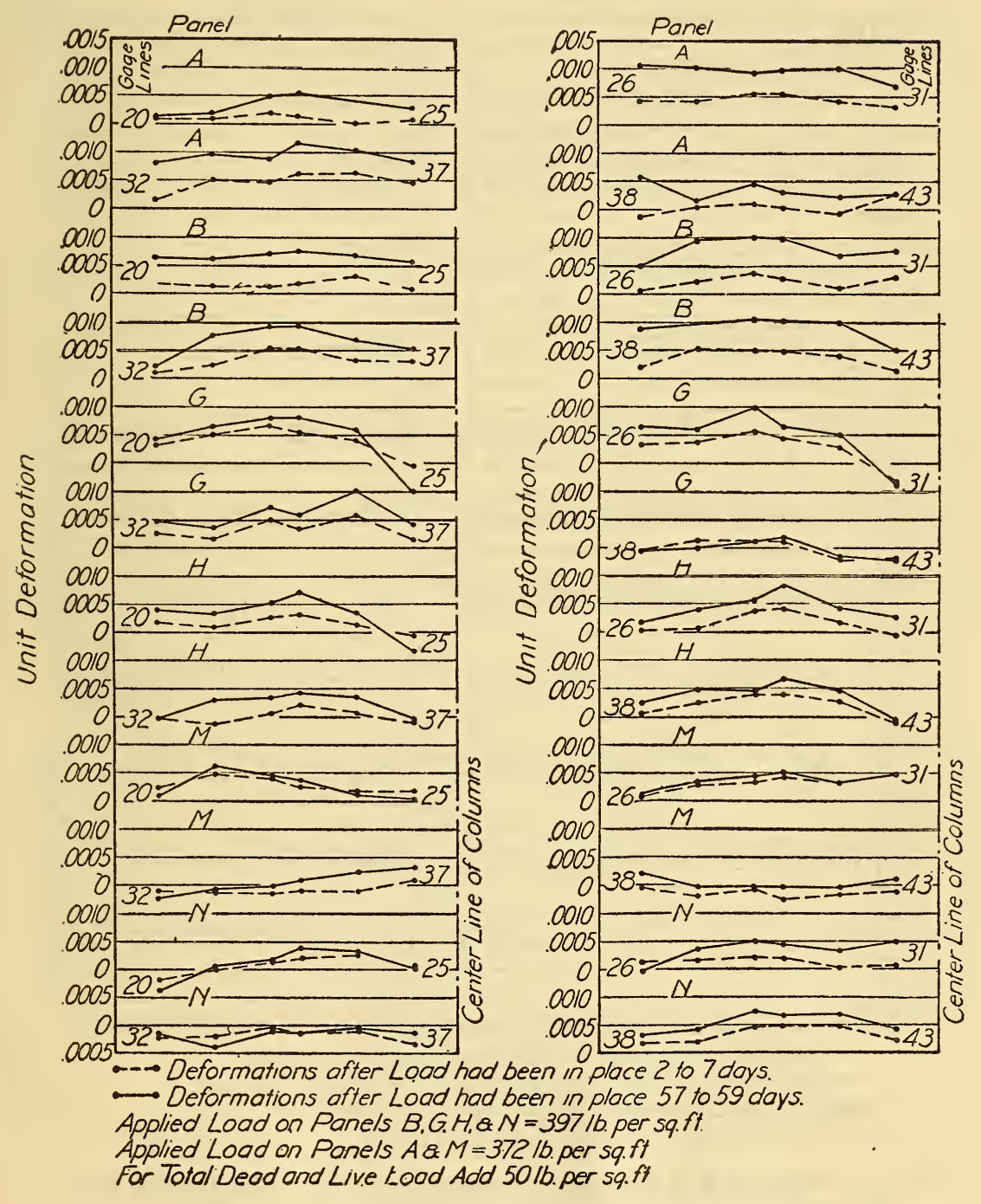

FIG. 50.-Distribution of deformation in concrete along edges of square panels. 


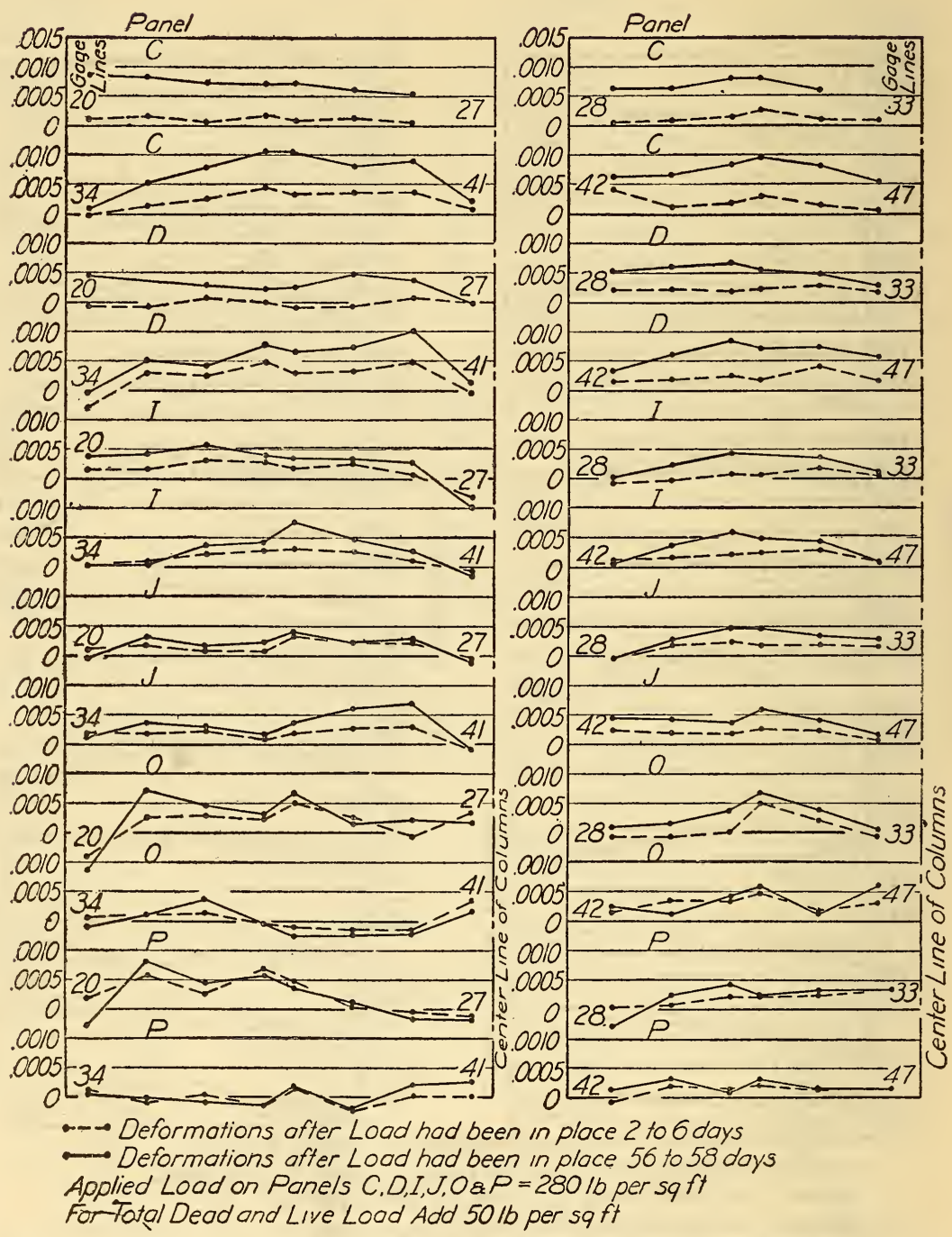

FIG. 5I.-Distribution of deformation in concrete along edges of intermediate panels. 


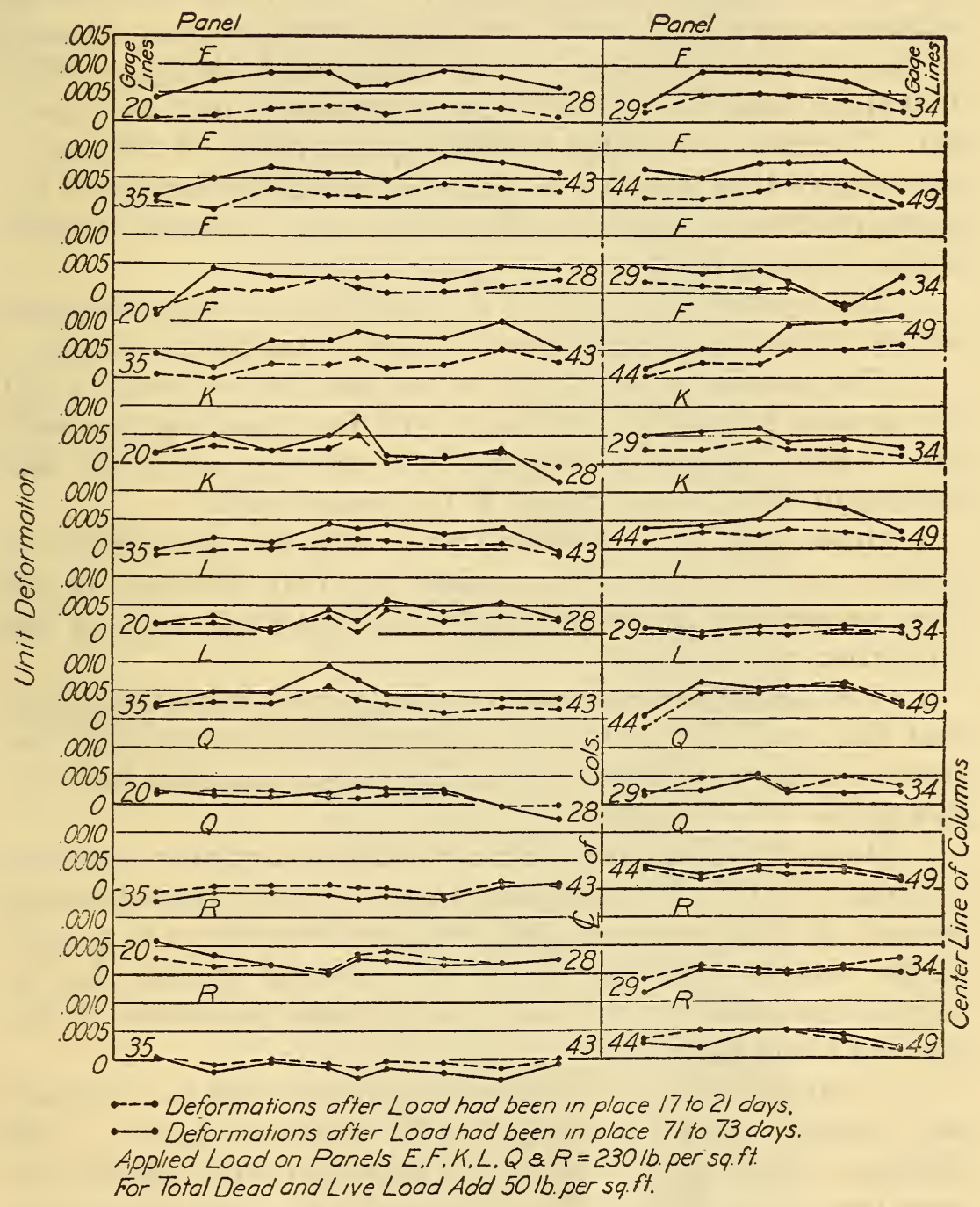

FIG. 52.-Distribution of deformation in concrete along edges of long panels. 
20. GENERAL COMMENTS.

It has been the purpose of this test to furnish data which will afford a basis for the design of slabs of the type tested. The essential requirement of a floor structure is that it carry the design load with a proper factor of safety. There is no objection to making use of any additional strength afforded by other elements of the structure than those usually considered in design provided that these elements of strength can be depended upon to be present. To guard against the extension of the results of this test to cases where they may not be properly applicable because of important differences from the Waynesburg slab, attention is called to the following points:

I. The moments measured by the coefficients given in this paper are the moments of the measured stresses in the reinforcement.

2. The increase in stress with a constant load on the slab and the increase in moment coefficients with increasing load are indications that the tensile strength of the concrete and of the tiles assisted in reducing the stresses in the reinforcement.

3. Other tests have indicated that with low percentages of reinforcement only a portion (often less than one-half) of the total moment is accounted for by the observed stress in the reinforcement.

4. With larger percentages of reinforcement it is to be expected that the proportion of the total moment to be resisted by the stresses in the reinforcement would be larger than that found in this test to be so resisted.

5. Most of the negative moment found analytically has been accounted for ${ }^{13}$ by assuming that the same ratio existed between moment of steel stress and total moment as was found in tests of simple beams. The moment of the observed stresses due to negative moment was between one-half and two-thirds of the moment found analytically.

6. A certain amount of dome or arch action within the structure may possibly have contributed to its carrying capacity. The likelihood of assistance from such a source probably will vary in some measure with the ratio of the span to the depth of the slab. Therefore, the moment coefficients found applicable to the structure tested should not be extended forthwith to structures having a larger ratio of span to slab thickness than that which existed in the slab tested.

\footnotetext{
$192 x$.

"Moments and stresses in slabs," Proc. Am. Concrete Inst., 17, Table XII, p. 498 and Fig. 33, p. 480;
} 
Technologic Papers of the Bureau of Standards, Vol. 16.

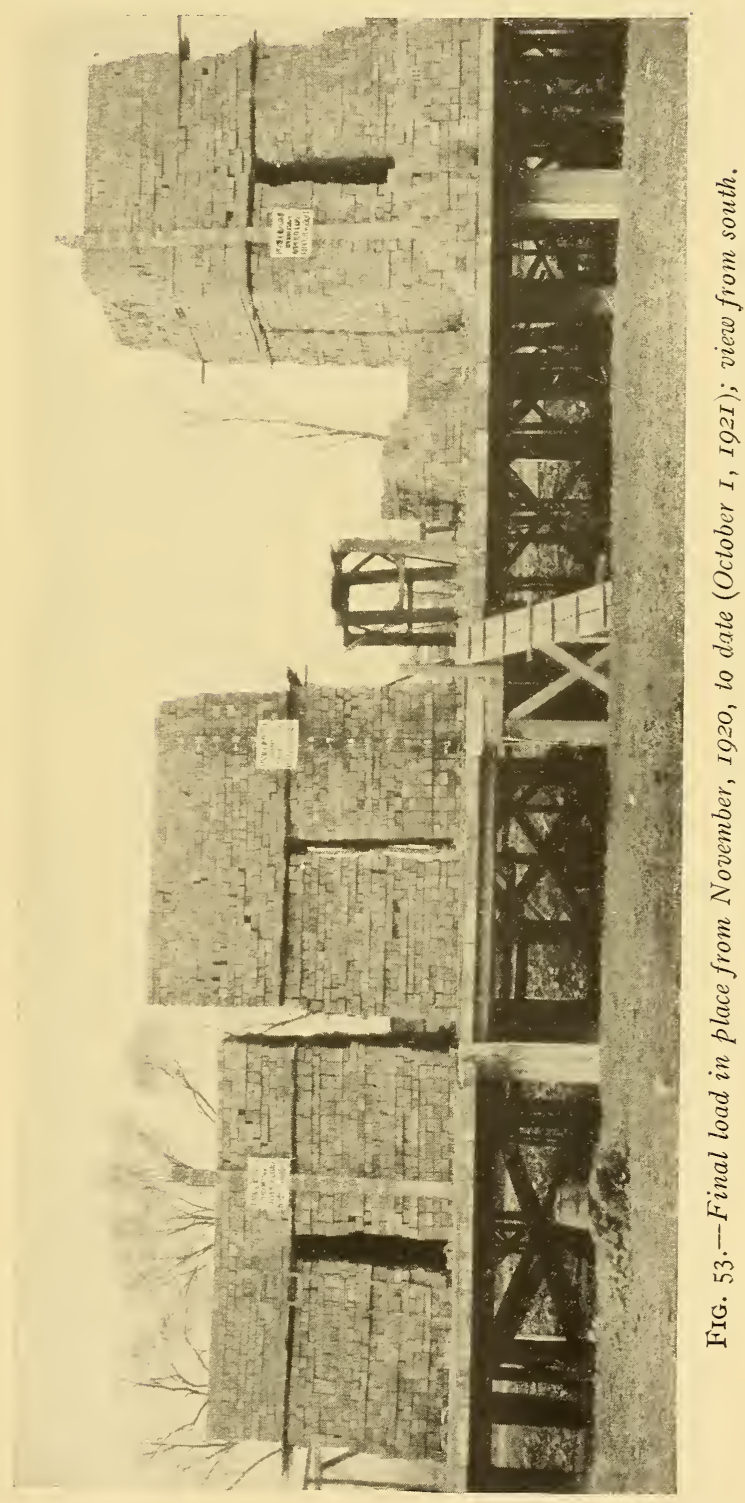



An analysis of a tied arch or dome, however, will generally indicate as much tension in the tie as though the load were carried by bending of a beam or slab of equal depth. It would seem, therefore, that dome action would constitute an additional source of strength for this slab only in case it were possible by this means to throw into the girders some of the tensile stresses which otherwise would have to be carried by the slab.

7. It is probable that with the loading of November, 1920 , there was some arching of the load. It would be difficult in most cases to apply a load of intensity equal to that load without having an equal amount of arching, but if dependence is deliberately placed upon arching of the load, consideration must be given to such factors as the span of the slab, the character of the loading material, and the possible distribution of the load.

8. The high yield point of the slab reinforcement, 54,000 1bs./in. ${ }^{2}$, permits more general cracking of the concrete within the elastic range of the slab's action than would have been possible with mild steel reinforcement. This is of advantage for studying the behavior of the slab under working loads, but the maximum load carried would, of course, be less with mild steel than with the hard-grade steel used.

9. In applying the results of this test to the formulation of standards for design proper consideration should be given to the possibility that in practice the workmanship may be inferior to that secured in the test slab. However, the concrete strengths and the depths to the reinforcing bars given in Tables 2 and 9 will indicate that the pains taken was not excessive.

In order that the tiles may be effective in resisting shearing stresses and compressive stresses, wherever this form of construction is used, it is obvious that a high degree of integrity between the tiles, the concrete, and the reinforcement is essential. This is emphasized by the probability previously indicated, that the resistance developed by the structure is, in part, accounted for by the tensile resistance of the concrete and tiles. This integrity can be secured only by having the concrete mixed wet enough and by having it worked into place sufficiently to insure proper filling of the concrete around the tiles and the reinforcement. At the same time the concrete should be dry enough that too large a quantity of it will not flow into the tiles. In order to avoid the loss of excessive quantities of concrete by flowing into the tiles there may be a temptation to mix the concrete so dry that the 
securing of the required integrity will be difficult. The misplacement of tiles also is likely to occur, and when it does the strength of the construction may be affected. These considerations make it clear that careful attention must be given to all phases of the construction in order to insure good workmanship.

ro. There is nothing in the type of construction described in this paper to distinguish its action sharply from that of a similarly reinforced solid concrete floor. It would seem desirable, however, before extending conclusions derived from this test to another form of construction that the other form of construction also be tested. This is especially true regarding features which are contrary to generally accepted practice.

In order to avoid danger of encouraging too great expectations from the type of construction described in this paper, specific attention has been called to all the features which, except for such caution, might foster overconfidence in the merits of such a structure. It seems proper, on the other hand, to call attention to the fact that the feature which finally should determine the merits of a given floor construction is its ability to carry load without objectionable distortion of the structure under longcontinued service.

In order to avoid wrong conclusions on account of the fact that the strain gauge measurements do not show directly what are the total moments, special efforts were made to determine what load the slab would carry without failure.

Obviously in order to be finally conclusive on such questions as repeated loading, vibration effects, shock, shrinkage, expansion, contraction, etc., which may decrease the tensile resistance of the concrete and the tile, more extensive tests would be needed than those which have been made. The tests which have been made are probably, however, more extensive and more thorough than any that have ever before been made in the introduction of a special form of construction.

\section{SUMMARY.}

Deformations in the tiles were on the average 70 per cent as great as those in the adjacent concrete. The compressive unit stresses in the tiles probably were equal to, or greater than, those in the concrete.

The walls of the tile in contact with the concrete ribs seem to have been effective in resisting shearing stresses at least equally with the concrete. It is reasonable that this should be so. 
The average negative moment as determined from the measured stresses for the interior square panels was o.or $86 \mathrm{Wl}$. That for the short span of the interior intermediate-size oblong panels was $0.0277 \mathrm{Wl}$ and the corresponding moment for the long panels was $0.0398 \mathrm{Wl}$. The average negative moment in the long span of the rectangular panels was $0.02 \mathrm{I}_{3} W l$ for interior intermediatesize panels and $0.0179 \mathrm{Wl}$ for the interior long panels. In all the above cases $l$ is the clear short span of ${ }_{5} 5$ feet. The quantities given represent only the moment of the observed stresses in the reinforcement. The true stresses may have been 5 to Io per cent greater than the observed stresses. The moment found analytically would probably be as much as 50 to 75 per cent greater than the values given.

The average negative bending moment for exterior panels was 20 per cent greater than that for interior panels of like size. This was for the reinforcement across the girder one span length from the wall. For interior panels the average positive moment under the concentrated loading of April 22, I920, was 49 per cent of the average negative moment under the maximum uniform load. The average positive moment for exterior panels was 25 per cent greater than the positive moment for interior panels. The slabs on which this comparison is based had both positive and negative reinforcement extending into the wall girders.

The average distance of the point of zero stress in the negative reinforcement from the edges of the girders was less than onefifth of the clear span.

For uniform live loads of $275 \mathrm{lbs} . / \mathrm{ft}^{2}$ on the square panels, $230 \mathrm{lbs} . / \mathrm{ft}^{2}{ }^{2}$ on the intermediate panels, and $\mathrm{I} 75 \mathrm{lbs} . / \mathrm{ft} .{ }^{2}$ on the long panels, the deflection at the center of the panels was about one nine-hundredth of the clear short span. These loads are about 3.5 times the "design loads" referred to in Section II, 2.

Ratios of live and dead load to the "design load" of Section II, 2 I, averaged approximately for all sizes of panel, 5.4 for the maximum uniform load, 9.4 for the loading of April 22, I920, and I 7.3 for the somewhat more concentrated loading of November, I 920 , which has been on three panels of the slab for over a year.

WASHINGTON, March 31, 1922. 



\section{INDEX TO VOLUME 16.}

A.

Aircraft engines, radiators.

Anthes, G. P., W. A. Slater, Arthur Hagener and, Test of a hollow tile and concrete floor slab reipforced in two directions...........

Automobile tires, power losses.............

B.

Bingham, E. C., Cutting fluids............ Bowker, R. C., Durability of sole leather filled with sulphite cellulose extract.

Briggs, C. A., and E. D. Gordon, Weighing by substitution.

Brumbargh, I. $V$, and $G, W$. Jones, Carbon monoxide in the products of combustion from natural gas burners. ...............

Burgess, G. K., and R. W. Woodward, Manufacture and properties of steel plates containing zirconium and other elements... - - Thermal stresses in chilled iron car wheels.

c.

Carbon monoxide in combustion products. Campression tests of steel angles............. Concrete floor slab test. . . . . . . . . . . . . . .

Cutting fluids

D.

Deformation and tensile properties of steel. . Dellinger, J.H., and J. L. Preston, Properties of electrical insulating materials of the laminated phenol-methylene type.

Durability of cement drain tile in alkali soils. Durability of concrete in alkali soils......... Durability of sole leather.................

\section{E.}

Effect of heat treatment on the properties of steel.

Effect of temperature on tensile properties of steel.................................. Engines, aircraft, radiators ..............

\section{F.}

Fuids, cutting..

French, $H$. $J$. Effect of temperature, deformation, and rate of loading on the tensile properties of low-carbon steel below the thermal critical range.

Tensile properties of some structural alloy steels at high temperatures.......... , and W. George Johnson, Effect of heat treatment on the mechanical properties of I per cent carbon steel.
G.

Gordon, E. D., C. A. Briggs and, Weighing by substitution......................... I77

Groesbeck, Edward C., Influence of phosphorus upon the microstructure and hardness of low-carbon, open-hearth steels.............

H.

Hagener, Arthur W. A. Slater, and G. P. Anthes, Test of a hollow tile and concrete floor slab reinforced in two directions...... Harper, D. R., $3 d, S . R$. Parsons and, Radiators for aircraft engines................. 247 Heat treatment of steel.................. Herschel, W. H., The Redwood viscometer.. 227 Hollow tile test....................... 727 Holt, W. L., and P. L. Wormeley, Power losses in automobile tires............... $45^{x}$

I.

Insulating materials (electrical).

J.

Johnson, W. George, H. J. French and, Effect of heat treatment on the mechanical properties of I per cent carbon steel. ........... Jones, G. W., I. V. Brumbaugh and, Carbon monoxide in the products of combustion from natural gas burners.

\section{L.}

Leather, sole ........................ Lofton, R. E., Photomicrography of paper fibers. ..................

\section{M.}

Manufacture of plates of zirconium steel...... Mechanical properties of steel............... Microstructure of steels...................

\section{N.}

Natural gas burners, carbon monoxide.....$$
\text { P. }
$$

Paper fibers, photomicrography........... Parsons, S. R., and D. R. Harper, 3d., Radiators for aircraft engines................. Phosphorus, effect on the microstructure and hardness of steels..................... Photomicrography of paper fibers. . . . . . .

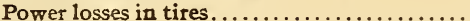
Preston, J. L., J. H. Dellinger and, Properties of electrical insulating materials of the laminated phenol-methylene type........ Properties of electrical insulating materials... Properties of steel plates containing zir-

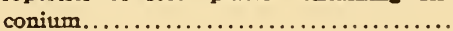


R.

Radiators for engines.

Redwood viscometer.

S.

Slater, W. A., Arthur Hagener, and G. P. Anthes, Test of a hollow tile and concrete floor slab reinforced in two directions.

Stang, A. H., and L. R. Strickenberg, Results of some compression tests of structural steel angles.

Stresses in car wheels

Strickenberg, L. R., A. H. Stang and, Results of some compression tests of structural steel angles.

Structural steel angles, tests

Substitution, weighing.
Page.

227

727

651

193

651

651

177
Page.

Tensile properties of steels............. 77

Test of a hollow tile and concrete floor slab... $\quad 727$

Thermal stresses in car wheels........... ${ }_{193}$

$\mathrm{V}$.

Viscometer, Redwood................ 227

W.

Weighing by substitution .............. $\quad 177$

Williams, G. M., Durability of cement drain tile and concrete in alkali soils: Third Prog-

ress Report (1919-20) ..................

Woodward, R. W., G. K. Burgess and, Manufacture and properties of steel plates containing zirconium and other elements..... - - Thermal stresses in chilled iron car wheels................................

Wormeley, P. L.,W.L. Holt and, Power losses in automobile tires.

\section{ADDITIONAL COPIES \\ OF THIS PUBLICATION MAY BE PROCURED FROM \\ THE SUPERINTENDENT OF DOCUMENTS GOVERNMENT PRINTING OFFICE WASHINGTON, D. C. \\ 5 CENTS $\stackrel{\text { AT }}{\text { PER COPY }}$}

PURCHASER AGREES NOT TO RESELL OR DISTRIBUTE THIS OOPY FOR PBOTTT.-PUB. RES. 57, APPROVED MAY 11, 1922 